\title{
COPD EXACERBATIONS
}

\section{Treatment and Outcome}

Marjolein Brusse-Keizer 
Thesis, University of Twente, 2009

ISBN 978-90-365-2792-7

(C) M.G.J. Brusse-Keizer

Printed by: Gildeprint B.V., Enschede

The studies in this thesis were performed at the department of Pulmonary Medicine of Medisch Spectrum Twente Enschede.

The printing of this thesis was kindly supported by Dr. G.J. van Hoytemastichting, GlaxoSmithKline B.V., Boehringer Ingelheim B.V., Pfizer B.V., AstraZeneca B.V., Novartis B.V., Nycomed B.V., Nutricia Advanced Medical Nutrition B.V.. 


\title{
COPD EXACERBATIONS
}

\section{Treatment and Outcome}

\author{
PROEFSCHRIFT
}

\author{
ter verkrijging van \\ de graad van doctor aan de Universiteit Twente, \\ op gezag van de rector magnificus, \\ prof.dr. H. Brinksma, \\ volgens besluit van het College voor Promoties \\ in het openbaar te verdedigen \\ op donderdag 16 april 2009 om 13.15 uur
}

door

Marjolein Geertruida Johanna Brusse-Keizer

geboren op 5 februari 1981

te Stad Delden 
Dit proefschift is goedgekeurd door de promotoren, Prof. dr. J.A.M. van der Palen en Prof. dr. H.A.M. Kerstjens en de assistent-promotor, Dr. P.D.L.P.M. van der Valk. 


\section{Promotiecommissie:}

Promotoren:

Assistent-promotor:

Leden:
Prof. dr. J.A.M. van der Palen

Prof. dr. H.A.M. Kerstjens

Dr. P.D.L.P.M. van der Valk

Prof. dr. T.S. van der Werf

Prof. dr. M.J. IJzerman

Prof. dr. M.A.F.J. van de Laar

Dr. M.G.R. Hendrix 



\section{CONTENTS}

Chapter 1 General introduction

Chapter 2 Clinical predictors of exacerbation frequency in

Chronic Obstructive Pulmonary Disease

Chapter 3 Relation of sputum colour to bacterial load in acute exacerbations of COPD

Chapter $4 \quad$ Necessity of antibiotics in outpatients with a COPD exacerbation: the ABC-Trial

Chapter 5 Relation between amoxicillin concentration in sputum of COPD patients and length of hospitalisation

Chapter 6 The impact on clinical decision making of quality control standards applied to sputum analysis in COPD

Chapter 7 General discussion

Chapter 8 Summary

Samenvatting

Dankwoord 



\section{CHAPTER 1}

GENERAL INTRODUCTION

Marjolein Brusse-Keizer 
This thesis describes the results of several studies on exacerbations in Chronic Obstructive Pulmonary Disease (COPD) that were performed at the department of Pulmonary Medicine of Medisch Spectrum Twente, Enschede, The Netherlands. In this introduction the definition and epidemiology of COPD and their associated exacerbations will be described. Furthermore, after presentation of the major themes of this thesis, an outline of the thesis is given.

\section{Chronic Obstructive Pulmonary Disease}

Chronic Obstructive Pulmonary Disease (COPD) is defined as a preventable and treatable disease with some significant extrapulmonary effects that may contribute to the disease severity in individual patients. The pulmonary component is characterised by airflow limitation that is not fully reversible. The airflow limitation is usually progressive and associated with an abnormal inflammatory response of the lung to noxious particles or gases(1).

COPD is a major cause of chronic morbidity and mortality throughout the world. The Global Burden of Disease Study has projected that COPD, which ranked sixth as the cause of death in 1990, will become the third leading cause of death worldwide by 2020 . This increased mortality is driven by the expanding epidemic of smoking and the changing demographics in most countries, with more of the population living longer(1). Morbidity and mortality among patients with COPD are for a large part related to acute exacerbations, which occur one to three times a year(2).

\section{Exacerbations in COPD}

The precise definition of an exacerbation is a controversial topic. Definitions based on healthcare utilisation (such as the prescription of medication by a health care provider or a COPD exacerbation related hospitalisation), have as important limitation that healthcare use can vary depending on access(3). Additionally, many exacerbations are not reported to health care professionals and are either selftreated or left untreated(4). The alternative to definitions based on health care utilisation is those based solely on patient reported symptom changes. Although these latter definitions identify a greater number of events, such definitions can be difficult to validate(3). The GOLD definition of an exacerbation attempts to compromise between the above mentioned approaches. The definition of an exacerbation that is now included in the revised GOLD guidelines of 2006 is "an event in the natural course of the disease characterised by a change in the patient's baseline dyspnoea, cough, and/or sputum that is beyond normal day-to-day 
variations, is acute in onset, and may warrant a change in regular medication in a patient with underlying COPD"(1).

An important issue to address is that, due to the use of multiple definitions of exacerbations which can lead to differences in numbers of exacerbations identified, it is sometimes difficult to compare results of studies on COPD exacerbations.

\section{Frequency of exacerbations}

Exacerbations of COPD typically occur one to three times a year(2). Since repeated exacerbations are associated with deterioration of health-related quality of life and a considerable economic burden, exacerbations are an important outcome in $\operatorname{COPD}(5)$. To reduce the associated morbidity and mortality of the exacerbations, and to improve the quality of life of patients(6), strategies to reduce exacerbation frequency are urgently needed. However, before these strategies can be introduced, patients at risk for frequent exacerbations need to be identified. Some potential predictive factors of COPD exacerbations have already been studied, such as airway inflammation(7) and bacterial colonisation(8;9). Additionally, other studies have looked at the severe end of the disease spectrum, analysing risk factors for exacerbations that lead to hospitalisation(10) and re-hospitalisation after a former hospitalisation $(11 ; 12)$. In Chapter 2 we tried to identify independent predictors for frequent exacerbations from multiple domains of COPD, including demographic data, clinical signs, sputum cultures, and quality of life during a stable phase of the disease in patients with moderate to severe COPD.

\section{Causes of exacerbations}

COPD exacerbations are events with a heterogeneous presentation that are now thought to be caused by complex interactions between the host, viruses, bacteria, and environmental pollution, leading to an increase in the inflammatory burden(13). The contributions that are suggested by published data is that $50-70 \%$ of exacerbations are due to respiratory infections (including bacteria, atypical organisms and respiratory viruses), $10 \%$ are due to environmental pollution (depending on season and geographical placement), and up to $30 \%$ are of unknown aetiology(13). 


\section{Most common bacterial and viral pathogens isolated from patients with COPD exacerbations}

\section{Bacteria}

Haemophilus influenzae

Moraxella catarrhalis

Streptococcus pneumoniae

Pseudomonas aeruginosa

\section{Viruses}

Rhinovirus

Coronavirus

Influenza

Parainfluenza

Adenovirus

Respiratory syncytial virus

Human metapneumovirus

\section{Viral infections}

COPD exacerbations are frequently triggered by upper respiratory tract infections, which are more common in the winter months, when respiratory viral infections are prevalent in the community(14). Exacerbations triggered by respiratory viral infections are more severe and are associated with longer recovery times than those triggered by other factors $(15 ; 16)$. Use of more sensitive molecular diagnostic techniques have now enabled detection of respiratory viruses at exacerbation in around half of all exacerbations $(17 ; 18)$. This finding might still be an underestimate due to difficulties in sampling at onset of symptoms. The most common viruses isolated are human rhinoviruses(14).

\section{Bacterial colonisation and infection}

The precise role of bacteria with regard to COPD exacerbations has been difficult to assess, since airway bacterial colonisation in stable state is often associated with the same organisms as those isolated at exacerbations, including Haemophilus influenzae, Streptococcus pneumoniae, Moraxella catarrhalis, Staphylococcus 
aureus, and Pseudomonas aeruginosa(13). Atypical bacteria such as chlamydia, legionella, and mycoplasma have also been implicated at COPD exacerbation, although evidence on their role is conflicting(14). A recent study using real-time PCR detection methods found no role for these three atypical bacteria at COPD exacerbation(19).

The reported rates of patients with bacterial colonisation in stable COPD patients vary from $33 \%$ to $100 \%$. Important causes of this wide range are the use of different airway samples (sputum, (protected) brush, BAL) and the risk factors influencing bacterial colonisation (smoking, airway obstruction severity, airway inflammation)(9). The significance of bacterial colonisation of the bronchial tree in terms of the development and progression of airway inflammation is not precisely known. There is however evidence that bacterial colonisation of the lower airways in stable COPD is not innocuous, since bacterial colonisation has been associated with greater levels of airway inflammation measured in sputum, increased frequency of exacerbations, and an accelerated decline in lung function(8;20-22).

Substantial progress has also been made in investigating the role of a bacterial infection as a possible cause of an exacerbation, with the development of molecular typing methods allowing the detection of changes in bacterial strains rather than species. Sethi et al. have suggested that isolation of a new bacterial strain in COPD patients who were regularly sampled during longitudinal follow-up was associated with an increased risk of an exacerbation(2). However, this finding does not conclusively prove that bacteria are direct causes of exacerbations, because not all exacerbations were associated with strain change, and not all strain changes resulted in exacerbations(14). The situation with airway infections is further complicated by the fact that in many COPD exacerbations both respiratory viruses and bacteria are isolated(23). Papi et al. reported greater lung function impairment and longer hospitalisations in patients with exacerbations associated with viral and bacterial co-infection than in those without co-infection(24). Thus, co-infection with bacteria and viruses might be of greater importance than bacterial infection alone in COPD exacerbations but consensus within this field has not yet been reached(14).

\section{Treatment of exacerbations}

The management of exacerbations is empirical and includes oral corticosteroids, often combined with broad spectrum antibiotics such as amoxicillin clavulanic acid or tetracyclines to treat a presumed bacterial infection(25). The need to prescribe 
these antibiotics, especially in mild to moderate exacerbations, is still not convincingly demonstrated(26). The controversy that exists around antibiotic prescription is mainly based on the unclear role of bacteria as cause of the exacerbation. Furthermore, even when there indeed is a bacterial infection, treatment is empirical since results of cultures and tests for sensitivity to antibiotics usually take days to one week to become available. Due to the increasing resistance to common anti-bacterial agents it is important to be reluctant with the prescription of antibiotics, and research into identification of easily measurable markers for a bacterial infection is urgently needed(27;28).

\section{Guidance for antibiotic prescription in COPD exacerbations}

The difficulty of predicting and verifying a bacterial cause of an exacerbation at clinical presentation without time consuming laboratory analyses, makes it difficult to decide up front whether antibiotic treatment is needed(29). International guidelines recommend prescription of antibiotics when two of the three following criteria are present: increased dyspnoea, increased sputum volume, and increased purulence of sputum(30;31). These criteria originate from the study by Anthonisen et al. that showed only a marginal benefit of antibiotics in a sub selection of patients(32). They divided COPD exacerbations into three categories (type I, II and III exacerbations), and concluded that in case of presence of all three of the abovementioned criteria (type I exacerbation) the cause of the exacerbation is probably bacterial and it is more likely to have a favourable outcome with antibiotics. Furthermore they stated that antibiotics confer no benefit in type III exacerbations and that treatment of type II exacerbations with antibiotics probably could be justified in case of antibiotic tolerance(32). These criteria have however never been validated. The problem with increased purulence, which is one of the three criteria in the international guidelines, is that purulence is a subjective and not clearly defined marker. The use of a colour chart has been suggested. Stockley et al. designed a sputum colour chart by which a distinction between purulent and mucoid sputum can be made(33). They stated that the presence of green or yellow (purulent) sputum was $94.4 \%$ sensitive and $77.0 \%$ specific for the yield of a high bacterial load and indicates a clear subset of patient that is likely to benefit most from antibiotic therapy. Allegra et al. provided additional evidence that purulent sputum is associated with bacterial growth in the airways of patients with moderate to severe COPD. They however recorded that also in mucoid sputum, the presence of bacterial growth was very common (78\%)(34). Results of a study by 
Soler et al. showed that self-reported purulence in the sputum predicts the presence of bacteria at low concentrations ( $\geq 10^{2} \mathrm{cfu} / \mathrm{mL}$ ) in the airways for protected brush specimens(35). However, in the COPE study by van der Valk et al. no association between sputum purulence and a bacterial infection was found(36). Instead they found that the combination of a positive Gram's stain of sputum, a clinically relevant decrease in lung function, and two or more exacerbations in the previous year, was $67 \%$ predictive for a bacterial origin of an exacerbation, which was postulated to warrant antibiotic treatment. The absence of all three characteristics gave a negative predictive value of $100 \%$ for a non-bacterial origin of an exacerbation, suggesting to abstain from administering antibiotics(36).

Due to the existing contradicting data and opinions about the association between sputum purulence and bacterial involvement in exacerbations, there is uncertainty whether sputum purulence can be used as an indicator for antibiotic treatment. Furthermore, since sputum purulence has only been related to the presence of bacterial growth and has not been demonstrated to be causally related to bacterial infection, it makes sputum purulence even less convincing as predictor for bacterial infection in COPD exacerbations. We therefore performed a study to determine whether sputum colour and purulence, as assessed by the nine-point Stockley colour chart, correlate with bacterial load in patients admitted for an exacerbation in COPD (Chapter 3).

Furthermore, with the algorithm suggested by van der Valk et al, there is still a patient group left with only one or two of the above mentioned characteristics, for which it is not known with sufficient certainty whether bacteria are involved in the exacerbation or not and whether antibiotic treatment is warranted. This question was addressed in the $A B C$-Trial, a randomised placebo controlled study assessing the effectiveness of antibiotics in COPD exacerbations (Chapter 4).

\section{Effectiveness of antibiotics in COPD exacerbations}

Effectiveness of antibiotics in COPD exacerbations depends not only on the correct prescription of antibiotics, but possibly also on the concentration of antibiotics reached in the target tissues. Theoretically, to be effective, the antibiotic concentration in target tissues should reach the Minimal Inhibiting Concentration of $90 \%$ (MIC90) for potential pathogenic micro-organisms (PPM) such as S.pneumoniae, H.influenzae and M.catarrhalis(37;38). Levels of antimicrobial agents in sputum, where many micro-organisms are located, may be a more relevant predictor of efficacy in COPD exacerbations than concentrations in 
blood(39). A widely used antibiotic in the treatment of exacerbations in COPD is amoxicillin clavulanic acid. Little is known about the excretion of this antibiotic into sputum of COPD patients. Due to the instability of clavulanic acid, levels in sputum and serum are difficult to measure; levels of amoxicillin however can be measured. In Chapter 5 the relationship between the concentration of amoxicillin in sputum in hospitalised COPD patients and length of hospitalisation, as a marker for the effectiveness of antibiotic use, was investigated.

\section{Sputum analysis in COPD exacerbations}

Sputum analysis is an important clinical tool in the management of COPD exacerbations for the decision to prescribe antibiotics. The most common test is culturing a sputum sample to determine the presence of bacteria. Next to culturing sputum samples, other characteristics of sputum have been used to determine the cause of an exacerbation. A marker that has been commonly used since the study of Anthonisen et al.(32) is sputum purulence, which is seen as a marker for the presence of bacteria(1). Furthermore, concentrations of inflammatory markers and cell types are also commonly analysed in sputum samples. When collecting sputum samples, there is a high variability in the quality of the samples obtained. In 1975 Murray et al. designed criteria for the quality of sputum. Specimens were categorised according to the number of leukocytes and squamous epithelial cells observed microscopically in a Gram-stained smear(40). When the number of squamous epithelial cells was far greater than the number of leucocytes in the sputum, they assumed that this specimen originated from the upper airways and therefore should not be further analysed. The American Society of Microbiologists (ASM) also advocates quality control standards and culture interpretation rules(41). Although these quality statements have now existed for many years, published studies involving sputum analysis often do not report on the quality control standards they used for sputum samples and whether samples of inadequate quality were removed from further analyses. In this thesis we present a retrospective study on sputum of COPD patients in stable phase and in acute exacerbations to study the differences in sputum outcomes between adequate and inadequate samples (Chapter 6). 


\section{Outline of the thesis}

- In Chapter 2, we identify independent predictors for frequent exacerbations from multiple domains of COPD, including demographic data, clinical signs, sputum cultures, and quality of life during a stable phase of the disease in patients with moderate to severe COPD.

- In Chapter 3, we determine whether sputum colour and purulence, as assessed by the nine-point Stockley colour chart, correlate with bacterial load in patients admitted for an exacerbation in COPD. To check the robustness of the colour and purulence assessment, the changes in these parameters and the corresponding change in bacterial load in sputum over the first seven days of hospitalisation are also correlated.

- In Chapter 4, we evaluate the effect of antibiotics on the duration and severity of exacerbations in outpatients with moderate to severe COPD and with one or two of the following characteristics: a positive Gram's stain of sputum, a clinically relevant decrease in lung function, and two or more exacerbations in the previous year.

- In Chapter 5, we investigate the relationship between the concentration of amoxicillin in sputum in hospitalised COPD patients and length of hospitalisation.

- In Chapter 6, we describe a retrospective study on sputum of COPD patients in stable phase and in acute exacerbations to study the differences in sputum outcomes between adequate and inadequate samples.

- In Chapter 7, the major results of all performed studies are discussed and put into perspective. Recommendations for clinical and public health practice, as well as for future research are given.

- In Chapter 8, a summary of the main findings concludes this thesis. 


\section{References}

(1) Rabe KF, Hurd S, Anzueto A, Barnes PJ, Buist SA, Calverley P, et al. Global Strategy for the Diagnosis, Management, and Prevention of COPD - GOLD Executive Summary. Am J Respir Crit Care Med 2007 Sep; 176:532-55.

(2) Sethi S, Evans N, Grant BJ, Murphy TF. New strains of bacteria and exacerbations of chronic obstructive pulmonary disease. N Engl J Med 2002 Aug 15;347(7):465-71.

(3) Hurst JR, Wedzicha JA. What is (and what is not) a COPD exacerbation: thoughts from the new GOLD guidelines. Thorax 2007 Mar;62(3):198-9.

(4) Seemungal TA, Donaldson GC, Paul EA, Bestall JC, Jeffries DJ, Wedzicha JA. Effect of exacerbation on quality of life in patients with chronic obstructive pulmonary disease. Am J Respir Crit Care Med 1998 May;157(5 Pt 1):1418-22.

(5) Celli BR, Barnes PJ. Exacerbations of chronic obstructive pulmonary disease. Eur Respir J 2007 Jun;29(6):1224-38.

(6) Wedzicha JA, Donaldson GC. Exacerbations of chronic obstructive pulmonary disease. Respir Care 2003 Dec;48(12):1204-13.

(7) Bhowmik A, Seemungal TA, Sapsford RJ, Devalia JL, Wedzicha JA. Comparison of spontaneous and induced sputum for investigation of airway inflammation in chronic obstructive pulmonary disease. Thorax 1998 Nov;53(11):953-6.

(8) Patel IS, Seemungal TA, Wilks M, Lloyd-Owen SJ, Donaldson GC, Wedzicha JA. Relationship between bacterial colonisation and the frequency, character, and severity of COPD exacerbations. Thorax 2002 Sep;57(9):759-64.

(9) Tumkaya M, Atis S, Ozge C, Delialioglu N, Polat G, Kanik A. Relationship between airway colonization, inflammation and exacerbation frequency in COPD. Respir Med 2007 Apr;101(4):729-37.

(10) Garcia-Aymerich J, Monso E, Marrades RM, Escarrabill J, Felez MA, Sunyer J, et al. Risk factors for hospitalization for a chronic obstructive pulmonary disease exacerbation. EFRAM study. Am J Respir Crit Care Med 2001 Sep 15;164(6):1002-7.

(11) Almagro P, Barreiro B, Ochoa de EA, Quintana S, Rodriguez CM, Heredia JL, et al. Risk factors for hospital readmission in patients with chronic obstructive pulmonary disease. Respiration 2006;73(3):311-7.

(12) Garcia-Aymerich J, Farrero E, Felez MA, Izquierdo J, Marrades RM, Anto JM. Risk factors of readmission to hospital for a COPD exacerbation: a prospective study. Thorax 2003 Feb;58(2):100-5. 
(13) Sapey E, Stockley RA. COPD exacerbations . 2: aetiology. Thorax 2006 Mar;61(3):250-8.

(14) Wedzicha JA, Seemungal TA. COPD exacerbations: defining their cause and prevention. Lancet 2007 Sep 1;370(9589):786-96.

(15) Hurst JR, Donaldson GC, Wilkinson TM, Perera WR, Wedzicha JA. Epidemiological relationships between the common cold and exacerbation frequency in COPD. Eur Respir J 2005 Nov;26(5):846-52.

(16) Seemungal TA, Harper-Owen R, Bhowmik A, Jeffries DJ, Wedzicha JA. Detection of rhinovirus in induced sputum at exacerbation of chronic obstructive pulmonary disease. Eur Respir J 2000 Oct;16(4):677-83.

(17) Seemungal T, Harper-Owen R, Bhowmik A, Moric I, Sanderson G, Message S, et al. Respiratory viruses, symptoms, and inflammatory markers in acute exacerbations and stable chronic obstructive pulmonary disease. Am J Respir Crit Care Med 2001 Nov 1;164(9):1618-23.

(18) Rohde G, Wiethege A, Borg I, Kauth M, Bauer TT, Gillissen A, et al. Respiratory viruses in exacerbations of chronic obstructive pulmonary disease requiring hospitalisation: a case-control study. Thorax 2003 Jan;58(1):37-42.

(19) Diederen BM, Van der Valk P, Kluytmans JA, Peeters MF, Hendrix R. The role of atypical respiratory pathogens in exacerbations of chronic obstructive pulmonary disease. Eur Respir J 2007 Aug;30(2):240-4.

(20) Banerjee D, Khair OA, Honeybourne D. Impact of sputum bacteria on airway inflammation and health status in clinical stable COPD. Eur Respir J 2004 May;23(5):685-91.

(21) Wilkinson TM, Patel IS, Wilks M, Donaldson GC, Wedzicha JA. Airway bacterial load and FEV1 decline in patients with chronic obstructive pulmonary disease. Am J Respir Crit Care Med 2003 Apr 15;167(8):1090-5.

(22) Hill AT, Campbell EJ, Hill SL, Bayley DL, Stockley RA. Association between airway bacterial load and markers of airway inflammation in patients with stable chronic bronchitis. Am J Med 2000 Sep;109(4):288-95.

(23) Wilkinson TM, Hurst JR, Perera WR, Wilks M, Donaldson GC, Wedzicha JA. Effect of interactions between lower airway bacterial and rhinoviral infection in exacerbations of COPD. Chest 2006 Feb;129(2):317-24.

(24) Papi A, Bellettato CM, Braccioni F, Romagnoli M, Casolari P, Caramori G, et al. Infections and airway inflammation in chronic obstructive pulmonary disease 
severe exacerbations. Am J Respir Crit Care Med 2006 May 15;173(10):111421.

(25) Wilson R. Bacterial infection and chronic obstructive pulmonary disease. Eur Respir J 1999 Feb;13(2):233-5.

(26) Puhan MA, Vollenweider D, Latshang T, Steurer J, Steurer-Stey C. Exacerbations of chronic obstructive pulmonary disease: when are antibiotics indicated? A systematic review. Respir Res 2007;8:30.

(27) Wilson R. Bacteria, antibiotics and COPD. Eur Respir J 2001 May;17(5):9951007.

(28) Goossens H, Ferech M, Vander SR, Elseviers M. Outpatient antibiotic use in Europe and association with resistance: a cross-national database study. Lancet 2005 Feb 12;365(9459):579-87.

(29) Stockley RA, O'Brien C, Pye A, Hill SL. Relationship of sputum color to nature and outpatient management of acute exacerbations of COPD. Chest 2000 Jun;117(6):1638-45.

(30) Ram FS, Rodriguez-Roisin R, Granados-Navarrete A, Garcia-Aymerich J, Barnes NC. Antibiotics for exacerbations of chronic obstructive pulmonary disease. Cochrane Database Syst Rev 2006;(2):CD004403.

(31) Wilson R. Short course of antibiotic treatment in acute exacerbations of COPD. Thorax 2008 May;63(5):390-2.

(32) Anthonisen NR, Manfreda J, Warren CPW, Hershfield ES, Harding GKM, Nelson NA. Antibiotic therapy in exacerbations of chronic obstructive pulmonary disease. Ann Intern Med 1987;106:196-204.

(33) Stockley RA, Bayley D, Hill SL, Hill AT, Crooks S, Campbell EJ. Assessment of airway neutrophils by sputum colour: correlation with airways inflammation. Thorax 2001 May;56(5):366-72.

(34) Allegra L, Blasi F, Diano P, Cosentini R, Tarsia P, Confalonieri M, et al. Sputum color as a marker of acute bacterial exacerbations of chronic obstructive pulmonary disease. Respir Med 2005 Jun;99(6):742-7.

(35) Soler N, Agusti C, Angrill J, Puig De la BJ, Torres A. Bronchoscopic validation of the significance of sputum purulence in severe exacerbations of chronic obstructive pulmonary disease. Thorax 2007 Jan;62(1):29-35.

(36) Van der Valk P, Monninkhof E, van der Palen J., Zielhuis G, van Herwaarden C., Hendrix R. Clinical predictors of bacterial involvement in exacerbations of chronic obstructive pulmonary disease. Clin Infect Dis 2004 Oct 1;39(7):980-6. 
(37) Baldwin DR, Honeybourne D, Wise R. Pulmonary disposition of antimicrobial agents: in vivo observations and clinical relevance. Antimicrob Agents Chemother 1992 Jun;36(6):1176-80.

(38) Fraschini F, Scaglione F, Falchi M, Dugnani S, Mezzetti M, Cicchetti F, et al. Pharmacokinetics and tissue distribution of amoxicillin plus clavulanic acid after oral administration in man. J Chemother 1990 Jun;2(3):171-7.

(39) Baldwin DR, Honeybourne D, Wise R. Pulmonary disposition of antimicrobial agents: methodological considerations. Antimicrob Agents Chemother 1992 Jun;36(6):1171-5.

(40) Murray PR, Washington JA. Microscopic and baceriologic analysis of expectorated sputum. Mayo Clin Proc 1975 Jun;50(6):339-44.

(41) Isenberg HD. Clinical microbiology procedures handbook. 2004.

(42) Rothman KJ, Greenland S. Clinical epidemiology. Modern Epidemiology. Second ed. 1998. p. 519-28.

(43) Burge PS, Calverley PM, Jones PW, Spencer S, Anderson JA, Maslen TK. Randomised, double blind, placebo controlled study of fluticasone propionate in patients with moderate to severe chronic obstructive pulmonary disease: the ISOLDE trial. BMJ 2000 May 13;320(7245):1297-303.

(44) Rabe KF, Atienza T, Magyar P, Larsson P, Jorup C, Lalloo UG. Effect of budesonide in combination with formoterol for reliever therapy in asthma exacerbations: a randomised controlled, double-blind study. Lancet 2006 Aug 26;368(9537):744-53. 


\section{CHAPTER 2}

CLINICAL PREDICTORS OF EXACERBATION FREQUENCY IN CHRONIC OBSTRUCTIVE PULMONARY DISEASE

Marjolein Brusse-Keizer, Job van der Palen, Paul van der Valk, Ron Hendrix, Huib Kerstjens

Submitted 


\begin{abstract}
Background: Reduction of exacerbation frequency plays an increasingly important role in interventions in COPD. To reduce this frequency efficiently, patients at risk for frequent exacerbations need to be identified. The study objective was to identify predictors for frequent exacerbations from multiple domains of COPD during a stable phase of the disease.
\end{abstract}

Methods: Data of multiple domains of COPD, including sputum cultures and clinical signs, were collected of 121 patients with moderate to severe COPD. Patients with less than 2 exacerbations per year were defined as infrequent exacerbators, whereas patients with 2 or more exacerbations were defined as frequent exacerbators.

Results: We found that SGRQ total score and a course of oral corticosteroids within 3 months prior to the study together predicted best whether patients would be infrequent or frequent exacerbators over the course of the next year. Each unit increase (deterioration) in total SGRQ score was associated with a $3 \%$ higher risk of being a frequent exacerbator $(O R=1.03 ; 95 \% \mathrm{Cl}: 1.00-1.06 ; p=0.047)$. Patients who received a course of oral corticosteroids in the period of 3 months prior to the study had a 3 -fold increased risk of being a frequent exacerbator $(\mathrm{OR}=3.17 ; 95 \% \mathrm{Cl}$ : $1.20-8.34 ; p=0.02)$.

Furthermore, we observed that a sizable number of patients switched from being a frequent to being an infrequent exacerbator and vice versa.

Conclusions: Health related quality of life and a course of oral corticosteroids in the past 3 months are the best predictors of future exacerbator status. Although these easily assessable parameters together can aid in the identification of patients at risk, the predictive value of the model is still not sufficient. Furthermore, our data suggest, in contrast to previous observations, that exacerbation frequency is not a constant feature. 


\section{Background}

Exacerbations are increasingly recognised as important events in the natural course of Chronic Obstructive Pulmonary Disease (COPD), and this is underlined in major international guidelines. They typically occur one to three times a year(1). Exacerbations are an important outcome because they pose a considerable economic burden but more importantly because repeated exacerbations lead to deteriorating health-related quality of life(2). Seemungal et al. showed that patients with more than two exacerbations per year experienced significantly worse health than those with 0-2 exacerbations per year(3). Exacerbation frequency is also an important determinant of lung function decline(4).

Strategies to reduce exacerbation frequency are urgently needed to reduce their associated morbidity and mortality and to improve the quality of life of patients(5), and some studies have already shown that it is possible to reduce exacerbation frequency. It is likely that the greatest reductions in the exacerbation-associated morbidity can be achieved in frequent exacerbators. These patients could be eligible to receive more intensive and elaborate action plans. Turnock et al. concluded that there is evidence that action plans aid patients with COPD in recognising and reacting appropriately to an exacerbation via the self-initiation of antibiotics or steroids, though it has not been shown that these action plans significantly reduce morbidity and mortality(6).

Before introducing strategies to reduce exacerbation frequency we first need to identify patients at risk for frequent exacerbations. This identification should be reliable with easy to measure factors. These factors will not only aid in identifying high risk patients, but will also aid in understanding exacerbation frequency. Some potential predictive factors of COPD exacerbations have already been studied, such as airway inflammation(7) and bacterial colonisation(8;9). Additionally, other studies have looked at the severe end of the disease spectrum, analysing risk factors for exacerbations that need hospitalisation(10) and re-hospitalisation after former hospitalisations $(11 ; 12)$. The aim of our study was to identify independent predictors for frequent exacerbations from multiple domains of COPD, including demographic data, clinical signs, sputum cultures, and quality of life during a stable phase of the disease in patients with moderate to severe COPD. 


\section{Methods}

\section{Study subjects}

This analysis is based on patients included in the control group of a selfmanagement study in COPD, the COPE study(13). Patients were recruited from May 1999 till March 2000 at the outpatient pulmonary clinic of Medisch Spectrum Twente Hospital in Enschede, The Netherlands. The recruitment criteria were: 1) a clinical diagnosis of COPD, as defined by American Thoracic Society criteria(14); 2) no history of asthma; 3) no exacerbation in the month prior to enrollment; 4) current or former smoker; 5) age between 40-75 years; 6) baseline prebronchodilator forced expiratory volume in 1 second $\left(\mathrm{FEV}_{1}\right)$ 25-80\% of predicted; 7) pre-bronchodilator ratio $\mathrm{FEV}_{1}$ inspiratory vital capacity (IVC) $\leq 60 \%$; 8) reversibility of $\mathrm{FEV}_{1} \leq 12 \%$ of predicted value post inhalation of $80 \mu \mathrm{g}$ of ipratropium bromide (Atrovent; Boehringer Ingelheim Inc; Alkmaar; the Netherlands) via metered dose inhalator with an aerochamber(15); 9) total lung capacity (TLC) greater than the TLC predicted minus 1.64*Standard Deviation (SD); 10) no maintenance treatment of oral steroids or antibiotics; 11) no medical condition with low survival or serious psychiatric morbidity (e.g. cardiac insufficiency, alcoholism); 12) absence of any other active lung disease (e.g. sarcoidosis). The research protocol was approved by the hospital's medical ethical committee and all patients gave written informed consent.

\section{Study design}

In total 121 patients were included in the control group of the self-management study and the first year of follow up of these patients contributed to the current analyses. Patients were instructed to phone the study office when they experienced worsening of their respiratory symptoms. They subsequently received usual care from one of the physicians. In order to complete the exacerbation data, patients' general practitioners were asked to report patient contacts and drugs prescribed for COPD exacerbations. Pharmacists reported all drugs used.

\section{Outcome measures}

The frequency of exacerbations was calculated over the one year follow-up period of the study. An exacerbation was defined as a worsening of respiratory symptoms that required treatment with a short course of oral corticosteroids and/or antibiotics as judged by the study physician. 
At the start of the study health related quality of life (HRQoL) was measured by means of the Dutch version of the St George Respiratory Questionnaire (SGRQ)(16), which is divided into three domains: symptoms, activity and impact. The total score provides a global view of the patient's respiratory health. Scores range from 0 (no disturbance of HRQoL) to 100. The Euroqol-5D VAS scale was used to record respondent's self-rated generic health status from 0 (worst imaginable health state) to 100 (best imaginable health state)(17).

Walking distance was measured by the 6 -minute walking test (6MW). Respiratory muscle strength was assessed by the maximal inspiratory pressure (MIP) measurement(18). $\mathrm{FEV}_{1}$ and IVC were measured until three reproducible recordings were obtained. Highest values were used for analyses. FEV $\mathrm{F}_{1}$ as percentage of the predicted value was calculated according to the American Thoracic Society guidelines. GOLD (Global Initiative on Obstructive Lung Disease) stage was determined and dichotomised in stage I-II and III-IV(19). This dichotomisation was based on statistically efficiency, with an equal amount of patients in both stage I-II and III-IV. Furthermore, body mass index (BMI) was measured. Use of a course of oral corticosteroids in the 3 months prior to the study, use of inhaled corticosteroids at baseline, and exacerbation frequency one year prior to the study was recorded from pharmacy records. Of each patient we approached their pharmacist and asked for a full listing of all medications the patient had used. Hospitalisations in the 3 months prior to the study were recorded from hospital records.

\section{Sputum analysis}

A spontaneously produced sputum sample was cultured at the start of the study during a stable phase of the disease. As potentially pathogenic micro-organisms (PPM) were considered Streptococcus pneumonia, Haemophilus influenzae, Moraxella catarrhalis, Pseudomonas aeruginosa, and Staphylococcus aureus. Other bacterial species were classified as normal flora (non-PPM). Infection was defined by the presence of PPM in pure culture or as the presence of one or more PPM in excess (one log or more) to normal microbiological flora in sputum(20;21). Bacterial colonisation was defined as the presence of PPM in culture in equal amount or less compared to normal microbiologic flora in sputum.

The concentrations of pro-inflammatory mediators Interleukin(IL)-6 and IL-8 in sputum were quantified using Pelikine Compact $^{\mathrm{TM}}$ human sandwich ELISA kits (Sanquin, CLB, Amsterdam, the Netherlands). 


\section{Statistical analyses}

\section{Primary analysis}

An annual exacerbation rate for each patient was calculated by dividing the number of exacerbations by the number of days they participated and multiplied by 365 . Patients with $<2$ exacerbations per year were defined as infrequent exacerbators, whereas patients with $\geq 2$ exacerbations were defined as frequent exacerbators. In this way we calculated a weighted exacerbation rate for the duration of participation in the study of each patient.

Baseline characteristics are reported as mean \pm SD or as numbers with corresponding percentages for categorical or dichotomous variables stratified by patients with infrequent or frequent exacerbations. Not normally distributed variables are reported as median with corresponding range.

To identify a subset of independent variables that were associated with infrequent or frequent exacerbations, t-tests or Wilcoxon's rank sum tests were performed as appropriate. Between-group comparisons of nominal or ordinal variables were performed by Chi-square tests. The a priori list of potential predicting variables is displayed in Table 1. Variables with a significance at or below $p=0.15$ were considered as candidate variables for multivariate logistic regression analysis and were all entered. Subsequently, variables with the highest $p$-value were eliminated step by step, until the fit of the model decreased significantly (based on the likelihood-ratio test). In case of multicollinearity between variables, the variable that produced the best model fit was included in the multivariate model. To assess over-fitting, the jackknife cross validation technique was applied to the prediction rule.

\section{Secondary analyses}

To check the robustness of the results, we also performed secondary analyses in which different thresholds for frequent exacerbators were used, namely $\geq 1$ and $\geq 3$ exacerbations per year.

Furthermore, since we had usable sputum samples of only a subset of patients $(n=46)$, the association with infrequent or frequent exacerbations and the results of the sputum culture obtained in stable phase (no infection or colonisation, infection), as well as IL-6 and IL-8 concentrations were analysed in this specific subset of patients in a secondary analysis. 


\section{Results}

\section{Primary analysis}

Table 1 shows baseline characteristics of the 121 patients. In total 9\% of the exacerbations resulted in a hospital admission.

The following variables were univariately associated with infrequent or frequent exacerbations and were included in the multivariate regression model: age, $\mathrm{FEV}_{1}$ in litres, $\mathrm{FEV}_{1}$ as percentage of the predicted value, GOLD stage, $\mathrm{FEV}_{1} /$ IVC, course of oral corticosteroids in the 3 months prior to the study, use of inhaled corticosteroids at baseline, exacerbation frequency in the year prior to the study, result of a stable sputum culture, Euroqol-5D VAS score, and SGRQ scores (total, impact, activity and symptom score). Because of multicollinearity between SGRQ total and the domain scores, and between $\mathrm{FEV}_{1}$ as percentage of the predicted value and GOLD stage we performed the multivariate model first with only the domain scores and then compared this model to the multivariate model in which we excluded the domain scores and included the total score based on the likelihood ratio test. The same was done for $\mathrm{FEV}_{1}$ as percentage of the predicted value and GOLD stage. The multivariate regression analyses revealed that SGRQ total score and a course of oral corticosteroids in the period of 3 months prior to the study together were the best independent predictors of whether patients would be infrequent or frequent exacerbators over the course of the next year. Each unit increase (deterioration) in total SGRQ score was associated with a $3 \%$ higher risk of being a frequent exacerbator (OR=1.03; 95\% $\mathrm{Cl}$ : $1.00-1.06 ; \mathrm{p}=0.047$ ). Patients who received a course of oral corticosteroids in the period of 3 months prior to the study had a 3-fold increased risk of being a frequent exacerbator (OR=3.17; $95 \% \mathrm{Cl}: 1.20-8.34 ; \mathrm{p}=0.02$ ).

To check the robustness of these coefficients, we conducted a jackknife cross validation for the multivariate prediction rule. The OR's of both variables, SGRQ total score and a course of oral corticosteroids remained largely the same, with respectively an OR of 1.03 and 2.96. The ROC (receiver operating curve) curve of the prediction model (see Fig 1) showed an AUC (area under the curve) of 0.717 (95\% Cl: $0.595-0.839 ; p=0.001)$. 
Table 1. Baseline characteristics of the patients stratified by infrequent or frequent exacerbators.

\begin{tabular}{|c|c|c|c|}
\hline & $\begin{array}{c}\text { Infrequent } \\
\text { exacerbators } \\
(n=90)\end{array}$ & $\begin{array}{c}\text { Frequent } \\
\text { exacerbators } \\
(n=31)\end{array}$ & $\mathrm{p}$-value \\
\hline Age in years (SD) & $64(7)$ & $67(7)$ & $0.07^{*}$ \\
\hline Sex (Number of men (\%)) & $76(84)$ & $26(84)$ & 0.94 \\
\hline Smoking status (Number (\%)) & & & 0.56 \\
\hline Ex-smokers & $66(75)$ & $18(69)$ & \\
\hline Current smokers & $22(25)$ & $8(31)$ & \\
\hline \multicolumn{4}{|l|}{ Lung function post bronchodilation (SD) } \\
\hline FEV1 in litres & $1.8(0.5)$ & $1.6(0.5)$ & $0.02 *$ \\
\hline FEV1 $\%$ predicted & $60(14)$ & $54(15)$ & $0.03^{*}$ \\
\hline FEV1/IVC in \% & $47(10)$ & $42(11)$ & $0.03 *$ \\
\hline IVC in litres & $3.9(0.9)$ & $3.8(0.7)$ & 0.48 \\
\hline GOLD stage (Number (\%)) & & & $0.05^{*}$ \\
\hline Stage I-II & $68(76)$ & $18(58)$ & \\
\hline Stage III-IV & $21(24)$ & $13(42)$ & \\
\hline Use of inhaled corticosteroids (Number (\%)) & $51(59)$ & $20(77)$ & $0.10^{*}$ \\
\hline BMI (SD) & $27.7(4.3)$ & $26.9(3.7)$ & 0.41 \\
\hline 6 minute walk distance in meters (SD) & $453(71)$ & $433(85)$ & 0.24 \\
\hline MIP in $\mathrm{kPa}(\mathrm{SD})$ & $-8.8(2.9)$ & $-8.0(2.7)$ & 0.21 \\
\hline \multicolumn{4}{|l|}{ Handgrip strength in kilograms (SD) } \\
\hline Left & $37(12)$ & $34(11)$ & 0.24 \\
\hline Right & $39(11)$ & $38(9)$ & 0.51 \\
\hline Number of frequent exacerbators ( $\geq 2$ / year) & $21(23)$ & $13(42)$ & $0.05^{*}$ \\
\hline \multicolumn{4}{|l|}{1 year prior to the study (\%) } \\
\hline $\begin{array}{l}\text { Number of patients with a course of oral } \\
\text { corticosteroids } 3 \text { months prior to the study (\%) }\end{array}$ & $16(18)$ & $12(46)$ & $<0.001^{*}$ \\
\hline $\begin{array}{l}\text { Number of patients with a hospitalisation } 3 \\
\text { months prior to the study (\%) }\end{array}$ & $2(2.3)$ & $2(7.7)$ & 0.23 \\
\hline Euroqol-5D VAS score (SD) & $67(11)$ & $62(14)$ & $0.02 *$ \\
\hline \multicolumn{4}{|l|}{ SGRQ scores (SD) } \\
\hline Total & $35(16)$ & $47(17)$ & $<0.001 *$ \\
\hline Impact & $23(16)$ & $37(19)$ & $<0.001 *$ \\
\hline Activity & $50(20)$ & $60(20)$ & $0.02 *$ \\
\hline Symptom & $46(22)$ & $55(21)$ & $0.05^{*}$ \\
\hline
\end{tabular}

* Variable entered in the multivariate logistic regression model based on $p$-value $\leq 0.15$.

$\mathrm{FEV}_{1}=$ forced expiratory volume in 1 second; IVC= inspiratory vital capacity; GOLD = Global Initiative on Obstructive Lung Disease, $\mathrm{BMI}=$ body mass index; $\mathrm{MIP}=$ maximal inspiratory pressure; SGRQ= St George Respiratory Questionnaire (higher numbers indicate poorer health status); Euroqol VAS = EuroQol visual analogue scale (higher numbers indicate better health status). 


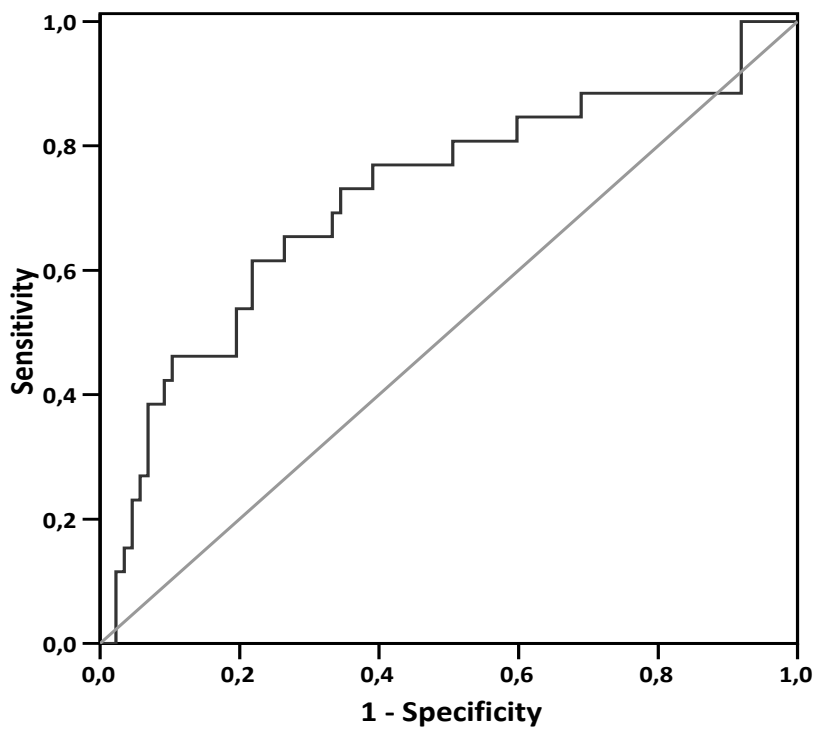

Fig 1. ROC (receiver operating curve) curve of the primary multivariate prediction model for being a frequent exacerbator ( $\geq 2$ exacerbations/year) over the course of the next year, including the variables SGRQ total score and a course of oral corticosteroids within 3 months prior to the study.

The black solid line represents the primary multivariate prediction model and has an AUC of 0.717 (95\% $\mathrm{Cl}: 0.595-0.839 ; \mathrm{p}=0.001$ ). This means that $71.7 \%$ of the patients will be correctly identified as frequent or infrequent exacerbator. Each step in the black solid line represents a combination of SGRQ score and the presence or absence of a course of oral corticosteroids.

\section{Secondary analyses}

In the secondary analysis in which frequent exacerbators were defined as patients with $\geq 1$ exacerbations, SGRQ total score and exacerbation frequency one year prior to the study $(0-1 /$ year $=$ infrequent and $\geq 1$ /year $=$ frequent $)$ predicted best whether patients were going to be frequent or infrequent exacerbators the next year. Each unit increase (deterioration) in SGRQ total score was associated with a $6 \%$ higher risk of being a frequent exacerbator (OR=1.06; 95\% Cl: $1.03-1.09$; $p=0.000)$. Patients who were frequent exacerbators one year prior to the study had an almost 3-fold increased risk of being a frequent exacerbator $(\mathrm{OR}=2.93 ; 95 \% \mathrm{Cl}$ : 1.22 - 6.99; $p=0.02$ ).

When frequent exacerbators were defined as patients with $\geq 3$ exacerbations, we observed that only a course of oral corticosteroids in the period of 3 months prior to the study predicted whether patients were to be frequent or infrequent 
exacerbators in the next year. These patients had a 10 -fold increased risk (OR=10.35; 95\% Cl: $3.18-33.68)$.

Of the variables measured in the subset of patients that could produce a sputum sample in stable phase, the results of the sputum culture (no bacterial infection or colonisation versus infection) was univariately associated with exacerbator status, both with "frequent" defined as $\geq 2$ and as $\geq 3$ exacerbations. This variable was then tested as a predictor in the final multivariate logistic regression model in this subset of patients.

When frequent exacerbator was defined as $\geq 1$ exacerbations, IL-8 was also a univariate predictor and therefore included in the multivariate model together with the results of the sputum culture, however both were not significant in the multivariate model.

Only in frequent exacerbator being defined as a patient with $\geq 3$ exacerbations, a bacterial infection according to the sputum culture was an independent predictor $(\mathrm{OR}=11.34 ; 95 \% \mathrm{Cl}: 1.07-120.0)$ in the multivariate model together with a course of oral corticosteroids in the period of 3 months prior to the study (OR=37.91; $95 \%$ Cl: $2.63-546.57)$.

\section{Discussion}

Our study in moderate to severe COPD patients showed that HRQoL and a course of oral corticosteroids in the past 3 months together predict best whether patients will exacerbate frequently over the course of the next year.

To reduce exacerbation frequency it is important that patients at risk for frequent exacerbations can be identified by easy to measure factors, because it has potential implications for treatment and self-management plans. We wanted to identify predictors for frequent exacerbations from multiple domains of COPD. Instead of looking at the severe end of the disease, analysing risk factors for exacerbations that need hospitalisation(10) and re-hospitalisation after former hospitalisations $(11 ; 12)$, we focused mainly on outpatient exacerbations ( $91 \%$ of the exacerbations).

Two easy to measure factors were identified. The first, courses of oral steroids in the last three months, can easily and validly be obtained from patients themselves, pharmacist records, and hospital records. Indeed, in many large current trials in 
COPD, exacerbations are routinely collected and frequently chosen as primary endpoint.

The second factor, HRQoL as assessed by the SGRQ is also easy measurable. Total SGRQ score is mainly determined by impact score which covers factors such as employment, being in control of health, panic, stigmatisation, the need for medication and its side effects, and expectations for health and disturbance of daily life(16). The factors "being in control of health", "panic", and "disturbance of daily life" could be worse in less stable patients and these patients could therefore be identified as being at higher risk of being frequent exacerbators, something that to our knowledge has not been analysed in this way before. Indeed, the question "I feel that I am not in control of my chest problem" was answered positively more often by frequent (35.5\%) than by infrequent exacerbators $(12.2 \%) \quad(p=0.004)$. Similarly, the question "I get afraid or panic when I cannot get my breath" was answered positively more often by frequent $(38.7 \%)$ than by infrequent exacerbators $(22.2 \%)(p=0.073)$. Although a similar direction of distribution was seen in questions that describe disturbance of life ("I cannot go out for entertainment or recreation / I cannot go out of the house to do the shopping / I cannot do housework" were answered with yes within a range of $4.5-12.2 \%$ in infrequent exacerbators and in $9.2-25.8 \%$ in frequent exacerbators), these differences were not significant or borderline significant.

Another explanation for the difference in HRQoL between infrequent and frequent exacerbators could be that patients with a lower HRQoL status complain more than patients with a higher HRQoL status and that these patients therefore contact their physician more often or with a lower threshold, and consequently receive more courses of oral corticosteroids or antibiotics.

Furthermore, we included patients if they were exacerbation-free for one month. The SGRQ however, can take longer than a month to return to baseline and the predictive value could therefore be related to an exacerbation within one to three months of enrolment. However, when we looked at the duration from the last exacerbation to enrolment, we observed no difference between frequent exacerbators or not (data not shown).

Patients who recently had an exacerbation are more susceptible to new exacerbations in the following period. Although this so called tracking can be clearly recognised in clinical practice, it is good to consider why it occurs. It could be due to bacterial colonisation of the airways, since Patel et al. concluded from 
their data that lower airway bacterial colonisation in stable state modulates the character and frequency of exacerbations(8). This finding about the relationship between airway colonisation and exacerbation frequency could however not be confirmed by Tumkaya et al.(9). In our univariate analysis we did find a significant relation between stable sputum cultures and exacerbation frequency, with frequent exacerbators having more often bacterial infections in stable state. However, in our multivariate analysis the outcome of the stable sputum cultures did not predict whether patients would become infrequent or frequent exacerbators over the course of the next year, when taking into account other variables. Additional multivariate analyses, where we classified frequent exacerbators as those with respectively $\geq 1$ exacerbation and $\geq 3$ exacerbations, showed that having an infection in stable sputum did become a predictor when frequent exacerbator was defined as those with $\geq 3$ exacerbations. It could therefore be that the effect of infection or colonisation on exacerbation frequency is only present in patients with higher exacerbation frequencies.

There is evidence that exacerbation frequency increases with disease severity(22), but there is little information in literature about change of exacerbation frequency over time in individual patients. Donaldson et al. suggested that the annual exacerbation rate remains fairly consistent within a patient from one year to the next(23). However, in contrast to Donaldson et al. we observed that a sizable number of patients switched from being frequent exacerbators to being infrequent exacerbators and vice versa (Table 1). Furthermore, we observed that exacerbation frequency prior to the study was not a multivariate predictor for being a frequent or infrequent exacerbator during the first year of the study. Even when we excluded a course of oral corticosteroids 3 months prior to the study from the multivariate model, the exacerbation frequency prior to the study still was not a significant predictor (data not shown). Only when we defined frequent exacerbators as patients with $\geq 1$ exacerbation, exacerbation frequency prior to the study was a multivariate predictor for being a frequent or infrequent exacerbator during the first year of the study.

What should be mentioned is that the annual exacerbation rate of patients is calculated as an average, which is described in the statistical analyses paragraph. The true annual exacerbation rate could therefore be slightly different. 
Another possible limitation of this study could be that the external validity of the results may be poorer since the patient population we studied is the control group of a clinical trial, which is recruited with certain restrictive criteria, and consisted of patients with moderate to severe COPD. We however feel that this is not a problem in this study, since the inclusion criteria used in this study, shown in the method section, were not that strict.

Bhowmik et al. showed that patients with more frequent exacerbations had higher baseline sputum cytokine levels, which predicted the frequency of future exacerbations(24). However, in our study the inflammation markers IL-6 and IL-8 were not univariate predictors of exacerbation frequency and therefore not included in the multivariate model. COPD severity in our study and Bhowmik 's study were comparable. Furthermore, frequent exacerbators in both studies were analysed (also) as patients with $\geq 3$ exacerbations. As Bhowmik et al. suggest, frequent exacerbations may increase airway inflammation, which will be represented by higher levels of IL- 6 and IL-8, and when exacerbation rates remain fairly consistent, which Donaldson showed(23), the amount of airway inflammation and therefore the levels of the inflammation markers IL-6 ad IL-8 will be predictors for exacerbation frequency.

In our study, exacerbation frequency prior to the study was not a predictor for being a frequent exacerbator during the first year of the study. Many patients becoming a frequent exacerbator during the first year of the study were not frequent exacerbators prior to the study. When frequent exacerbators were defined as patients with $\geq 3$ exacerbations, $66.7 \%$ of the frequent exacerbators were infrequent exacerbators prior to the study. Since exacerbations frequency was not stable, the increased airway inflammation due to high exacerbation frequency prior to the study was not present in a large group of our patients.

\section{Conclusions}

In conclusion, it seems that only a few factors are predictive of frequent exacerbations in the near future. Although the model can increase identification of patients at risk for frequent exacerbations, the predictive value of the model is not sufficient in individual patients.

Furthermore, our data suggest, in contrast to previous observations, that exacerbation frequency is not a constant feature. This warrants further exploration 
over longer time periods, since if it were confirmed, it would have implications for guidelines for prescription of ICS to patients with GOLD stage III and IV that suffer from repeated exacerbations. 


\section{References}

(1) Sethi S, Evans N, Grant BJ, Murphy TF. New strains of bacteria and exacerbations of chronic obstructive pulmonary disease. N Engl J Med 2002 Aug 15;347(7):465-71.

(2) Celli BR, Barnes PJ. Exacerbations of chronic obstructive pulmonary disease. Eur Respir J 2007 Jun;29(6):1224-38.

(3) Seemungal TA, Donaldson GC, Paul EA, Bestall JC, Jeffries DJ, Wedzicha JA. Effect of exacerbation on quality of life in patients with chronic obstructive pulmonary disease. Am J Respir Crit Care Med 1998 May;157(5 Pt 1):1418-22.

(4) Donaldson GC, Seemungal TA, Bhowmik A, Wedzicha JA. Relationship between exacerbation frequency and lung function decline in chronic obstructive pulmonary disease. Thorax 2002 Oct;57(10):847-52.

(5) Wedzicha JA, Donaldson GC. Exacerbations of chronic obstructive pulmonary disease. Respir Care 2003 Dec;48(12):1204-13.

(6) Turnock AC, Walters EH, Walters JA, Wood-Baker R. Action plans for chronic obstructive pulmonary disease. Cochrane Database Syst Rev 2005;(4):CD005074.

(7) Bhowmik A, Seemungal TA, Sapsford RJ, Devalia JL, Wedzicha JA. Comparison of spontaneous and induced sputum for investigation of airway inflammation in chronic obstructive pulmonary disease. Thorax 1998 Nov;53(11):953-6.

(8) Patel IS, Seemungal TA, Wilks M, Lloyd-Owen SJ, Donaldson GC, Wedzicha JA. Relationship between bacterial colonisation and the frequency, character, and severity of COPD exacerbations. Thorax 2002 Sep;57(9):759-64.

(9) Tumkaya M, Atis S, Ozge C, Delialioglu N, Polat G, Kanik A. Relationship between airway colonization, inflammation and exacerbation frequency in COPD. Respir Med 2007 Apr;101(4):729-37.

(10) Garcia-Aymerich J, Monso E, Marrades RM, Escarrabill J, Felez MA, Sunyer J, et al. Risk factors for hospitalization for a chronic obstructive pulmonary disease exacerbation. EFRAM study. Am J Respir Crit Care Med 2001 Sep 15;164(6):1002-7.

(11) Almagro P, Barreiro B, Ochoa de EA, Quintana S, Rodriguez CM, Heredia JL, et al. Risk factors for hospital readmission in patients with chronic obstructive pulmonary disease. Respiration 2006;73(3):311-7. 
(12) Garcia-Aymerich J, Farrero E, Felez MA, Izquierdo J, Marrades RM, Anto JM. Risk factors of readmission to hospital for a COPD exacerbation: a prospective study. Thorax 2003 Feb;58(2):100-5.

(13) Monninkhof E, Van der Valk P, Van der Palen J, van HC, Zielhuis G. Effects of a comprehensive self-management programme in patients with chronic obstructive pulmonary disease. Eur Respir J 2003 Nov;22(5):815-20.

(14) American Thoracic Society. Standards for the diagnosis and care of patients with chronic obstructive pulmonary disease. Am J Respir Crit Care Med 1995;152:s77-s120.

(15) Brand PL, Quanjer PH, Postma DS, Kerstjens HA, Koeter GH, Dekhuijzen PN, et al. Interpretation of bronchodilator response in patients with obstructive airways disease. The Dutch Chronic Non-Specific Lung Disease (CNSLD) Study Group. Thorax 1992 Jun;47(6):429-36.

(16) Jones PW, Quirk FH, Baveystock CM, Littlejohns P. A self-complete measure of health status for chronic airflow limitation. The St. George's Respiratory Questionnaire. Am Rev Respir Dis 1992 Jun;145(6):1321-7.

(17) EuroQol--a new facility for the measurement of health-related quality of life. The EuroQol Group. Health Policy 1990 Dec;16(3):199-208.

(18) Black LF, Hyatt RE. Maximal respiratory pressures: normal values and relationship to age and sex. Am Rev Respir Dis 1969 May;99(5):696-702.

(19) Pauwels RA, Buist AS, Calverley PM, Jenkins CR, Hurd SS. Global strategy for the diagnosis, management, and prevention of chronic obstructive pulmonary disease. NHLBI/WHO Global Initiative for Chronic Obstructive Lung Disease (GOLD) Workshop summary. Am J Respir Crit Care Med 2001 Apr;163(5):125676.

(20) Van der Valk P, Monninkhof E, van der Palen J., Zielhuis G, van Herwaarden C., Hendrix R. Clinical predictors of bacterial involvement in exacerbations of chronic obstructive pulmonary disease. Clin Infect Dis 2004 Oct 1;39(7):980-6.

(21) Isenberg HD. Clinical microbiology procedures handbook. 2004.

(22) Burge PS, Calverley PM, Jones PW, Spencer S, Anderson JA, Maslen TK. Randomised, double blind, placebo controlled study of fluticasone propionate in patients with moderate to severe chronic obstructive pulmonary disease: the ISOLDE trial. BMJ 2000 May 13;320(7245):1297-303. 
(23) Donaldson GC, Seemungal TA, Patel IS, Lloyd-Owen SJ, Wilkinson TM, Wedzicha JA. Longitudinal changes in the nature, severity and frequency of COPD exacerbations. Eur Respir J 2003 Dec;22(6):931-6.

(24) Bhowmik A, Seemungal TA, Sapsford RJ, Wedzicha JA. Relation of sputum inflammatory markers to symptoms and lung function changes in COPD exacerbations. Thorax 2000 Feb;55(2):114-20. 


\section{CHAPTER 3}

\section{RELATION OF SPUTUM COLOUR TO BACTERIAL LOAD IN}

ACUTE EXACERBATIONS OF COPD

Marjolein Brusse-Keizer, Anne Grotenhuis, Huib Kerstjens, Maaike Telgen, Job van der Palen, Ron Hendrix, Paul van der Valk

Respir Med. 2009 Apr;103(4):601-6 


\begin{abstract}
Background: When COPD patients present with an exacerbation, one cannot verify a bacterial cause of an exacerbation without time-consuming laboratory analyses. This makes it difficult to decide up front if antibiotic treatment is needed. Therefore, in clinical practice sputum colour and purulence are often used.

Objective: To determine whether sputum colour and purulence, assessed by the Stockley colour chart, correlate with overall bacterial load in COPD patients admitted for an exacerbation. To check the robustness of the colour and purulence assessment, we correlated the changes in these parameters and the corresponding change in bacterial load in sputum over the first seven days of hospitalisation.
\end{abstract}

Methods: Twenty-two COPD patients admitted to the hospital for an exacerbation were included. During the first seven days daily sputum samples were collected.

Results: A very weak association between bacterial load and sputum colour was found. There was no difference in bacterial load between patients with purulent sputum or not. Also, no consistent relationship between change in sputum colour and change in bacterial load during admission was found.

Conclusions: The very weak association between bacterial load and sputum colour confirms concerns over the usefulness of the colour chart. The distinction between purulent and mucoid sputum at exacerbation is insufficient for distinction between patients that are likely to benefit from antibiotic therapy and those who are not. Complementary studies are needed to determine which other, easily measurable factors can be used as predictors for an indication for use of antibiotics; sputum colour is not the one. 


\section{Introduction}

Morbidity and mortality among patients with Chronic Obstructive Pulmonary Disease (COPD) are for an important part related to acute exacerbations, which occur on average one to three times a year but much more frequently in some patients(1;2). Exacerbations are characterised by a heterogeneous aetiology. Recent studies showed that at least one-third of the exacerbations might be triggered by viral infections(3-6). Furthermore, bacteria play an important role in the onset of exacerbations(7). Several studies have shown the presence of potential pathogenic micro-organisms (PPMs) in approximately $50 \%$ of exacerbations(8;9). On the other hand, these PPMs might also colonise the airways of COPD patients.

Treatment of exacerbations with antibiotics is usually empirical. At clinical presentation it is hard to predict and verify a bacterial cause without timeconsuming laboratory analyses, which makes it difficult to decide up front if antibiotic treatment is needed(10). According to the GOLD criteria, patients with an exacerbation who meet the Anthonisen type I criteria (increase in dyspnoea, sputum volume and sputum purulence) benefit from antibiotic treatment(11). However, van der Valk et al. reported that an Anthonisen type I exacerbation does not predict a bacterial origin of an exacerbation and that sputum purulence was not associated with a bacterial infection(1).

Since purulence is subjective and not clearly defined, the use of colour charts has been suggested. Stockley et al. designed and validated a sputum colour chart by which a distinction between purulent and mucoid exacerbations can be made(12). Also Allegra et al. provided additional evidence that purulent sputum is associated with bacterial growth in the airways of patients with moderate to severe COPD. They however recorded that also in mucoid sputum presence of bacterial growth was very common (78\%)(13). Results of a study by Soler et al. showed that selfreported purulence in the sputum predicts the presence of bacteria at concentrations in the airways of $\geq 10^{2} \mathrm{cfu} / \mathrm{mL}$ for protected specimen brush specimens(14).

So, contradictory data and opinions about the association between sputum purulence and bacterial involvement in exacerbations result in uncertainty whether to use sputum purulence as an indicator for antibiotic treatment. The aim of the present study was to determine whether sputum colour and purulence, as assessed by the nine-point Stockley colour chart, correlate with bacterial load in patients admitted for an exacerbation of COPD. To check the robustness of the colour and 
purulence assessment, the changes in these parameters and the corresponding change in bacterial load in sputum over the first seven days of hospitalisation were correlated.

\section{Methods}

\section{Patients and study design}

Patients hospitalised from April 2007 through June 2007 for an exacerbation of COPD at the inpatient pulmonary department of Medisch Spectrum Twente in Enschede, the Netherlands, were recruited. This study is part of our COPD cohort study, the COMIC study. Recruitment criteria were: 1 ) a clinical diagnosis of COPD as defined by the GOLD-criteria, 2) admitted with signs and symptoms of an exacerbation of COPD, defined as an acute negative change from the baseline, reported by the patient, in dyspnoea and/or sputum volume and/or colour of sputum (yellowish or greenish sputum) and/or cough, which warranted additional treatment with prednisolone with or without antibiotics by a physician 3) current or former smoker, 4) age 40 years or over, 5) no pneumonia, defined as an acute respiratory tract illness associated with radiographic shadowing on a chest radiograph which was neither pre-existing nor of any other cause, 6) no maintenance treatment with antibiotics, 7) able to produce spontaneous sputum, and 8) no other medical condition with low survival or a serious psychiatric morbidity.

All patients included received care according to the hospital protocol for treatment of COPD exacerbations. The hospital's medical ethical committee approved the study. All patients provided written informed consent.

\section{Baseline characteristics}

Demographic and baseline data were collected using medical records. Smoking history was determined by the Vlagtwedde Questionnaire(15). Exacerbation frequency in the preceding year and courses of antibiotics and prednisolone during the last four weeks before admission were registered from pharmacy records. Exacerbation frequency was estimated by counting the number of separate courses of antibiotics or prednisolone patients used for lung associated illness. Data on antibiotics and prednisolone during the first seven hospital days were obtained from hospital pharmacy records. 


\section{Sputum colour and microbiology}

During the first seven days of admission, spontaneously expectorated sputum samples were collected. Samples were collected once a day, preferably in the morning. Immediately after collection, sputum colour was determined according to the Stockley protocol (BronkoTest, Heredilab Inc, Salt Lake City, UT, USA)(12).

A Gram's stain and quantitative culture were performed for all collected sputum samples. Additionally, a semi-quantitative culture was performed for each patient's first sputum sample after admission. Bacterial load was defined as total amount of $\mathrm{cfu} / \mathrm{ml}$. Infection was defined by the presence of PPM in pure culture or as the presence of one or more PPM in excess (one log or more) to normal microbiological flora in sputum. Bacterial colonisation was defined as the presence of PPM in culture in equal amount or less compared to normal microbiologic flora in sputum(1;16).

One day after admission a $10 \mathrm{cc}$ blood sample was obtained. In all sputum and blood samples IL-6, IL-8 and IL-10 were quantified using PeliKine Compact ${ }^{\text {TM }}$ human sandwich ELISA kits (Sanquin, CLB, Amsterdam, the Netherlands). C-reactive protein (CRP) level in sputum and blood was determined using the NycoCard ${ }^{\circledR}$ CRP Single Test (Clindia Diagnostics(C). MPO enzymatic activity in sputum was determined by colorimetric change in absorbance during a reaction with $\mathrm{O}$ Dianisidine dihydrochloride (Sigma-Aldrich (C).

\section{Statistical analyses}

Baseline characteristics were reported as mean \pm SD for continuous variables or as number with percentage for categorical variables. Not normally distributed variables were reported as median with range. For non-parametric variables we applied a natural logarithm to obtain a normal distribution. If this was ineffective, variables were dichotomised based on median values.

Linear regression analysis was used to test the relation between sputum colour and bacterial load. Correlation coefficients were calculated to identify variables associated with sputum colour. In case of dichotomous variables this was performed by t-tests. The a priori list of potential confounding variables included: IL-6, IL-10 and CRP in sputum and blood, result of semi-quantitative culture of the first sputum sample (no colonisation and no infection versus colonisation or infection), smoking status, use of antibiotics or prednisolone during the four weeks prior to admission (yes/no) and use of antibiotics during the first seven days of admission (yes/no). Variables associated with sputum colour with $p<0.15$ were 
subsequently tested for an association with bacterial load and considered as potential confounders when $\mathrm{p}<0.15$. Also of the variables IL-8, MPO in sputum, number of leukocytes in sputum, we analysed the association with both sputum colour and bacterial load. Since these variables are in the assumed pathway they were not entered in the multivariate model. We started the multivariate model with all potential confounders. Variables with the highest $p$-value were eliminated step by step, and at each step we verified whether the beta-coefficient of sputum colour had not changed by $10 \%$ or more from its initial value. The interaction between sputum colour and antibiotic use during the four weeks prior to admission and interaction between sputum colour and use of antibiotics during the first seven days of admission were assessed by adding these interaction variables into the multivariate model.

In a secondary analysis the association between sputum purulence and bacterial load was tested. Sputum with a colour value $\leq 2$ was defined as mucoid and sputum colour $\geq 3$ was defined as purulent. Potential confounding variables were identified by an essentially similar approach as described above, but the formal testing of associations was now performed with t-tests or Mann-Whitney $U$ tests as appropriate for continuous variables and by Chi-square tests or Fisher's Exact tests as appropriate for between-group comparisons of categorical variables. The association of variables in the pathway with sputum purulence and bacterial load were analysed. Interaction between sputum purulence and antibiotic use during the four weeks prior to admission and interaction between sputum purulence and use of antibiotics during the first seven days of admission were assessed by adding these interaction variables into the multivariate model.

Repeated measurements analysis was performed to test for change in sputum colour and bacterial load during the first seven days of admission. Finally, we looked at the relationship between a change in sputum colour and a change in bacterial load during hospital admission by means of scatter plots and correlation coefficients.

Data-analysis was performed with the statistical package SPSS/PC for Windows (version 12.0.1) (SPSS, Inc., Chicago, IL).

\section{Results}

Table 1 shows the baseline characteristics of the 22 included patients. In total, 124 sputum samples were obtained. 
Table 1. Baseline characteristics of participating COPD patients

\begin{tabular}{|c|c|}
\hline & $\mathrm{N}=22$ \\
\hline Mean age at enrolment in years (SD) & $68(10)$ \\
\hline \multicolumn{2}{|l|}{ Gender (Number (\%)) } \\
\hline Male & $10(45)$ \\
\hline Female & $12(55)$ \\
\hline \multicolumn{2}{|l|}{ Smoking status (Number (\%)) } \\
\hline Current smokers & $12(55)$ \\
\hline Ex-smokers & $10(45)$ \\
\hline Median exacerbation frequency/year (range)* & $1.5(0-5)$ \\
\hline \multicolumn{2}{|l|}{ GOLD classification (Number (\%)) } \\
\hline GOLD stage 1 & $1(5)$ \\
\hline GOLD stage 2 & $5(23)$ \\
\hline GOLD stage 3 & $10(45)$ \\
\hline GOLD stage 4 & $6(27)$ \\
\hline \multicolumn{2}{|l|}{ Lung function (post-bronchodilator) } \\
\hline Median FEV1 in litres (range) & $0.95(0.43-2.97)$ \\
\hline Median FEV1 as $\%$ of predicted (range) & $36(19-83)$ \\
\hline Mean FEV1/VC in \% (SD) & $40(13)$ \\
\hline \multicolumn{2}{|l|}{ Previous treatment (Number (\%)) } \\
\hline Antibiotics $<4$ weeks before study entry & $15(68)$ \\
\hline Finished course of antibiotics before admission & $10(45)$ \\
\hline Still receiving antibiotics at admission & $5(23)$ \\
\hline Prednisolone $<4$ weeks before study entry & $14(64)$ \\
\hline Finished course of prednisolone before admission & $11(50)$ \\
\hline Still receiving prednisolone at admission & $3(14)$ \\
\hline Prednisolone maintenance therapy & $2(9.1)$ \\
\hline
\end{tabular}

\footnotetext{
* Exacerbation frequency refers to the number of exacerbations during the year preceding admission and is based on the number of separate courses of antibiotics or prednisolone prescribed for lung associated illness according to the database of the patient's pharmacy.

FEV1 = forced expiratory volume in 1 second; IVC= inspiratory vital capacity; GOLD = Global Initiative on Obstructive Lung Disease
}

\section{Relationship between sputum colour and bacterial load}

The univariate linear regression analysis showed no significant relation between sputum colour and bacterial load $(p=0.16)$. Variables univariately associated with sputum colour were: IL-8 in sputum, MPO in sputum, leucocytes in sputum (yes or no), CRP in blood ( $\leq 14$ versus $>14 \mathrm{mg} / \mathrm{L}$ ), use of antibiotics during the first seven days of admission and result of semi-quantitative culture of the first sputum sample. Of these variables, IL-8 in sputum, MPO in sputum and use of antibiotics 
during the first seven days of admission were also associated with bacterial load. The association between bacterial load and sputum colour was only adjusted for the use of antibiotics, since IL-8 and MPO are part of the assumed pathway between bacterial load and sputum colour, and adjustment for these factors would make a potential relationship disappear. There was no interaction between sputum colour and antibiotic use during the four weeks prior to admission, nor was there an interaction between sputum colour and use of antibiotics during the first seven days of admission. The multivariate model showed a significant positive regressioncoefficient for sputum colour $(0.41(95 \% \mathrm{Cl}$ : $0.01-0.81 ; \mathrm{p}=0.045))$ and a significant negative coefficient for antibiotic use during admission $(-2.19(95 \% \mathrm{Cl}$ : $-3.67--0.71$; $p=0.004))$. Both regression coefficients are on a log base. The explained variance of this model was only 0.087 .

\section{Relationship between sputum purulence and bacterial load}

The univariate linear regression analysis showed no significant relationship between sputum purulence and bacterial load $(p=0.64)$. Variables univariately associated with sputum purulence were: IL-8 in sputum, MPO in sputum and leucocytes in sputum (yes or no). IL-8 in sputum and MPO in sputum were also associated with bacterial load. Since, IL-8 and MPO are both part of the assumed pathway between bacterial load and sputum purulence, these variables were again not included in the multivariate analysis and no potential confounders remained. Furthermore there was no interaction between sputum purulence and antibiotic use during the four weeks prior to admission, nor was there interaction between sputum purulence and use of antibiotics during the first seven days of admission.

\section{Longitudinal change in sputum colour and bacterial load during admission}

Repeated measurements analysis showed no change in sputum colour $(p=0.16)$ and bacterial load $(p=0.99)$ during the first seven days of admission. Figure 1 shows the mean value of sputum colour and bacterial load at days 2, 4 and 6 of admission. Figure $2 \mathrm{a}$ and $\mathrm{b}$ show respectively the change in colour and the change in bacterial load during the first seven days of admission on a patient level. 


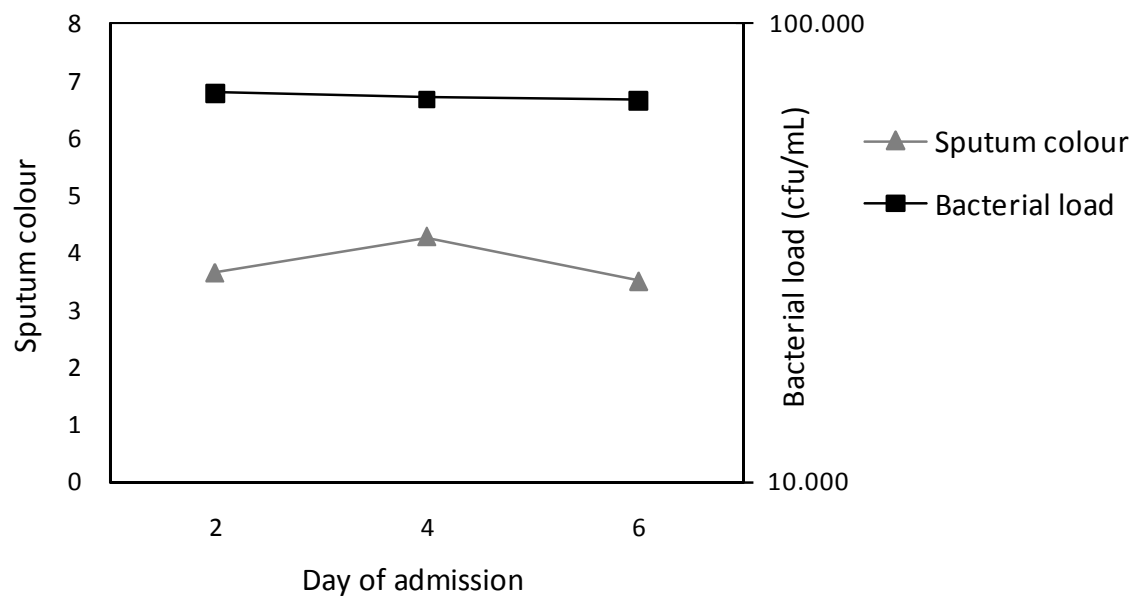

Figure 1. Longitudinal change in mean value of sputum colour and bacterial load during admission.

\section{Relationship between change in sputum colour and change in bacterial load}

There was no consistent relationship between change in sputum colour and change in bacterial load during admission, as judged by the constructed scatter plots and correlation coefficients comparing baseline data with follow-up days and between consecutive follow-up days. The correlation coefficients varied from -0.819 to 0.884 .
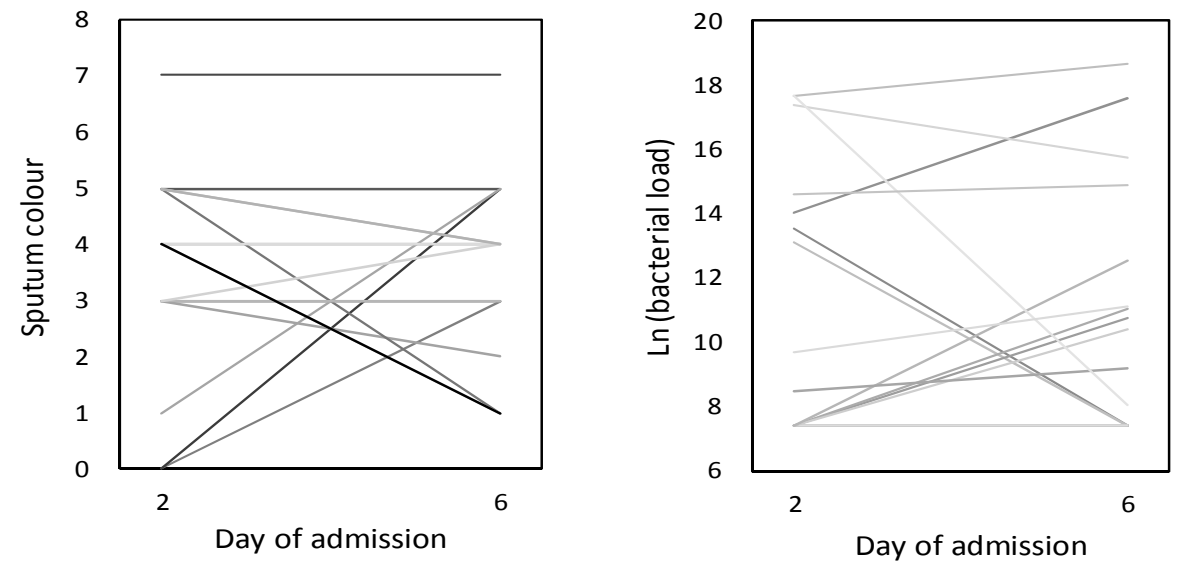

Figure $2 \mathrm{a}$ and $\mathrm{b}$. Longitudinal changes of sputum colour (a) and bacterial load (b) during admission on a patient level. 


\section{Discussion}

This study found a significant but very weak association between bacterial load and sputum colour after correction for confounding by antibiotic use during admission. Only $8.7 \%$ of the variance in bacterial load could be explained by this model. Furthermore when we dichotomised the 9-point score of sputum colour into purulent and mucoid sputum, the relationship with bacterial load vanished completely. Also, no consistent relationship between change in sputum colour and change in bacterial load during admission was found.

Our findings on the relationship between sputum colour and purulence with bacterial load are in contrast to the results of other study groups. Stockley et al showed that the presence of purulent sputum was $94.4 \%$ sensitive and $77.0 \%$ specific for the yield of a high bacterial load(10). Soler et al. who looked at the selfreported presence of purulent sputum, concluded that the self-reported presence of purulent sputum predicted the presence of bacterial infection in the distal airways(14). Allegra et al. found an association between purulent sputum and bacterial growth, in which growth was classified as the presence of $>10^{6}$ $\mathrm{CFU} / \mathrm{mL}(13)$. They however did not only find a high number of positive cultures in purulent sputum samples (95\%), but also in mucoid sputum samples (78\%). So, although they concluded that purulent sputum was associated with bacterial growth, the distinction between purulent and mucoid sputum was not sufficient for the distinction between bacterial growth or not.

There are some differences that possibly could explain some of the contradictory results. One explanation might be that contrary to the abovementioned studies, we looked at total bacterial load on a continuous scale and not classified into bacterial growth or not, or infection or not. Another difference is that in the studies by Stockley, Allegra and Soler, patients had not received antibiotic treatment 4 weeks before admission. In our study $68 \%$ of the patients received antibiotics 4 weeks prior to the study and $23 \%$ received antibiotics at admission. The decision not to exclude these patients was based on the fact, that if we want to use sputum colour as an indication for antibiotic treatment, it should be usable in clinical practice. And as in our study, many patients already receive antibiotics from their GP or chest physician before admission. By performing multivariate analyses, correcting for the use of antibiotics we addressed this item. 
Another difference is that Allegra et al. developed their own colour-coding chart, which might have introduced some differences in coding the colour of the sputum samples.

Like in our study, Stockley et al. also looked at changes in sputum colour over time. However, they compared sputum samples during exacerbations and during stable state after 2 months. They showed that sputum colour of patients with mucoid exacerbations remained similar. On the other hand, in patients presenting with purulent sputum, colour changed from a median of 4.0 to a median of 3.0 in stable state. This indicates that many patients do not return to mucoid sputum, which would implicate that these patients would be treated again with antibiotics during their next exacerbation. If one believes in the value of sputum colour determination, this maintenance of purulent sputum should elicit different/longer/higher dose antibiotics. We however, observed absolutely no change in both mean sputum colour and mean bacterial load on a group level over the first seven days of admission, although the majority of patients was treated with antibiotics. This might implicate that change in sputum colour takes a long time, and also bacterial load does not seem to be immediately changed by a course of antibiotics. Within-patient changes were however often present, but changes were in all directions, and varied from day to day. Furthermore, there appeared to be no consistent relationship between the individual changes in sputum colour and the accompanied change in bacterial load. This makes us reluctant about the usefulness of sputum colour as indicator for bacterial load and therefore for treatment with antibiotics.

The current study showed that there is only a very weak association between bacterial load and sputum colour, which confirms the results of a previous study performed by our study group(1) and that of others. Furthermore when sputum colour was divided into purulent and mucoid sputum, the relationship with bacterial load vanished completely The distinction between purulent and mucoid sputum at the moment patients present themselves with an exacerbation seems therefore insufficient for distinction between patients who are likely to benefit form antibiotic therapy and those who are not. More studies are needed to determine which easy measurable factors could be used as a predictor for an indication for use of antibiotics; sputum colour is not the one. 


\section{References}

(1) Van der Valk P, Monninkhof E, van der Palen J., Zielhuis G, van Herwaarden C., Hendrix R. Clinical predictors of bacterial involvement in exacerbations of chronic obstructive pulmonary disease. Clin Infect Dis 2004 Oct 1;39(7):980-6.

(2) Seemungal TA, Donaldson GC, Bhowmik A, Jeffries DJ, Wedzicha JA. Time course and recovery of exacerbations in patients with chronic obstructive pulmonary disease. Am J Respir Crit Care Med 2000 May;161(5):1608-13.

(3) Seemungal TA, Donaldson GC, Paul EA, Bestall JC, Jeffries DJ, Wedzicha JA. Effect of exacerbation on quality of life in patients with chronic obstructive pulmonary disease. Am J Respir Crit Care Med 1998 May;157(5 Pt 1):1418-22.

(4) Greenberg SB, Allen M, Wilson J, Atmar RL. Respiratory viral infections in adults with and without chronic obstructive pulmonary disease. Am J Respir Crit Care Med 2000 Jul;162(1):167-73.

(5) Greenberg SB. Viral respiratory infections in elderly patients and patients with chronic obstructive pulmonary disease. Am J Med 2002 Apr 22;112 Suppl 6A:28S-32S.

(6) Seemungal TA, Harper-Owen R, Bhowmik A, Jeffries DJ, Wedzicha JA. Detection of rhinovirus in induced sputum at exacerbation of chronic obstructive pulmonary disease. Eur Respir J 2000 Oct;16(4):677-83.

(7) Saint S, Bent S, Vittinghoff E, Grady D. Antibiotics in chronic obstructive pulmonary disease exacerbations. A meta-analysis. JAMA 1995 Mar 22;273(12):957-60.

(8) Sethi S, Murphy TF. Bacterial infection in chronic obstructive pulmonary disease in 2000: a state-of-the-art review. Clin Microbiol Rev 2001 Apr;14(2):336-63.

(9) Fagon JY, Chastre J, Trouillet JL, Domart Y, Dombret MC, Bornet M, et al. Characterization of distal bronchial microflora during acute exacerbation of chronic bronchitis. Use of the protected specimen brush technique in 54 mechanically ventilated patients. Am Rev Respir Dis 1990 Nov;142(5):1004-8.

(10) Stockley RA, O'Brien C, Pye A, Hill SL. Relationship of sputum color to nature and outpatient management of acute exacerbations of COPD. Chest 2000 Jun;117(6):1638-45. 
(11) Anthonisen NR, Manfreda J, Warren CPW, Hershfield ES, Harding GKM, Nelson NA. Antibiotic therapy in exacerbations of chronic obstructive pulmonary disease. Ann Intern Med 1987;106:196-204.

(12) Stockley RA, Bayley D, Hill SL, Hill AT, Crooks S, Campbell EJ. Assessment of airway neutrophils by sputum colour: correlation with airways inflammation. Thorax 2001 May;56(5):366-72.

(13) Allegra L, Blasi F, Diano P, Cosentini R, Tarsia P, Confalonieri M, et al. Sputum color as a marker of acute bacterial exacerbations of chronic obstructive pulmonary disease. Respir Med 2005 Jun;99(6):742-7.

(14) Soler N, Agusti C, Angrill J, Puig De la BJ, Torres A. Bronchoscopic validation of the significance of sputum purulence in severe exacerbations of chronic obstructive pulmonary disease. Thorax 2007 Jan;62(1):29-35.

(15) van der Lende R., Jansen-Koster EJ, Knijpstra S, Meinesz AF, Wever AM, Orie NG. [Prevalence of cold in Vlagtwedde and Vlaardingen (computer diagnosis versus doctors' diagnosis)]. Ned Tijdschr Geneeskd 1975 Dec 13;119(50):198896.

(16) Isenberg HD. Clinical microbiology procedures handbook. 2004. 


\section{CHAPTER 4}

NECESSITY OF ANTIBIOTICS IN OUTPATIENTS WITH A COPD EXACERBATION: THE ABC-TRIAL

Marjolein Brusse-Keizer, Paul van der Valk, Ron Hendrix, Huib Kerstjens, Job van der Palen

Submitted 


\begin{abstract}
Background: The effectiveness of antibiotics in COPD exacerbations is still matter of debate, especially in outpatients with an intermediate probability of bacterial infection.
\end{abstract}

Methods: 35 COPD outpatients seen by their chest-physician with a moderately severe COPD exacerbation, but without pneumonia, were randomised in a double blind, placebo controlled study. Patients had one or two of the following characteristics; a positive Gram's stain of the sputum, 2 or more exacerbations in the previous year, a decrease in lung function of $\geq 200 \mathrm{ml}$ and $\geq 12 \%$. Patients received amoxicillin clavulanic acid or placebo for 7 days combined with a course of prednisolone for 7 days. Primary outcome was duration of the exacerbation. Additionally we measured severity of the exacerbation, health related quality of life, sputum parameters, number of relapses within 28 days, and number of reexacerbations within 4 months after the study.

Findings: There was no difference in duration of the exacerbation between the two groups (hazard rate $=1.12(95 \% \mathrm{Cl}$ : $0.5-2.3 ; \mathrm{p}=0.77)$, nor in any other treatment parameter.

Interpretation: We detected no evidence for effectiveness of antibiotic treatment of moderately severe COPD outpatient exacerbations with an intermediate probability of bacterial infection, and treated at home with prednisolone. 


\section{Introduction}

Chronic Obstructive Pulmonary Disease (COPD) is characterised by periodic exacerbations that are associated with substantial morbidity and mortality. Management of exacerbations is empirical and includes oral corticosteroids, often combined with broad spectrum antibiotics to treat a presumed bacterial infection(1).The use of antibiotics remains controversial due to several reasons. One is that only approximately one third of exacerbations are due to bacterial infections(2). Second, given the existence of bacterial infections, the treatment is empirical since culture and resistance results usually take one week to become available. Third, and perhaps most importantly, antibiotics appeared to offer no benefits in outpatients with mild to moderate exacerbations(3). Finally, growing resistance against anti-bacterial agents is an additional reason to be reluctant with prescription of antibiotics $(4 ; 5)$. It is therefore not surprising that frequency and choice of antibiotic use is highly variable not only between countries, but also within countries. International guidelines recommend antibiotics if two of the three following criteria are present: increased dyspnoea, increased sputum volume, and increased purulence of sputum(6;7). These criteria from the study by Anthonisen et al. showed only a marginal benefit of antibiotics in a subgroup of patients(8). They divided COPD exacerbations into three categories, and concluded that in case of presence of all three of the abovementioned criteria (type I) the cause of the exacerbation is probably bacterial and the exacerbation is more likely to have a favourable outcome with antibiotics(8). These criteria have never been validated.

There are also other placebo controlled studies that demonstrated a benefit of antibiotics. A relatively old meta-analysis of Saint et al, that included trials comparing antibiotics with placebo, showed various small but significant improvements due to antibiotics in patients with exacerbations of COPD, especially in patients with low baseline flow rates(9). Ram et al. conclude in their review that in COPD exacerbations with increased cough and sputum purulence, antibiotics reduce the risk of short term-mortality by $77 \%$ and decrease the risk of treatment failure by $53 \%$. Nevertheless, they state that the review only supports using antibiotics for COPD patients who are moderately to severely ill. In the communitybased studies they found no difference between antibiotic and placebo(6). Puhan et al. showed in a recent systematic review that only exacerbations requiring hospital admission benefit substantially from antibiotics. In outpatients with mild to moderate exacerbations, antibiotics appeared to offer no benefits. They conclude that further research is needed to identify the subgroup of patients with 
mild to moderate exacerbations that might benefit from antibiotics(3). The European Respiratory Society and European Society for Clinical Microbiology and Infectious Diseases state that in COPD patients with exacerbations not requiring hospitalisation, an antibiotic should only be given in case of type I exacerbations presenting with all three of the cardinal symptoms. In addition in patients with severe underlying COPD, antibiotics should be considered for outpatient exacerbations, irrespective of exacerbation severity.

In an earlier study in exacerbations treated at home, we reported that an Anthonisen type I exacerbation did not predict a bacterial origin of an exacerbation and that sputum purulence was not associated with bacterial infection(10). We showed that the combination of a positive Gram's stain of sputum, a clinically relevant decrease in lung function, and two or more exacerbations in the previous year were $67 \%$ predictive for a bacterial origin of an exacerbation, which was postulated to warrant antibiotic treatment. The absence of all three characteristics gave a negative predictive value of $100 \%$ for a non-bacterial origin of an exacerbation, suggesting to abstain from administering antibiotics(10). This leaves patients that have only one or two of these three clinical characteristics. Therefore, in this double-blind randomised placebo controlled study we evaluated the effect of an antibiotic on the duration and severity of exacerbations in moderate to severe COPD outpatients with one or two of the three mentioned characteristics.

\section{Methods}

\section{Patients}

COPD patients were recruited from May 2005 till January 2007 from the outpatient pulmonary clinic of Medisch Spectrum Twente, Enschede, The Netherlands. Patients had to meet the following criteria: 1) a clinical diagnosis of COPD as defined by the GOLD-criteria,(post-bronchodilator $\mathrm{FEV}_{1}$ percent of predicted $<80 \%$ and $\mathrm{FEV}_{1} / \mathrm{IVC}<70 \%$ ); 2) current or ex-smoker; 3) age $40-80$ years; 4) presenting at the outpatient clinic with signs and symptoms of an exacerbation, defined as an acute negative change in dyspnoea and/or sputum volume and/or colour of sputum (yellowish or greenish) and/or cough, which warrants additional treatment with prednisolone with or without antibiotics by a physician; 5) no pneumonia(11) 6) producing a spontaneous sputum sample; 7) presenting with one or two of the clinical characteristics: a positive Gram's stain of sputum, a clinically relevant decrease in lung function (a decrease in $\mathrm{FEV}_{1}$ of $\geq 200 \mathrm{ml}$ and $\geq 12 \%$ from baseline), or $\geq 2$ exacerbations in the previous year; 8 ) no exacerbation or use of antibiotics or 
prednisolone 4 weeks prior to enrolment, except low-dose prednisolone $(\leq 5 \mathrm{mg})$ as maintenance therapy; 9) no disease that influences bronchial symptoms or lung function; 10) no maintenance therapy with antibiotics; 11) no known hypersensitivity to amoxicillin clavulanic acid; 13) no medical condition with low survival or serious psychiatric morbidity; 14) no uncontrolled diabetes mellitus; 15) no need for domiciliary oxygen therapy.

The hospital's medical ethics committee approved the study. All patients provided written informed consent.

\section{Study design}

This study was a randomised, double blind, placebo controlled study. Eligible patients were randomly assigned to either the intervention or control group according to a computer generated randomisation list. Patients in both groups received oral prednisolone, $30 \mathrm{mg} /$ day for seven days. Patients in the intervention group additionally received oral amoxicillin clavulanic acid (Augmentin ${ }^{\circledR}$ ) 500/125 $\mathrm{mg}$ three times daily for seven days, while control patients received a matching placebo. The choice for this antibiotic is based on a negligible prevalence of organisms resistance to amoxicillin clavulanic acid in our region (less than $5 \%$ ). All patients continued their prescribed inhaled regimen. Patients were followed for 28 days for the primary outcome and for 4 months to detect new exacerbations.

\section{Outcome measures}

The primary outcome was the duration of the exacerbation. Start of the exacerbation was defined as the day that the patient presented himself with an exacerbation at the outpatient clinic. The end day of the exacerbation was based on a symptom diary, which patients completed daily. In this diary patients reported whether their major symptoms and minor symptoms according to Anthonisen(8), (Table 1), were beyond normal. At inclusion all patients received a "what is normal" card on which their individual levels of major symptoms in stable health state were recorded. This card was used as a reference for the diary. When patients experienced no increase in severity of any symptoms listed on the diary, they could tick "no change in symptoms". In all other cases, they had to report on all the symptoms in the diary, whether the level of each symptom was normal, whether there was a small increase, or an evident increase in severity compared to their stable state. 
The last day of the exacerbation was defined as the first day of: 1) three consecutive days when the patient had returned to his normal health state; or 2) seven consecutive days on which patients only reported a small increase in symptoms compared to baseline without fever or changed sputum colour.

Secondary outcome measures were the severity of the exacerbation, number of relapses of exacerbations within 28 days, number of exacerbations within 4 months, lung function parameters, sputum parameters, and quality of life.

Severity of the exacerbation was calculated based on the symptom scores in the diary. On each day of the exacerbation a severity score was calculated (Table 1 ). Adding the symptom scores resulted in a daily score ranging from $0-11$ points. $A$ mean severity score per exacerbation day was calculated by dividing the sum scores of each exacerbation day by the number of days the exacerbation lasted.

Table 1. Scoring of COPD exacerbation symptoms

\begin{tabular}{llll}
\hline & Normal & Small increase & Evident increase \\
\hline Major symptoms & 0 & 1 & 2 \\
Dyspnoea & 0 & 1 & 2 \\
Sputum production & 0 & & $2^{*}$ \\
Sputum colour & & & \\
Minor symptoms & 0 & 0.5 & 1 \\
Cough & 0 & 0.5 & 1 \\
Wheeze & 0 & 0.5 & 1 \\
Running nose & 0 & 0.5 & 1 \\
Sore throat & 0 & & $1 * *$ \\
Fever & 0.5 & & 1 \\
\hline
\end{tabular}

* Sputum colour: normal =0; different from normal=2.

$* *$ Fever $\left(>38.5^{\circ} \mathrm{C}\right):$ no=0; yes $=1$.

A relapse was defined as an exacerbation that resolved following the blinded treatment but re-occurred within 28 days of the treated exacerbation. The number of exacerbations within 4 months was estimated by counting the number of courses of prednisolone and antibiotics prescribed for lung associated illness, based on data from pharmacy records. In our region, this provides very accurate coverage of consumption. Pharmacy data were similarly used to determine the number of exacerbations in the year prior to the start of the study.

At the start of the study and after 28 days lung function was measured. Spontaneous sputum samples were collected and immediately after collection 
sputum colour was determined according to the Stockley protocol (BronkoTest, Heredilab Inc, Salt Lake City, UT, USA)(12). Sputum with a colour value $\leq 2$ was defined as mucoid and sputum colour $\geq 3$ was defined as purulent. Subsequently, a Gram's stain and a semi-quantitative culture were made. Infection was defined by the presence of potentially pathogenic micro-organisms (PPM) in pure culture or as the presence of one or more PPM in excess (one log or more) to background microbiological flora in sputum(10;13). Bacterial colonisation was defined as the presence of PPM in culture in equal amount or less compared to background microbiologic flora in sputum. Health related quality of life was measured by means of the Chronic Respiratory Questionnaire(14). The minimum important difference (MID) within each domain is 0.5. Health status was measured with the Clinical COPD Questionnaire(15). The MID of the total score is $0.4(16)$.

\section{Statistical analyses}

Prior to the study we defined a difference of 3 days in length of exacerbation between the treatment groups as clinically relevant. With a standard deviation of 4 days, a power of $80 \%$, and a type I error probability of $5 \%, 58$ patients were required to detect this difference.

The relation between treatment and the duration of the exacerbation was analysed by Cox regression analysis. To identify variables that were different by treatment group, t-tests in case of normally distributed variables were performed. For not normally distributed variables this was done by Mann-Whitney $U$ test. Betweengroup comparisons of categorical variables were performed by Chi-square tests or Fisher's Exact tests as appropriate. The a-priori list of potential confounding variables is displayed in Table 2. Only variables different by treatment group $(p<=0.20)$ were tested for an association with duration of the exacerbation. Variables associated with duration of the exacerbation with $p<=0.20$ were considered as potential confounders in the relation between treatment and duration of the exacerbation, and entered into the multivariate Cox-regression analysis. Time to resolution was displayed as a Kaplan-Meier graph.

\section{Results}

Of 63 potentially eligible patients with a COPD exacerbation, 35 patients were randomised; 18 received amoxicillin clavulanic acid and 17 placebo. Two patients were on low-dose prednisolone maintenance therapy. Of the 28 excluded patients, 16 produced sputum samples not meeting the American Society of Microbiologists 
quality criteria(13). In two patients, all three criteria suggestive of a bacterial infection were present, while six had none of the three criteria. Furthermore, two had pneumonia, and two were hospitalised. Baseline characteristics are displayed in Table 2.

Table 2. Baseline characteristics of the two treatment groups

\begin{tabular}{|c|c|c|c|}
\hline & $\begin{array}{c}\text { Amoxicillin clavulanic } \\
\text { acid } \mathrm{N}=18\end{array}$ & $\begin{array}{l}\text { Placebo } \\
\mathrm{N}=17\end{array}$ & $\begin{array}{c}\mathrm{p}- \\
\text { value }\end{array}$ \\
\hline Gender (Number of men (\%)) & $9(50)$ & 12(71) & 0.21 \\
\hline Smoking status (Number(\%)) & & & 0.42 \\
\hline Ex-smokers & $14(78)$ & $11(65)$ & \\
\hline Current smokers & $4(22)$ & $6(35)$ & \\
\hline Age (Median (range)) & $68(54-74)$ & $65(47-76)$ & 0.38 \\
\hline \multicolumn{4}{|l|}{$\begin{array}{l}\text { Lung function post bronchodilation at } \\
\text { inclusion(SD) }\end{array}$} \\
\hline FEV1 in litres & $1.24(0.44)$ & $1.53(0.54)$ & 0.06 \\
\hline FEV1 \% predicted & $44.7(15.4)$ & $52.2(15.1)$ & 0.16 \\
\hline FEV1/VC \% & $38.3(13.0)$ & $42.9(11.2)$ & 0.27 \\
\hline Positive Gram's stain (Number(\%)) & $15(83)$ & $15(88)$ & 1.00 \\
\hline Sputum culture at inclusion (Number(\%)) & & & 0.18 \\
\hline No colonisation nor infection & $3(17)$ & $5(29)$ & \\
\hline Colonisation & $2(11)$ & $5(29)$ & \\
\hline Infection & $13(72)$ & $7(41)$ & \\
\hline \multicolumn{4}{|l|}{ year (Number(\%)) } \\
\hline$<2$ exacerbations & 7 (39) & $8(47)$ & \\
\hline$>=2$ exacerbations & $11(61)$ & $9(53)$ & \\
\hline $\begin{array}{l}\text { Lung function decline of }>=200 \mathrm{ml} \text { and } \\
>=12 \% \text { at start of exacerbation compared } \\
\text { to baseline (Number(\%)) }\end{array}$ & $2(11)$ & $2(12)$ & 1.00 \\
\hline Sputum colour score* (SD) & $4.4(1.2)$ & $3.4(1.1)$ & 0.02 \\
\hline Sputum purulence (Number(\%)) & & & 0.17 \\
\hline Mucoid & $1(6)$ & $4(24)$ & \\
\hline Purulent & $17(94)$ & $13(77)$ & \\
\hline Type of exacerbation according to & & & 0.44 \\
\hline Anthonisen (Number(\%)) & & & \\
\hline Type I (3 major symptoms) & $15(83)$ & $12(71)$ & \\
\hline Type II (2 major symptoms) & $3(17)$ & $5(29)$ & \\
\hline Type III (1 major + 1 minor symptom) & 0 & 0 & \\
\hline
\end{tabular}

* score according to the Stockley protocol (BronkoTest, Heredilab Inc, Salt Lake City, UT, USA)(12). 
At baseline, FEV1 in litres and as percentage of predicted, sputum culture, sputum colour, and sputum purulence were different between the treatment groups $(p=<0.20)$ and therefore tested for association with duration of treatment. Since this was not the case for any variable, no adjustment of treatment effect on the duration of the exacerbation was necessary.

In 15 patients (83\%) in the intervention group, the exacerbation resolved within 28 days compared to 14 patients (82\%) that received placebo (see Table 3 ). The crude hazard-ratio of time to resolution of the exacerbation in patients in the intervention group was $1.12(95 \% \mathrm{Cl} 0.54-2.32 ; \mathrm{p}=0.77)$ compared to the placebo group (Figure 1).

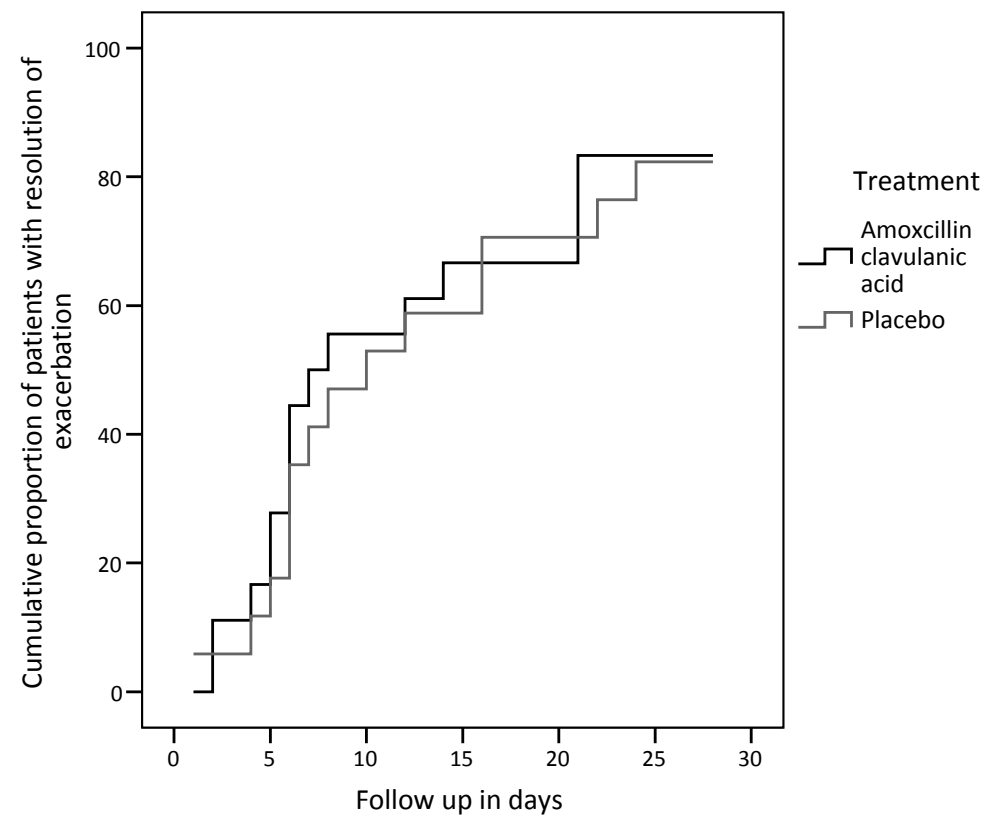

Figure 1. Cumulative proportion of patients with resolution of exacerbation

Table 3 shows that there were no differences in treatment effects between the groups. 
Table 3. Treatment effects in the two groups

\begin{tabular}{|c|c|c|c|}
\hline & $\begin{array}{l}\text { Amoxicillin clavulanic } \\
\text { acid }(\mathrm{N}=18)\end{array}$ & $\begin{array}{l}\text { Placebo } \\
(\mathrm{N}=17)\end{array}$ & $p$-value \\
\hline $\begin{array}{l}\text { Resolution of exacerbation within } 28 \\
\text { days (Number(\%)) }\end{array}$ & $15(83)$ & $14(82)$ & 1.00 \\
\hline $\begin{array}{l}\text { Mean daily exacerbation severity score } \\
\text { (Median(range)) }\end{array}$ & $5.7(4.3-7.8)$ & $5.4(2.4-8.4)$ & 0.70 \\
\hline $\begin{array}{l}\text { Number of exacerbation days with a } \\
\text { severity score } \geq 6 \text { (Median(range)) }\end{array}$ & $3(0-25)$ & $3(0-24)$ & 0.68 \\
\hline Relapse within 28 days (Number(\%)) & $2(11)$ & $1(6)$ & 1.0 \\
\hline $\begin{array}{l}\text { Number of exacerbations within } 4 \\
\text { months after end of study (Number(\%)) }\end{array}$ & \multicolumn{2}{|c|}{ months after end of study (Number(\%)) } & 0.66 \\
\hline 0 & $7(39)$ & $10(59)$ & \\
\hline 1 & $6(33)$ & $4(24)$ & \\
\hline 2 & $4(22)$ & $3(18)$ & \\
\hline 3 & $1(16)$ & $0(0)$ & \\
\hline \multicolumn{4}{|l|}{$\begin{array}{l}\text { Change in CCQ scores from inclusion to } \\
\text { day } 28 \text { (Mean(SD)) }\end{array}$} \\
\hline Total & $-2.3(2.7)$ & $-2.3(2.7)$ & 0.88 \\
\hline Mental state & $-0.6(1.5)$ & $-0.3(1.3)$ & 0.55 \\
\hline Functional state & $-0.6(1.0)$ & $-0.8(1.0)$ & 0.72 \\
\hline Symptom & $-1.2(1.4)$ & $-1.2(1.4)$ & 0.92 \\
\hline \multicolumn{4}{|l|}{$\begin{array}{l}\text { Change in CRQ scores from inclusion to } \\
\text { day } 28 \text { (Mean(SD)) }\end{array}$} \\
\hline Dyspnoea & $0.5(1.3)$ & $0.5(1.6)$ & 0.91 \\
\hline Fatigue & $1.2(1.2)$ & $0.4(1.3)$ & 0.07 \\
\hline Emotional function & $0.1(0.9)$ & $0.6(1.2)$ & 0.23 \\
\hline Mastery & $0.3(1.4)$ & $0.4(1.4)$ & 0.94 \\
\hline \multicolumn{4}{|l|}{$\begin{array}{l}\text { Change in lung function post } \\
\text { bronchodilation from inclusion to day }\end{array}$} \\
\hline FEV1 in litres & $0.02(0.21)$ & $0.07(0.27)$ & 0.51 \\
\hline FEV1 \% predicted & $1.6(8.8)$ & $2.4(8.9)$ & 0.80 \\
\hline $\begin{array}{l}\text { Change in sputum colour from } \\
\text { inclusion to day } 28 \text { (Mean (SD)) }\end{array}$ & $-0.46(1.1)$ & $0.2(2.7)$ & 0.39 \\
\hline $\begin{array}{l}\text { Change in sputum purulence from } \\
\text { inclusion to day } 28 \text { (Number(\%)) }\end{array}$ & & & 0.57 \\
\hline Mucoid to mucoid & $1(6)$ & $2(12)$ & \\
\hline Mucoid to purulent & 0 & $2(12)$ & \\
\hline Purulent to purulent & $11(61)$ & $8(47)$ & \\
\hline Purulent to mucoid & $6(33)$ & $5(29)$ & \\
\hline
\end{tabular}




\section{Additional analyses}

In Table 4 the change in sputum culture from the day of inclusion to day 28 is shown for both treatment groups. There was a borderline significant change in sputum cultures between inclusion and day 28 in patients of the placebo group (McNemar test, $p=0.08$ ), while there was no change in culture results in patients of the intervention group ( $p=0.39)$. In the intervention group we observed that 6 of the 10 patients with a bacterial infection at inclusion (60\%) still had a bacterial infection on day 28. Of these 6 patients, 3 had a different PPM isolated from the culture at inclusion and day 28 . The patient with colonisation at inclusion and a bacterial infection on day 28 had a different PPM isolated on day 28.

In the placebo group, 2 of the 6 patients with a bacterial infection at inclusion still had a bacterial infection on day 28. Of these 2 patients, 1 had a different PPM isolated on day 28.

Table 4a. Change in sputum culture in the amoxicillin clavulanic acid group. Numbers displayed are numbers of patients.

\begin{tabular}{lccc}
\hline Amoxicillin clavulanic acid & No colononisation & $\begin{array}{c}\text { Sputum culture at day 28 } \\
\text { Colonisation nor } \\
\text { infection }\end{array}$ & Infection \\
\hline Sputum culture at inclusion & 1 & 1 & 0 \\
No colonisation or infection & 1 & 0 & 1 \\
Colonisation & 3 & 1 & 6 \\
Infection & & & \\
\hline
\end{tabular}

Table 4b. Change in sputum culture in the placebo group. Numbers displayed are numbers of patients.

\begin{tabular}{lccc}
\hline Placebo & No colonisation & $\begin{array}{c}\text { Sputum culture at day 28 } \\
\text { Colonisation nor } \\
\text { infection }\end{array}$ & Infection \\
\hline Sputum culture at inclusion & 3 & 1 & 0 \\
No colonisation or infection & 3 & 1 & 0 \\
Colonisation & 4 & 0 & 2 \\
Infection & & & \\
\hline
\end{tabular}

Patients were asked on day 28 , whether they thought they had received antibiotics or placebo. Seventy-nine percent of patients in the intervention group and $82 \%$ in the placebo group thought they had received placebo.

At inclusion the treating physician of each patient was asked what would have been prescribed had the patient not participated in the trial. In $34 \%$ of patients the 
physician would have treated the patient with prednisolone only and in $66 \%$ with both prednisolone and antibiotics.

\section{Discussion}

This randomised placebo controlled trial demonstrated no difference in time to resolution of an exacerbation in COPD outpatients treated with either amoxicillin clavulanic acid or placebo in addition to prednisolone. Also no difference in severity, number of relapses, number of exacerbations 4 months after the study, or quality of life was observed. These conclusions apply only to patients with one or two of the following characteristics: a positive Gram's stain of sputum, a clinically relevant decrease in lung function, and two or more exacerbations in the previous year.

There is a lack of placebo controlled studies on the effect of antibiotics in COPD exacerbations. Reviews have concluded that antibiotics are useful in COPD exacerbations(3;6), but this applies most to patients with severe exacerbations needing hospitalisation. Many of the included studies are old and were done without treating these exacerbations with prednisolone which now has been demonstrated to be beneficial(17-19), but these reviews have nevertheless recommended to treat severe exacerbations with antibiotics next to prednisolone. Even less clear is the role of antibiotics in the treatment of outpatients, with less severe exacerbations. Though there are large differences in prescription between and within country, many physicians tend to be on the "safe" side and therefore also give antibiotics. Also in the current trial we observed that $66 \%$ of the patients would have been treated with antibiotics by their physician. This routine may have implications for costs, adverse effects and especially for the surge in antibiotic resistance $(4 ; 5)$.Therefore evidence needs to be established also in the group with less severe exacerbations.

Anthonisen et al performed post hoc analyses stating that type I exacerbations were likely to be bacterial and that in these exacerbations treatment with antibiotics was favourable. They stated that antibiotics confer no benefit in type III exacerbations and that treatment of type II exacerbations with antibiotics probably could be justified in case of antibiotic tolerance(8). A remarkable finding in our study was that of the 27 type I exacerbations a bacterial infection was present in only 15 (56\%). Additionally, although 15 (83\%) and 12 (71\%) of the exacerbations in the amoxicillin clavulanic acid and the placebo group respectively, were type I 
Anthonisen, no effect of antibiotics was observed. These results give food for thought about the effectiveness of antibiotics in this type of exacerbation. The main difference between the study by Anthonisen and ours is the concomitant use of prednisolone, which is the standard recommendation nowadays. In the Anthonisen study only $42 \%$ received systemic steroids. The authors state that the success rate with antibiotics was favourable in both steroid and non-steroid users, but no data are provided. We believe that the room for improvement by antibiotics will generally be less in patients treated with prednisolone, certainly in less severe exacerbations.

In this study we observed that even though 20 (57\%) of our patients with an exacerbation experienced a bacterial infection, antibiotics had no added value in these patients. Although this suggests refraining from administering antibiotics in outpatient exacerbations, this inference should not be generalised from our data to all outpatients, since our patients were selected for not having a high probability of bacterial infection. We believe, however, that our results merit a supplementary randomised placebo controlled trial in patients with a high probability of an exacerbation of bacterial origin.

In our additional analyses we observed not only resolution of bacterial infections in the amoxicillin group ( $40 \%$ of infections), but also in the placebo group ( $66 \%$ of infections). So, without antibiotic treatment there are still a substantial number of bacterial infections that resolve with prednisolone alone. In patients with a bacterial infection at start of exacerbation the PPM isolated on day 28 were different in $50 \%$ of cases. Another indication for the lack of effect of antibiotics is the fact that the large majority of patients on antibiotics thought they had received placebo $(79 \%)$ which was very similar to this percentage in the group that really received placebo (82\%).

An important limitation of this study is the number of patients included. Based on our power calculation we needed to include 58 patients to be able to detect a difference of 3 days in exacerbation duration between the treatment groups. We were able to include only 35 patients within the time allotted. With the observed hazard ratio of 1.12 and the median time to resolution of 7.5 days in the control group, the required sample size would be 2450 patients. We therefore feel that the lack of effect of antibiotics is not based on not including 58 patients. 
In conclusion, this randomised placebo controlled study demonstrated that treatment of outpatient COPD exacerbations with antibiotics has no added value in outpatients with moderate to severe exacerbations. Instead of more equivalence trials comparing two antibiotics, we need more placebo controlled studies to determine whether we can properly define subgroups of COPD outpatients in which antibiotics indeed are of additional value. 


\section{References}

(1) Wilson R. Bacterial infection and chronic obstructive pulmonary disease. Eur Respir J 1999 February;13(2):233-5.

(2) El Moussaoui R., Roede BM, Speelman P, Bresser P, Prins JM, Bossuyt PM. Short-course antibiotic treatment in acute exacerbations of chronic bronchitis and COPD: a meta-analysis of double-blind studies. Thorax 2008 May;63(5):415-22.

(3) Puhan MA, Vollenweider D, Latshang T, Steurer J, Steurer-Stey C. Exacerbations of chronic obstructive pulmonary disease: when are antibiotics indicated? A systematic review. Respir Res 2007;8:30.

(4) Wilson R. Bacteria, antibiotics and COPD. Eur Respir J 2001 May;17(5):9951007.

(5) Goossens H, Ferech M, Vander SR, Elseviers M. Outpatient antibiotic use in Europe and association with resistance: a cross-national database study. Lancet 2005 February 12;365(9459):579-87.

(6) Ram FS, Rodriguez-Roisin R, Granados-Navarrete A, Garcia-Aymerich J, Barnes NC. Antibiotics for exacerbations of chronic obstructive pulmonary disease. Cochrane Database Syst Rev 2006;(2):CD004403.

(7) Wilson R. Short course of antibiotic treatment in acute exacerbations of COPD. Thorax 2008 May;63(5):390-2.

(8) Anthonisen NR, Manfreda J, Warren CPW, Hershfield ES, Harding GKM, Nelson NA. Antibiotic therapy in exacerbations of chronic obstructive pulmonary disease. Ann Intern Med 1987;106:196-204.

(9) Saint S, Bent S, Vittinghoff E, Grady D. Antibiotics in chronic obstructive pulmonary disease exacerbations. A meta-analysis. JAMA 1995 March 22;273(12):957-60.

(10) Van der Valk P, Monninkhof E, van der Palen J., Zielhuis G, van Herwaarden C., Hendrix R. Clinical predictors of bacterial involvement in exacerbations of chronic obstructive pulmonary disease. Clin Infect Dis 2004 October 1;39(7):980-6.

(11) Lim WS, van der Eerden MM, Laing R, Boersma WG, Karalus N, Town Gl et al. Defining community acquired pneumonia severity on presentation to hospital: an international derivation and validation study. Thorax 2003 May;58(5):37782. 
(12) Stockley RA, Bayley D, Hill SL, Hill AT, Crooks S, Campbell EJ. Assessment of airway neutrophils by sputum colour: correlation with airways inflammation. Thorax 2001 May;56(5):366-72.

(13) Isenberg HD. Clinical microbiology procedures handbook. 2004.

(14) Schunemann HJ, Goldstein R, Mador MJ, McKim D, Stahl E, Puhan M et al. A randomised trial to evaluate the self-administered standardised chronic respiratory questionnaire. Eur Respir J 2005 January;25(1):31-40.

(15) van der Molen T., Willemse BW, Schokker S, ten Hacken NH, Postma DS, Juniper EF. Development, validity and responsiveness of the Clinical COPD Questionnaire. Health Qual Life Outcomes 2003 April 28;1(1):13.

(16) Kocks JW, Tuinenga MG, Uil SM, van den Berg JW, Stahl E, van der MT. Health status measurement in COPD: the minimal clinically important difference of the clinical COPD questionnaire. Respir Res 2006;7:62.

(17) Aaron SD, Vandemheen KL, Hebert P, Dales R, Stiell IG, Ahuja J et al. Outpatient oral prednisone after emergency treatment of chronic obstructive pulmonary disease. N Engl J Med 2003 June 26;348(26):2618-25.

(18) Davies L, Angus RM, Calverley PM. Oral corticosteroids in patients admitted to hospital with exacerbations of chronic obstructive pulmonary disease: a prospective randomised controlled trial. Lancet 1999 August 7;354(9177):45660.

(19) Niewoehner DE, Erbland ML, Deupree RH, Collins D, Gross NJ, Light RW et al. Effect of systemic glucocorticoids on exacerbations of chronic obstructive pulmonary disease. Department of Veterans Affairs Cooperative Study Group. N Engl J Med 1999 June 24;340(25):1941-7. 


\section{CHAPTER 5}

\section{RELATION BETWEEN AMOXICILLIN CONCENTRATION IN SPUTUM OF COPD PATIENTS AND LENGTH OF HOSPITALISATION}

Marjolein Brusse-Keizer, Leonore ten Bokum, Kris Movig, Paul van der Valk, Huib Kerstjens, Job van der Palen, Ron Hendrix

Submitted 


\begin{abstract}
Background: Amoxicillin is a widely used antibiotic in COPD. Little is known about the excretion of amoxicillin into sputum of COPD patients. The objective was to investigate the relationship between the concentration of amoxicillin in sputum in hospitalised COPD patients and length of hospitalisation. To be effective against bacterial pathogens, the amoxicillin concentration in target tissues should be higher than the Minimal Inhibiting Concentration of $90 \%$ (MIC90) being $2 \mathrm{mg} / \mathrm{l}$. Therefore, this was also used as the cut-off value for the amoxicillin concentration in sputum, as a marker for lung tissue concentration.
\end{abstract}

Methods: Fifty-two COPD inpatients with an exacerbation, treated with amoxicillin clavulanic acid, were included in this cohort study. Of these patients 7 also had pneumonia. Patients were divided in patients with an amoxicillin sputum concentration $\geq 2 \mathrm{mg} / \mathrm{l}$ and $<2 \mathrm{mg} / \mathrm{l}$. Furthermore, inflammation markers in sputum and serum and clinical parameters were obtained.

Results: Of the 33 patients with usable sputum, 11 had a concentration in sputum $\geq 2 \mathrm{mg} / \mathrm{l}$. The mean length of hospitalisation for patients with concentrations below the MIC90 to common respiratory pathogens was 11.0 days, while for patients with concentrations at or above the MIC90 this was 7.0 days $(p=0.005)$.

Conclusions: COPD patients admitted for an acute exacerbation of COPD, with a sputum concentration of amoxicillin $\geq 2 \mathrm{mg} / \mathrm{l}$ had a markedly reduced length of hospitalisation compared to patients with a concentration $<2 \mathrm{mg} / \mathrm{l}$. It is worthwhile testing whether individualised treatment based on sputum amoxicillin concentrations of patients during hospitalisation for acute exacerbations can effectively reduce hospital stay. 


\section{Introduction}

Patients with COPD are prone to exacerbations and these are an important cause of morbidity and mortality. The management of exacerbations is usually empirical and includes oral corticosteroids combined with broad spectrum antibiotics, such as amoxicillin clavulanic acid, to treat presumed bacterial infection(1). However, evidence of the efficacy of adding antibiotics is debatable since some controlled studies showed a clear benefit, whereas others did not $(2 ; 3)$.

Theoretically, to be effective, the amoxicillin concentration in target tissues should reach the Minimal Inhibiting Concentration of 90\% (MIC90) for potential pathogenic micro-organisms (PPM) such as S.pneumoniae, H.influenzae and $M$. catarrhalis $(4 ; 5)$. Since these micro organisms involved are often located in the bronchial lumen, levels of antimicrobial agents in sputum may be the relevant predictor of efficacy(6).

Little is known about the excretion of amoxicillin clavulanic acid into sputum of COPD patients. Due to the instability of clavulanic acid, levels in sputum and serum are difficult to measure. The concentration of amoxicillin reached in sputum may differ markedly from the concentration in serum due to various factors such as the diffusion of amoxicillin into the airways $(4 ; 7 ; 8)$. Theoretically, steady state sputum concentrations should be reached after three days of oral or intravenous treatment. In non-COPD patients and in healthy subjects the concentration of amoxicillin in sputum ranged from 0.05 to $0.54 \mathrm{mg} / \mathrm{l}$ with a median of $0.11 \mathrm{mg} / \mathrm{l}$ (3 times daily oral 500/125 mg amoxicillin clavulanic acid)(9). In contrast, peak amoxicillin levels in serum were excellent, with a mean of $8.7( \pm 6.0) \mathrm{mg} / \mathrm{l}$. Other studies using higher doses of amoxicillin (with or without clavulanic acid) showed concentrations of amoxicillin in sputum between 0.23 and $4.4 \mathrm{mg} / \mathrm{l}(5 ; 10-14)$ with serum concentrations between 3.87 en $45.2 \mathrm{mg} / \mathrm{l}$ depending on for example dosing and timing of blood samples.

Since some clinical studies have suggested that with regard to clinical efficacy of amoxicillin, sputum concentration is a better predictor of efficacy than serum concentration $(4 ; 6)$, the objective of the present study was to investigate the relationship between the concentration of amoxicillin in sputum in hospitalised COPD patients and length of hospitalisation. 


\section{Methods}

\section{Study subjects}

Patients hospitalised from January 2006 through February 2007 for an exacerbation of COPD at the inpatient pulmonary department of Medisch Spectrum Twente in Enschede, the Netherlands, were recruited. This study is part of our COPD cohort study, the COMIC study. The recruitment criteria were: 1) a clinical diagnosis of COPD, as defined by GOLD criteria(15), 2) admitted with signs and symptoms of an exacerbation of COPD, defined as an acute negative change from the baseline, reported by the patient, in dyspnoea and/or sputum volume and/or colour of sputum (yellowish or greenish sputum) and/or cough, which warranted additional treatment of prednisolone with or without antibiotics by a physician. Patients with pneumonia were not excluded from the study. Pneumonia was defined as an acute respiratory tract illness associated with radiographic shadowing on a chest radiograph which was neither pre-existing nor of any other cause. Chest radiographs were judged independently by two pulmonary physicians. In case of discrepancy the judgment of a radiologist was used for consensus, 3 ) age 40 years or over, 4) current or former smoker.

Patients received care, according to daily practice, by their chest physician, which included amoxicillin clavulanic acid either orally or intravenously starting on the day of admission. Doses for oral administration varied from 3 to 4 times daily amoxicillin (500mg), dose for intravenous administration was 4 times daily $1000 \mathrm{mg}$ amoxicillin. Some patients received both treatment forms sequentially. One patient received 2 doses of amoxicillin with and 2 doses of amoxicillin without clavulanic acid. This was due to renal insufficiency.The hospital's medical ethical committee approved the study. All patients provided written informed consent.

\section{Outcome measurements}

Amoxicillin concentrations were measured, by high performance liquid chromatography method using ultraviolet detection at $225 \mathrm{~nm}$, in sputum samples collected on the third day of antibiotic treatment. Patients were divided in patients with an amoxicillin sputum concentration on the third day of antibiotic treatment at or above $(\geq)$ or below $(<)$ the MIC90 of PPM being $2 \mathrm{mg} / \mathrm{l}$. This cut-off of $2 \mathrm{mg} / \mathrm{I}$ was determined in advance. Amoxicillin concentrations were determined after hospital discharge, so this information could not influence the decision of discharge made by the physicians. The primary outcome measure was length of stay, defined as number of days between day of admission and day of medical discharge, which 
was distinguished from the actual day of discharge because some patients remain in hospital longer than medically necessary (e.g. waiting time before referral to a nursing home).

On the first day of hospital admission a sputum sample was collected to perform a Gram's stain and a semi quantitative culture. Bacterial infection was considered to be present in case of the presence of $\geq 1$ PPM in excess ( $\geq 1 \mathrm{log}$ ) of the normal microbiological flora in sputum. Bacterial colonisation was declared in case of the presence of $\geq 1$ PPM in equal or less amount compared with the background flora(16;17).

Furthermore the concentration of IL(interleukin)-6, IL-8, and IL-10, the number of leucocytes and MPO (myeloperoxidase) were measured in this sputum. CRP (Creactive protein), IL-6, IL-8 and II-10 were measured in blood, one and ten days after hospital admission.

\section{Statistical analyses}

Prior to the study conduct, we defined a difference of 3 days in length of stay between the patient groups as clinically relevant. Based on this difference, a standard deviation of 3 days, a power of $80 \%$ and a type I error probability for a two sided test of $5 \%$, it was calculated that 34 persons were required to detect this difference. This power calculation was based on the assumption that the ratio of patients with an amoxicillin concentration at or above $(\geq)$ to a concentration below $(<)$ the MIC90 of PPM being $2 \mathrm{mg} / \mathrm{l}$, would be $1: 1$. When a more conservative ratio of $1: 2$ was used, 36 patients needed to be included.

Descriptive statistics were compared across antibiotic levels by the chi-square test for categorical variables or the Fisher's exact test. Normally distributed variables were compared by the Student's t-test and the Mann-Whitney $U$ test was used for nonparametrically distributed factors (Table 1). Survival curves were used to examine time to discharge as a function of appropriate antibiotic level. The curves were compared by the log-rank test. All tests were two-sided and a $p$ value of < 0.05 was deemed statistically significant.

The impact of amoxicillin sputum concentration on length of hospitalisation was evaluated by a Cox-proportional hazards model. A priori, we placed in this model factors that were biologically likely to affect length of hospital stay and factors that differed across antibiotic levels. Specifically, we controlled for age, gender, smoking status, sputum culture, II-6 and CRP levels in blood on day 1 . The level of amoxicillin was retained in the model because we evaluated the independent association of 
this with length of hospital stay. In addition, variables were examined for colinearity. Variables with a $\mathrm{p}$ value of $<0.15$ in the univariate analyses were considered for inclusion in the multivariate Cox models. Stepwise regression procedures were used to evaluate significance along with the evaluation of fit statistics (-2 Log likelihood). Data-analysis was performed with the statistical package SPSS/PC for Windows (version 12.2) (SPSS, Inc., Chicago, IL).

\section{Results}

Fifty-two COPD inpatients with an exacerbation, treated with amoxicillin clavulanic acid, were included in the study. Of the 52 patients enrolled only 33 patients produced usable sputum on day 3 . The other 19 patients could either not produce enough sputum ( $n=16)$ or the sputum sample could not be analysed due to analytic problems $(n=3)$. Baseline characteristics, stratified by amoxicillin concentration in sputum are presented in Table 1 . Baseline characteristics of the enrolled patients and the 19 patients without usable sputum were comparable (data not shown).

Table 1. Baseline characteristics

\begin{tabular}{|c|c|c|c|}
\hline & $\begin{array}{c}\text { Amoxicillin } \\
\text { concentration }<2 \mathrm{mg} / \mathrm{l} \\
\mathrm{N}=22\end{array}$ & $\begin{array}{c}\text { Amoxicillin } \\
\text { concentration } \geq 2 \mathrm{mg} / \mathrm{l} \\
\mathrm{N}=11\end{array}$ & $\begin{array}{c}\mathrm{p}- \\
\text { value }\end{array}$ \\
\hline Age in years (SD) & $67(10.3)$ & $68(9.1)$ & 0.83 \\
\hline Sex (Number of men (\%)) & $13(59)$ & $10(91)$ & 0.09 \\
\hline Smoking status (Number (\%)) & & & 0.05 \\
\hline Ex-smokers & $12(54)$ & $10(91)$ & \\
\hline Current smokers & $10(46)$ & $1(9)$ & \\
\hline \multirow{2}{*}{\multicolumn{4}{|c|}{$\begin{array}{l}\text { Lung function post bronchodilation } \\
\text { (SD) }\end{array}$}} \\
\hline & & & \\
\hline FEV1 in litres & $1.0(0.4)$ & $1.2(0.5)$ & 0.69 \\
\hline FEV1 \% predicted & $39.6(13.5)$ & $41.6(14.0)$ & 0.22 \\
\hline FEV1/IVC in \% & $37.4(15.1)$ & $43.8(11.6)$ & 0.22 \\
\hline GOLD classification (Number (\%)) & & & 0.66 \\
\hline$|-| \mid$ & $4(18)$ & $3(27)$ & \\
\hline III-IV & $18(82)$ & $8(73)$ & \\
\hline Administration of amoxicillin & & & 1.00 \\
\hline \multicolumn{4}{|l|}{ (Number (\%)) } \\
\hline Intravenous & $4(18)$ & $2(18)$ & \\
\hline Oral & $18(82)$ & $9(82)$ & \\
\hline
\end{tabular}




\begin{tabular}{|c|c|c|c|}
\hline Doses of amoxicillin oral & & & 0.65 \\
\hline $1500 \mathrm{mg}$ & $4(22)$ & $3(33)$ & \\
\hline $2000 \mathrm{mg}$ & $14(78)$ & $6(67)$ & \\
\hline Reason of hospitalisation & & & 0.66 \\
\hline (Number (\%)) & & & \\
\hline Exacerbation & $18(82)$ & $8(73)$ & \\
\hline Pneumonia & $4(18)$ & $3(27)$ & \\
\hline IL-6 concentration in sputum $(\mathrm{pg} / \mathrm{mL})$ & $140(0-1200)$ & $8.5(3.6-800)$ & 0.64 \\
\hline at day of admission, median (range) & & & \\
\hline IL-8 concentration in sputum $(\mathrm{pg} / \mathrm{mL})$ & $1.75 * 10^{4}$ & $1.15 * 10^{4}$ & 0.58 \\
\hline at day of admission, median (range) & $\left(0.9 * 10^{3}-2.4^{*} 10^{5}\right)$ & $\left(2 * 10^{3}-6.8 * 10^{4}\right)$ & \\
\hline IL-10 concentration in sputum & $2.5(0-120)$ & $0(0-84)$ & 0.39 \\
\hline$(\mathrm{pg} / \mathrm{mL})$ at day of admission, median & & & \\
\hline (range) & & & \\
\hline Number of leucocytes in Gram stain & $10^{7}\left(0-10^{8}\right)$ & $10^{7}\left(0-10^{8}\right)$ & 0.56 \\
\hline of sputum, median (range) & & & \\
\hline MPO concentration in sputum & $1.25(0-2.11)$ & $0.25(0-3.12)$ & 0.39 \\
\hline (extinction) at day of admission, & & & \\
\hline median (range) & & & \\
\hline Sputum culture at day of admission & & & 0.20 \\
\hline (Number (\%)) & & & \\
\hline No colonisation or infection & $13(65)$ & $10(91)$ & \\
\hline Colonisation or infection & $7(35)$ & 1 (9) & \\
\hline IL-6 concentration in blood $(\mathrm{pg} / \mathrm{mL})$ & $3.6(0-34)$ & $3.6(0-6.9)$ & 0.57 \\
\hline day 1 , median (range) & & & \\
\hline IL-8 concentration in blood $(\mathrm{pg} / \mathrm{mL})$ & $0(0-40)$ & $0(0-11)$ & 0.86 \\
\hline day 1 , median (range) & & & \\
\hline IL-10 concentration in blood $(\mathrm{pg} / \mathrm{mL})$ & $4.1(0-10)$ & $4.2(1.7-17)$ & 0.47 \\
\hline day 1 , median (range) & & & \\
\hline CRP concentration in blood $\mathrm{mg} / \mathrm{L}$ day & $2.5(0-77)$ & $12.5(0-112)$ & 0.04 \\
\hline 1 , median (range) & & & \\
\hline IL-6 concentration in blood $(\mathrm{pg} / \mathrm{mL})$ & $6.4(0-110)$ & $5.6(0-20)$ & 0.67 \\
\hline day 10 , median (range) & & & \\
\hline IL-8 concentration in blood $(\mathrm{pg} / \mathrm{mL})$ & $0(0-10)$ & $0(0-11)$ & 0.58 \\
\hline day 10 , median (range) & & & \\
\hline IL-10 concentration in blood (pg/mL) & $1.8(0-15)$ & $4.8(0-7.5)$ & 0.41 \\
\hline day 10 , median (range) & & & \\
\hline CRP concentration in blood $\mathrm{mg} / \mathrm{L}$ day & $8.5(0-127)$ & $25.5(0-50)$ & 0.47 \\
\hline 10, median (range) & & & \\
\hline
\end{tabular}

FEV1= forced expiratory volume in 1 second; IVC= inspiratory vital capacity; GOLD = Global Initiative on Obstructive Lung Disease; $I L=$ interleukin; $M P O=$ myeloperoxidase; $C R P=C$-reactive protein. 
Of the 33 patients with usable sputum, 11 (33\%) had a concentration in sputum $\geq 2$ $\mathrm{mg} / \mathrm{l}$. All isolated organisms had a MIC $<2 \mathrm{mg} / \mathrm{L}$. The mean length of hospitalisation for patients with concentrations $<2 \mathrm{mg} / \mathrm{l}$ was 11.0 days, while for patients with concentrations $\geq 2 \mathrm{mg} / \mathrm{l}$ this was 7.0 days ( $p=0.005$ ) (see Figure 1$)$. The unadjusted hazard ratio of time to discharge in the patients with concentrations $\geq 2 \mathrm{mg} / \mathrm{l}$ as compared to $<2 \mathrm{mg} / \mathrm{l}$ was $3.02(95 \% \mathrm{Cl} 1.34-6.81 ; \mathrm{p}=0.008)$ representing a faster rate of discharge.

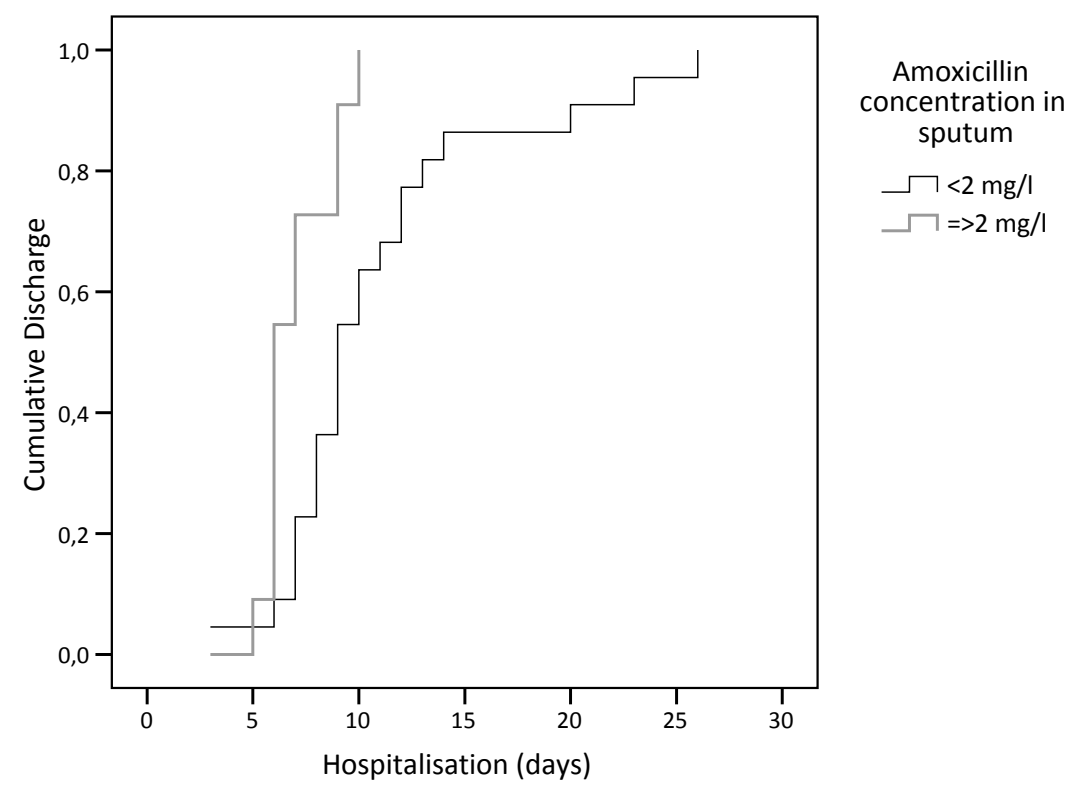

Figure 1. Cumulative discharge curve

Of the potential confounding variables displayed in Table 1, only smoking status (ex-smoker versus current smoker) and CRP concentration in blood one day after hospital admission were significantly associated with an amoxicillin concentration at or above and below the MIC90 of $2 \mathrm{mg} / \mathrm{l}$ (see Table 1). We included these two variables as well as other factors that were biologically likely to affect length of hospital stay including age, gender, sputum culture and II-6 levels in blood on day 1 in a multivariable model. Due to colinearity between II- 6 and CRP levels in blood on day 1 , we only included CRP levels in blood on day 1 in the multivariate model 
based on the best fit statistics. We found that only amoxicillin levels remained predictive of length of hospital stay (Table 2).

Table 2. Hazard ratio and 95\% confidence interval for factors predictive of length of hospital stay among patients with COPD

\begin{tabular}{|c|c|c|}
\hline Factor & Unadjusted HR $(95 \% \mathrm{Cl})$ & Adjusted HR1 $(95 \% \mathrm{Cl})$ \\
\hline \multicolumn{3}{|l|}{ Amoxicillin level } \\
\hline$<2 \mathrm{mg} / \mathrm{dl}$ & 1.0 & 1.0 \\
\hline$\geq 2 \mathrm{mg} / \mathrm{dl}$ & $3.020(1.338-6.814)$ & $3.515(1.011-12.216)$ \\
\hline \multicolumn{3}{|l|}{ Smoking status } \\
\hline Ex-smoker & 1.0 & 1.0 \\
\hline Current smoker & $0.735(0.408-1.324)$ & $0.371(0.124-1.108)$ \\
\hline \multirow{2}{*}{\multicolumn{3}{|c|}{$\begin{array}{l}\text { Sputum culture at day of } \\
\text { admission }\end{array}$}} \\
\hline & & \\
\hline No infection & 1.0 & 1.0 \\
\hline Infection & $0.605(0.317-1.154)$ & $1.570(0.536-4.598)$ \\
\hline \multicolumn{3}{|l|}{ Gender } \\
\hline Male & 1.0 & 1.0 \\
\hline Female & $0.660(0.368-1.206)$ & $0.238(0.070-1.140)$ \\
\hline Age (years) & $0.980(0.951-1.011)$ & $0.947(0.891-1.006)$ \\
\hline CRP concentration in blood day 1 & $0.995(0.985-1.005)$ & $1.007(0.992-1.023)$ \\
\hline
\end{tabular}

\section{Discussion}

Our study demonstrated that COPD patients admitted to the hospital with an acute exacerbation of COPD who have a sputum concentration of amoxicillin $\geq 2 \mathrm{mg} / \mathrm{l}$ on the third day of dosing have a markedly reduced length of hospitalisation compared to patients with a concentration $<2 \mathrm{mg} / \mathrm{l}$.

Host-related as well as drug-related factors may influence the penetration of antimicrobial drugs across the blood-bronchus and alveolar-capillary barriers. The most important host-related factor is the integrity of the anatomical barriers which may be damaged by inflammation and mechanical injury(4). In the presence of inflammation, the distribution of antimicrobial agents in tissue compartments may be altered because of an increase in membrane permeability $(18 ; 19)$. Thus, for a drug such as amoxicillin clavulanic acid, a beta-lactam, which does not cross membranes readily, the penetration might increase in the presence of inflammation(4). In our study the concentration of amoxicillin in sputum was increased in patients with an elevated CRP concentration in blood one day after 
admission and in ex-smokers. Since CRP is a marker of systemic inflammation this might explain the higher concentrations of amoxicillin in patients with higher CRP levels due to increased inflammation. Studies exist where patients with a high CRP level were identified. Stolz et al. showed that CRP was significantly higher in patients presenting with an Anthonisen type I exacerbation(20) and two other studies also reported that patients with increased sputum purulence at admission had higher CRP values than those without increased sputum volume, which suggests that CRP is a marker of bacterial infection(21;22). Pinto-Plata et al. showed that the CRP levels were higher in non-inhaled corticosteroids (ICS) users than in ICS users(23). These results were in agreement with the study of Sin et al. that showed that withdrawal of ICS was associated with an increase in the baseline CRP level, which suggests corticosteroids reduce systemic inflammation(24). In our study, all patients however, received systemic corticosteroids, so this is not likely the explanation of our findings.

Besides the relationship between CRP and the concentration of amoxicillin in sputum, we also observed that in current smokers the concentration of amoxicillin in sputum was more often under the MIC, suggesting a decreased permeability in current smokers. Willemse et al. showed that after 1 year smoking cessation, airway inflammation in sputum persisted and even increased(25). This increase in airway inflammation could possible explain why the ex-smokers in our study had more often a higher concentration of amoxicillin. Furthermore, Willemse et al. suggest that this persistent inflammation in ex-smokers may be, at least partly, related to repair of the smoke-induced tissue damage in the airways(25). Since also mechanical injury influences the penetration of antimicrobial drugs across the blood-bronchus and alveolar-capillary barriers(4) this could be another explanation for the higher percentage of patients with a concentrations of amoxicillin $\geq 2 \mathrm{mg} / \mathrm{I}$ in ex-smokers.

Another explanation could be that smoking might interfere with the amoxicillin concentration. However, this is not known from studies performed on smoking and drug interactions.

Our study demonstrated that COPD patients admitted to the hospital with an acute exacerbation of COPD, with a sputum concentration of amoxicillin $\geq 2 \mathrm{mg} / \mathrm{l}$ had a markedly reduced length of hospitalisation by 4 days compared to patients with a concentration $<2 \mathrm{mg} / \mathrm{l}$. This leads to the question whether individual tailoring of 
amoxicillin dosing to reach at least the MIC90 in sputum will reduce the length of stay in patients hospitalised for a COPD exacerbation, which then leads to a remarkable reduction of costs and the pressure of demand on hospital beds, since the length of stay is the key cost driver(26). In case of individual tailoring, patients not able to reach the MIC90 with the standard treatment can be identified by collecting a sputum sample during antibiotic treatment for an exacerbation in which antibiotic concentrations are measured.

The consequence of finding lower concentrations, below the MIC, should be to consider increasing the dose of antibiotics in patients that do not reach sufficient concentrations. Alternatively, other antibiotics or routes of administration such as inhalation of antibiotics could be considered like in cystic fibrosis(27). Aerosolised antibiotics have been proven to deliver high concentrations of antibiotics into the airways with low systemic bioavailability, thus reducing toxicity(28).

Our results need to be confirmed. We suggest doing this by testing the usefulness of a prospective algorithm of antibiotic dosing based on sputum amoxicillin concentrations with the aim to reduce hospitalisation length for acute exacerbations of COPD. 


\section{References}

(1) Wilson R. Bacterial infection and chronic obstructive pulmonary disease. Eur Respir J 1999 Feb;13(2):233-5.

(2) Saint S, Bent S, Vittinghoff E, Grady D. Antibiotics in chronic obstructive pulmonary disease exacerbations. A meta-analysis. JAMA $1995 \mathrm{Mar}$ 22;273(12):957-60.

(3) Anthonisen NR, Manfreda J, Warren CPW, Hershfield ES, Harding GKM, Nelson NA. Antibiotic therapy in exacerbations of chronic obstructive pulmonary disease. Ann Intern Med 1987;106:196-204.

(4) Baldwin DR, Honeybourne D, Wise R. Pulmonary disposition of antimicrobial agents: in vivo observations and clinical relevance. Antimicrob Agents Chemother 1992 Jun;36(6):1176-80.

(5) Fraschini F, Scaglione F, Falchi M, Dugnani S, Mezzetti M, Cicchetti F, et al. Pharmacokinetics and tissue distribution of amoxicillin plus clavulanic acid after oral administration in man. J Chemother 1990 Jun;2(3):171-7.

(6) Baldwin DR, Honeybourne D, Wise R. Pulmonary disposition of antimicrobial agents: methodological considerations. Antimicrob Agents Chemother 1992 Jun;36(6):1171-5.

(7) Pennington JE. Penetration of antibiotics into respiratory secretions. Rev Infect Dis 1981 Jan;3(1):67-73.

(8) Neu HC. Contribution of beta-lactamases to bacterial resistance and mechanisms to inhibit beta-lactamases. Am J Med 1985 Nov 29;79(5B):2-12.

(9) Wallace RJ, Jr., Steele LC, Brooks DL, Luman JI, Wilson RW, McLarty JW. Amoxicillin-clavulanic acid in the treatment of lower respiratory tract infections caused by beta-lactamase-positive Haemophilus influenzae and Branhamella catarrhalis. Antimicrob Agents Chemother 1985 Jun;27(6):912-5.

(10) Maesen FP, Davies BI, Baur C. Amoxycillin/clavulanate in acute purulent exacerbations of chronic bronchitis. J Antimicrob Chemother 1987 Mar;19(3):373-83.

(11) Havard CW, Fernando A, Brumfitt W, Hamilton-Miller JM. A pilot study of 'Augmentin' in lower respiratory tract infections: pharmacokinetic and clinical results. Br J Dis Chest 1982 Jul;76(3):255-60.

(12) Ingold A. Sputum and serum levels of amoxycillin in chronic bronchial infections. Br J Dis Chest 1975 Jul;69:211-6. 
(13) Lovering AM, Pycock CJ, Harvey JE, Reeves DS. The pharmacokinetics and sputum penetration of ampicillin and amoxycillin following simultaneous i.v. administration. J Antimicrob Chemother 1990 Mar;25(3):385-92.

(14) Hill SL, Burnett D, Lovering AL, Stockley RA. Use of an enzyme-linked immunosorbent assay to assess penetration of amoxicillin into lung secretions. Antimicrob Agents Chemother 1992 Jul;36(7):1545-52.

(15) Pauwels RA, Buist AS, Calverley PM, Jenkins CR, Hurd SS. Global strategy for the diagnosis, management, and prevention of chronic obstructive pulmonary disease. NHLBI/WHO Global Initiative for Chronic Obstructive Lung Disease (GOLD) Workshop summary. Am J Respir Crit Care Med 2001 Apr;163(5):125676.

(16) Isenberg HD. Clinical microbiology procedures handbook. 2004.

(17) Van der Valk P, Monninkhof E, van der Palen J., Zielhuis G, van Herwaarden C., Hendrix R. Clinical predictors of bacterial involvement in exacerbations of chronic obstructive pulmonary disease. Clin Infect Dis 2004 Oct 1;39(7):980-6.

(18) Braude AC, Cohen RD, Penner JL, Preston MA, Rebuck AS. Pulmonary disposition of moxalactam. Chest 1984 Dec;86(6):881-3.

(19) Bergogne-Berezin E. Penetration of antibiotics into the respiratory tree. J Antimicrob Chemother 1981 Sep;8(3):171-4.

(20) Stolz D, Christ-Crain M, Morgenthaler NG, Leuppi J, Miedinger D, Bingisser R, et al. Copeptin, C-reactive protein, and procalcitonin as prognostic biomarkers in acute exacerbation of COPD. Chest 2007 Apr;131(4):1058-67.

(21) Stockley RA, O'Brien C, Pye A, Hill SL. Relationship of sputum color to nature and outpatient management of acute exacerbations of COPD. Chest 2000 Jun;117(6):1638-45.

(22) Weis N, Almdal T. C-reactive protein--can it be used as a marker of infection in patients with exacerbation of chronic obstructive pulmonary disease? Eur J Intern Med 2006 Mar;17(2):88-91.

(23) Pinto-Plata VM, Mullerova H, Toso JF, Feudjo-Tepie M, Soriano JB, Vessey RS, et al. C-reactive protein in patients with COPD, control smokers and nonsmokers. Thorax 2006 Jan;61(1):23-8.

(24) Sin DD, Lacy P, York E, Man SF. Effects of fluticasone on systemic markers of inflammation in chronic obstructive pulmonary disease. Am J Respir Crit Care Med 2004 Oct 1;170(7):760-5. 
(25) Willemse BW, ten Hacken NH, Rutgers B, Lesman-Leegte IG, Postma DS, Timens W. Effect of 1-year smoking cessation on airway inflammation in COPD and asymptomatic smokers. Eur Respir J 2005 Nov;26(5):835-45.

(26) O'Reilly JF, Williams AE, Rice L. Health status impairment and costs associated with COPD exacerbation managed in hospital. Int J Clin Pract 2007 Jul;61(7):1112-20.

(27) Touw DJ, Brimicombe RW, Hodson ME, Heijerman HG, Bakker W. Inhalation of antibiotics in cystic fibrosis. Eur Respir J 1995 Sep;8(9):1594-604.

(28) Rubin BK. Other medications for aerosol delivery. Paediatr Respir Rev 2006;7 Suppl 1:S76-S79. 


\section{CHAPTER 6}

THE IMPACT ON CLINICAL DECISION MAKING OF QUALITY CONTROL STANDARDS APPLIED TO SPUTUM ANALYSIS IN COPD

Maaike Telgen, Marjolein Brusse-Keizer, Paul van der Valk, Job van der Palen, Huib Kerstjens, Ron Hendrix

Submitted 


\begin{abstract}
Background: Sputum analysis is an important tool in the management of COPD exacerbations, for decisions to prescribe antibiotics. The most common test, apart from assessing sputum color, is determining in a sputum sample the presence and abundance of potentially pathogenic micro-organism in Gram's stain and/or culture. Since there is a high variability in the quality of sputum samples it is plausible that using samples of inadequate quality can have major consequences on the interpretation of culture results and therefore on clinical decisions.
\end{abstract}

Objective: To determine whether the application of stringent quality control criteria for sputum samples obtained from COPD patients during stable disease and during acute exacerbations have an impact on culture results.

Methods: We analysed sputum samples obtained from 108 COPD patients from the COPE study during stable disease and during exacerbations. To these samples we applied the quality control standards and culture interpretation rules according to the American Society of Microbiologists (ASM).

Results: In sputum exacerbation samples considered appropriate according to the ASM quality standards, criteria for infection (40\%) were met more often compared to inappropriate sputum samples $(13 \%)(p<0.001)$. The same pattern was observed when applying the same rules in sputum samples obtained during stable disease, $(50 \%$ vs $18 \%, p<0.001)$. No statistically significant difference was seen in the percentage of infectious cultures obtained during stable state and during exacerbations.

Conclusions: Applying stringent quality control criteria to sputum samples can have a profound effect on the labeling of sputum samples as infectious, and therefore on clinical decision making. 


\section{Introduction}

Chronic Obstructive Pulmonary Disease (COPD) is a major cause of chronic morbidity and mortality throughout the world. Morbidity and mortality among patients with COPD are for a large part related to acute exacerbations of COPD, which occur on average 1-3 times a year(1). COPD exacerbations are heterogeneous events that are thought to be caused by complex interactions between the host, respiratory viruses, airway bacteria, and environmental pollution, leading to an increase in the inflammatory burden(2). Sputum analysis is an important clinical tool in the management of COPD, especially in COPD exacerbations, for decisions to prescribe antibiotics. The most common test in exacerbations is taking a sputum sample for culture to determine the presence, abundance, and resistance pattern of bacteria. Multiple studies show that there is a variety of microorganisms present in cultures of patients with acute exacerbations of $\operatorname{COPD}(3 ; 4)$. The presence of micro-organisms however does not directly signify that these organisms are the causative agent of an infection; patients can just be colonised. Next to culturing sputum samples, other characteristics of sputum have been used to determine the cause of an exacerbation. A marker that has been commonly used since the study of Anthonisen et al. in 1987, is sputum purulence(5), which is seen as an indirect marker for the presence of bacteria. Also Stockley et al. used sputum color (or purulence) as the primary parameter to decide whether or not to start antibiotic treatment(6). Additionally, the concentration of inflammatory markers and cell types are also commonly analysed in sputum samples. Sethi and colleagues showed that neutrophilic airway inflammation and systemic inflammation are more intense with well-defined bacterial exacerbations than with nonbacterial exacerbations(7). Other parameters that can indicate the presence of a bacterial infection are Creactive protein, TNF alpha and interleukins (IL-6, IL-8)(8-10).

All these studies show that sputum analysis is an important clinical tool in the management of COPD.

When collecting sputum samples, there is a high variability in the quality of the samples obtained. In 1975 Murray et al. designed criteria for the quality of sputum. Specimens were categorised according to the number of leukocytes and squamous epithelial cells observed microscopically in a Gram-stained smear(11). When the number of squamous epithelial cells was far greater than the number of leucocytes in the sputum, they assumed that this specimen originated from the upper airways and therefore should not be further analysed. The American Society of 
Microbiologists (ASM) also advocates quality control standards and culture interpretation rules(12). Although these quality statements have now existed for many years, published studies involving sputum analysis often do not report on the quality control standards they used for sputum samples and whether sputum samples of inadequate quality were removed from further analyses. We hypothesise that using sputum samples of inadequate quality might have major consequences on the interpretation of culture results and therefore on clinical decision making. Therefore, we performed a study on sputa of COPD patients in stable state and during acute exacerbations to study the differences between sputum outcomes in adequate and inadequate sputum samples as based on the ASM criteria.

\section{Methods}

\section{Patients}

To be eligible for the study the patients had to meet the following criteria: 1) a clinical diagnosis of COPD, as defined by American Thoracic Society criteria(13); 2) no history of asthma; 3) no exacerbation in the month prior to enrolment; 4) current or former smoker; 5) age between 40-75 years; 6) baseline prebronchodilator forced expiratory volume in one second $\left(\mathrm{FEV}_{1}\right) 25-85 \%$ of predicted; 7) pre-bronchodilator ratio $\mathrm{FEV}_{1}$ to inspiratory vital capacity (IVC) $60 \%$ or less; 8) reversibility of $\mathrm{FEV}_{1}$ post inhalation of $80 \mu \mathrm{g}$ of ipratropium bromide via metered dose inhalator with an aerochamber $\leq 12 \%$ predicted(14); 9) total lung capacity (TLC) greater than the TLC predicted minus $1.64 *$ SD; 10) no maintenance treatment of oral steroids or antibiotics; 11 ) no medical condition with low survival or serious psychiatric morbidity (e.g. cardiac insufficiency, alcoholism); 12) absence of any other active lung disease (e.g. sarcoidosis).

The use of medication such as nasal corticosteroids, theophyllines, chronic use of acetylcysteine and all other bronchodilators was allowed.

The hospital's medical ethical committee approved this study. All patients provided written informed consent.

\section{Study design}

This study was performed on data of the COPE study $(15 ; 16)$. Patients were instructed to contact the study personnel any time they experienced a worsening of their respiratory symptoms. They were subsequently invited to attend the outpatient department within 12 hours for lung function measurements, sputum 
collection and consultation by one of the study physicians. Exacerbations were defined as worsening of respiratory symptoms that required treatment with a short course of oral corticosteroids and/or antibiotics as judged by the study physician. Stable state was defined as a period of 4 weeks with no change in respiratory symptoms beyond day to day variations.

\section{Outcome measures}

Sputum samples were taken in stable state and at acute exacerbation. During the collection of stable state sputa all patients were on inhaled corticosteroids (ICS) according to the COPE protocol. The samples obtained during exacerbation were taken both from patients on ICS and patients on placebo in line with the design of the COPE study(17). Sputum samples were collected in sterile vials and processed in the laboratory within 4 hours. Sputa were homogenised by incubation at $37^{\circ} \mathrm{C}$ for 15 minutes with an equal volume of 0.1 percent dithiothreitol. Conform the ASM criteria, sputum samples with less than $10^{5} * \mathrm{~mL}^{-1}$ squamous epithelial cells were considered representative bronchial samples and were defined as adequate samples. All other samples were classified as inadequate(12;18). A Gram's stain and semi quantitative culture were performed for all collected sputum samples, irrespective of whether the sample was defined as adequate. Bacterial infection was defined per ASM criteria as the presence of potential pathogenic microorganisms (PPM) in pure culture or as the presence of one or more PPM in excess (one log or more) to normal microbiological flora in sputum. Criteria for bacterial colonisation were defined also by ASM criteria as the presence of PPM in culture in equal amount or less compared to normal microbiologic flora in sputum(12;19).

In all sputum samples IL-6, IL-8 and TNF- $\alpha$ concentrations were quantified using PeliKine Compact ${ }^{\mathrm{TM}}$ human sandwich ELISA kits (Sanquin, CLB, Amsterdam, the Netherlands). MPO enzymatic activity in sputum was determined by colorimetric change in absorbance during a reaction with O-Dianisidine dihydrochloride (SigmaAldrich(C). Spirometry was performed according to standardised guidelines(20). $\mathrm{FEV}_{1}$ and IVC were measured until three reproducible recordings (less than $5 \%$ difference) were obtained. Highest values were used for analyses.

\section{Statistical analyses}

Baseline characteristics are reported as mean \pm SD or as numbers with corresponding percentages for categorical or dichotomous variables. Not normally distributed variables are reported as median with corresponding range. 
To identify whether there were differences between sputum of adequate and inadequate samples, Chi-square or Fisher exact tests were performed as appropriate.

\section{Results}

Sputum samples of 108 patients were used for analyses. A total of 261 sputum samples were collected, of which 122 in stable state and 139 at acute exacerbation. Baseline characteristics of all patients are shown in Table 1.

Table 1. Baseline characteristics. Data are presented as mean (SD) or number (\%).

\begin{tabular}{lc}
\hline & $(\mathrm{N}=108)$ \\
\hline Age in years & $64.0(7.3)$ \\
Male & $91(84 \%)$ \\
Lung function post bronchodilation & \\
$\quad$ FEV $_{1}$ in L & $1.68(0.57)$ \\
FEV $_{1} \%$ predicted & $57.4(14.5)$ \\
$\quad$ IVC in L & $3.8(0.87)$ \\
$\quad$ FEV 1 / IVC $\%$ & $44.4(10.8)$ \\
Total number of sputum samples at exacerbation & 139 \\
Total number of sputum samples at stable state & 122 \\
\hline
\end{tabular}

Sixty of the 139 (43\%) samples collected during exacerbations were classified as inadequate (Table 2). In sputum samples of adequate quality the probability of meeting the criteria for bacterial infection was 3-fold increased $(\mathrm{Cl}$ 95\%: 1.58 3.05; $p<0.001$ ) compared to inadequate sputum samples. Without the application of the quality criteria standard the overall percentage of sputa meeting the criteria for bacterial infection was $29 \%$, compared to $40.5 \%$ in sputum samples of adequate quality.

Table 2. Number of sputa that met criteria for bacterial infection in adequate and inadequate sputum samples obtained at COPD exacerbation

\begin{tabular}{lcc}
\hline & Bacterial infection & No bacterial infection \\
\hline Adequate sputum quality & $32(40.5 \%)$ & $47(59.5 \%)$ \\
Inadequate sputum quality & $8(13.3 \%)$ & $52(86.7 \%)$ \\
\hline
\end{tabular}

Table 3 shows the number of sputa obtained in stable state, again divided into adequate and inadequate sputum samples. Sixty six of the 122 (54\%) collected 
samples were classified as inadequate. In adequate sputum samples the probability of meeting criteria for bacterial infection was 2.8-fold increased $(\mathrm{Cl}$ 95\%: $1.49-$ $2.88 ; \mathrm{p}<0.001)$ compared to inadequate sputum samples. Without the application of the standard ASM quality criteria the overall percentage of sputa meeting the criteria for bacterial infection was $36 \%$, compared to $50 \%$ in sputum samples of adequate quality.

Table 3. Number of sputa that met criteria for bacterial infection in adequate and inadequate sputum samples obtained in stable state

\begin{tabular}{lcc}
\hline & Bacterial infection & No \\
\hline Adequate sputum quality & $28(50.0 \%)$ & $28(50.0 \%)$ \\
Inadequate sputum quality & $12(18.2 \%)$ & $54(81.8 \%)$ \\
\hline
\end{tabular}

In sputa obtained at stable state 1.25 times ( $\mathrm{Cl} 95 \%$ : $1.01-1.56 ; \mathrm{p}=0.04)$ more sputa were classified as inadequate compared to sputa collected during exacerbation. Furthermore, the adequate sputa samples obtained at stable state and during exacerbations showed no difference in the number of sputa that met the criteria for bacterial infection $(p=0.2)$.

The concentration of TNF- $\alpha$ in sputum samples obtained during COPD exacerbations was significantly higher in adequate samples than in inadequate sputum samples, both in sputum samples that met criteria for bacterial infection or not (Table 4). No significant differences were found in other inflammation markers (IL-6, IL-8, and MPO). 
Table 4. Concentration of inflammation markers in adequate and inadequate sputum samples obtained at COPD exacerbation. Concentrations are displayed as median (25-75 percentiles).

\begin{tabular}{lcccc}
\hline & $\begin{array}{c}\text { TNF- } \alpha \\
(\mathrm{pg} / \mathrm{ml})^{2}\end{array}$ & $\begin{array}{c}\mathrm{IL}-6 \\
(\mathrm{pg} / \mathrm{ml})\end{array}$ & $\begin{array}{c}\mathrm{IL}-8 \\
(\mathrm{pg} / \mathrm{ml})^{1}\end{array}$ & $\begin{array}{c}\text { MPO } \\
\text { (extinction) }\end{array}$ \\
\hline Bacterial infection & & & & \\
Adequate sputum & $600\left(179-1001^{2}\right)$ & $7(1.3-32)$ & $241^{1}\left(150-241^{1}\right)$ & $1.3(0.7-2.1)$ \\
Inadequate sputum & $175(61-453)$ & $8.9(0.6-58.1)$ & $200\left(16-241^{1}\right)$ & $1.3(0.5-1.8)$ \\
p-value & 0.044 & 0.753 & 0.130 & 0.787 \\
No bacterial infection & & & & \\
Adequate sputum & $39(9-725)$ & $34(8-100)$ & $50\left(15-241^{1}\right)$ & $1.0(0.1-2.1)$ \\
Inadequate sputum & $13(0.0-115)$ & $17(4.6-46.5)$ & $36(4.4-70)$ & $0.3(0.1-1.0)$ \\
p-value & 0.010 & 0.100 & 0.052 & 0.067 \\
\hline
\end{tabular}

\footnotetext{
${ }^{1}$ All IL-8 concentrations $>240$ were labeled $241 ;{ }^{2}$ All TNF- $\alpha$ concentrations $>1000 \mathrm{pg} / \mathrm{ml}$ were labeled 1001
}

Table 5 shows that in sputum samples obtained in stable state the concentration of IL-8 is significantly higher in adequate samples than in inadequate sputum samples in sputum samples that met criteria for bacterial infection. In sputum samples that did not meet criteria for bacterial infection, adequate sputum sample showed significantly higher concentrations of TNF- $\alpha$ and IL- 6 than inadequate samples.

Table 5. Concentration of inflammation markers in adequate and inadequate sputum samples obtained in stable state. Concentrations are displayed as median (25-75 percentiles).

\begin{tabular}{lcccc}
\hline & $\begin{array}{c}\text { TNF- } \alpha \\
(\mathrm{pg} / \mathrm{ml})^{2}\end{array}$ & $\begin{array}{c}\mathrm{IL}-6 \\
(\mathrm{pg} / \mathrm{ml})\end{array}$ & $\begin{array}{c}\mathrm{IL}-8 \\
(\mathrm{pg} / \mathrm{ml})^{1}\end{array}$ & $\begin{array}{c}\text { MPO } \\
\text { (extinction) }\end{array}$ \\
\hline $\begin{array}{l}\text { Bacterial infection } \\
\text { Adequate sputum }\end{array}$ & $715\left(220-1001^{2}\right)$ & $18.5(1.2-78.3)$ & $241^{1}\left(241^{1}-241^{1}\right)$ & $1.5(0.8-2.2)$ \\
Inadequate sputum & $1001^{2}\left(225-1001^{2}\right)$ & $17.5(3.1-77.5)$ & $122.5\left(65.8-241^{1}\right)$ & $1.7(0.2-2.9)$ \\
$\begin{array}{l}\text { p-value } \\
\text { No bacterial infection }\end{array}$ & 0.588 & 0.376 & 0.009 & 0.651 \\
Adequate sputum & $120(4.5-792.5)$ & $78.0(15.3-388.3)$ & $90\left(9-241^{1}\right)$ & $0.6(0.2-2,0)$ \\
Inadequate sputum & $10.3(0.0-99.8)$ & $19(1.7-50)$ & $22\left(3.5-241^{1}\right)$ & $0.2(0.1-1.1)$ \\
p-value & 0.035 & 0.020 & 0.068 & 0.156 \\
\hline
\end{tabular}

\footnotetext{
${ }^{1}$ All IL-8 concentrations > 240 were labeled $241 ;{ }^{2}$ All TNF- $\alpha$ concentrations $>1000 \mathrm{pg} / \mathrm{ml}$ were labeled 1001
}

In Table 6 we compared the concentration of inflammation markers in adequate samples obtained in stable state and at COPD exacerbation. There were no 
significant differences in the concentrations of TNF- $\alpha, \mathrm{IL}-6, \mathrm{IL}-8$, and MPO between samples obtained in stable state and at COPD exacerbation.

Table 6. Concentration of inflammation markers in adequate samples obtained in stable state and at COPD exacerbation. Concentrations are displayed as median (25-75 percentiles).

\begin{tabular}{lcccc}
\hline & $\begin{array}{c}\text { TNF- } \alpha \\
(\mathrm{pg} / \mathrm{ml})^{2}\end{array}$ & $\begin{array}{c}\mathrm{IL}-6 \\
(\mathrm{pg} / \mathrm{ml})\end{array}$ & $\begin{array}{c}\mathrm{IL}-8 \\
(\mathrm{pg} / \mathrm{ml})^{1}\end{array}$ & $\begin{array}{c}\text { MPO } \\
\text { (extinction) }\end{array}$ \\
\hline Bacterial infection & & & & \\
Stable state & $715\left(220-1001^{2}\right)$ & $18.5(1.2-78)$ & $241^{1}\left(241^{1}-241^{1}\right)$ & $1.5(0.8-2.2)$ \\
Exacerbation & $600\left(179-1001^{2}\right)$ & $7(1.3-32)$ & $241^{1}\left(150-241^{1}\right)$ & $1.3(0.7-2.1)$ \\
p-value & 0.806 & 0.504 & 0.329 & 0.657 \\
No bacterial infection & $120(4.5-792)$ & $78.0(15.3-388)$ & $90\left(9-241^{1}\right)$ & $0.6(0.2-2.0)$ \\
Stable state & $39(9-725)$ & $34(8-100)$ & $50\left(15-241^{1}\right)$ & $1.0(0.1-2.1)$ \\
Exacerbation & 0.973 & 0.158 & 0.986 & 0.814 \\
p-value & & & &
\end{tabular}

\footnotetext{
${ }^{1}$ All IL-8 concentrations $>240$ were labeled $241 ;{ }^{2}$ All TNF- $\alpha$ concentrations $>1000 \mathrm{pg} / \mathrm{ml}$ were labeled 1001
}

\section{Discussion}

In sputum samples obtained during acute exacerbations in COPD, considered appropriate according to the ASM quality standards, criteria for bacterial infection (40\%) were met more often as compared to inappropriate sputum samples (13\%). Moreover, when applying these well defined ASM criteria to sputum samples obtained during stable disease exactly the same pattern of more infections in adequate samples was observed (50\% infections vs 18\%). Applying stringent quality control criteria to sputum samples can therefore have a profound effect on clinical decision making.

This study showed that both during exacerbations and in stable state a large number, respectively $54 \%$ and $43 \%$ of the sputum samples were inadequate. Roche et al. also observed a low percentage of sputum samples from COPD patients $(20.5 \%)$ that satisfied their quality criteria (i.e. $>25$ polymorphonuclear leukocytes and $<10$ epithelial cells per field at $x 100)(21)$. These criteria are equal to the Murray criteria(22). Although the study of Roche et al. was performed in COPD patients admitted to the hospital for an exacerbation and they used quality criteria that differed from the ASM criteria, both studies show that collection of inadequate sputum samples is a very common feature in COPD patients. 
It matters that so many inadequate samples are found since we observed that the criteria for infections were met considerably more frequently in adequate samples compared to inadequate samples, both for samples collected during exacerbations and during stable state. Since PPM causing bacterial infections have been suggested to be located in the lower airways(23) it is not surprising that samples from the upper airways, i.e. inadequate samples, meet criteria for bacterial infection less often. Furthermore, dilution of sputum with saliva can cause lower concentrations of PPM in the obtained samples and therefore failure to meet criteria for bacterial infection. As mentioned earlier, our study showed a higher percentage of inadequate samples collected during stable state compared to samples collected during exacerbation. A possible explanation for this might be the difficulty of coughing up of spontaneous sputum in stable state. A solution would be the use of sputum induction. Sputum induction has been proven to be safe in stable state, even in patients with moderate to severe $\operatorname{COPD}(24)$ and recently it has also been shown to be safe in COPD exacerbations in patients with mild to moderate $\operatorname{COPD}(25)$.

Many contradictory results have been published on sputum inflammation markers in $\operatorname{COPD}(26-30)$. In our study we also looked at sputum markers. Before discussing our results we however should mention that half of our patients received ICS. Since the literature is not consistent about the effect of ICS(31;32) on inflammation markers associated with neutrophils, we combined the data of the groups with and without ICS in the analyses presented here.

We found that levels of TNF- $\alpha$ differed between adequate and inadequate samples obtained during exacerbation. In samples obtained in stable state that met criteria for bacterial infection, the concentration of IL-8 differed between adequate and inadequate samples. In samples obtained in stable state that did not meet criteria for bacterial infection, the concentrations of TNF- $\alpha$ and IL- 6 differed between adequate and inadequate samples. A possible explanation for the variability in observed levels of inflammation markers and associations with various outcomes in literature can therefore be due to different criteria used for sputum quality.

A remarkable finding of this study was that not only a high percentage of samples collected at exacerbation met criteria for bacterial infection, but an almost equal percentage of samples collected during stable state met the same criteria for 
bacterial infection. Additionally the concentrations of the inflammation markers TNF- $\alpha$, IL-6, IL-8 and MPO also did not differ between adequate samples obtained in stable state and at exacerbation. This raises the question whether the criteria for bacterial infection are adequate to distinguish bacterial infection during exacerbation from bacterial colonisation either at exacerbation or during stable state. We know from literature that a large number of COPD patients is colonised, varying from $33 \%$ to $100 \%(33)$. Like us, Sethi et al. also did not find an increase in bacterial load during exacerbations in their longitudinal cohort of COPD patients(34).

In conclusion, applying stringent quality control criteria to sputum samples can have a profound effect on the percentage of positive sputum cultures and by inference on clinical decision making.

This is probably also true for the application and analysis of other biomarkers in sputum samples. It is therefore necessary that quality criteria are used and published in study reports on sputum outcomes in COPD. Furthermore, more longitudinal research is needed on the change in bacterial load from stable state to exacerbations. 


\section{References}

(1) Rabe KF, Hurd S, Anzueto A, Barnes PJ, Buist SA, Calverley P, et al. Global Strategy for the Diagnosis, Management, and Prevention of COPD - GOLD Executive Summary. Am J Respir Crit Care Med 2007 Sep;176:532-55.

(2) Wedzicha JA, Seemungal TA. COPD exacerbations: defining their cause and prevention. Lancet 2007 Sep 1;370(9589):786-96.

(3) Soler N, Agusti C, Angrill J, Puig De la BJ, Torres A. Bronchoscopic validation of the significance of sputum purulence in severe exacerbations of chronic obstructive pulmonary disease. Thorax 2007 Jan;62(1):29-35.

(4) Patel IS, Seemungal TA, Wilks M, Lloyd-Owen SJ, Donaldson GC, Wedzicha JA. Relationship between bacterial colonisation and the frequency, character, and severity of COPD exacerbations. Thorax 2002 Sep;57(9):759-64.

(5) Anthonisen NR, Manfreda J, Warren CPW, Hershfield ES, Harding GKM, Nelson NA. Antibiotic therapy in exacerbations of chronic obstructive pulmonary disease. Ann Intern Med 1987;106:196-204.

(6) Stockley RA, O'Brien C, Pye A, Hill SL. Relationship of sputum color to nature and outpatient management of acute exacerbations of COPD. Chest 2000 Jun;117(6):1638-45.

(7) Sethi S, Wrona C, Eschberger K, Lobbins P, Cai X, Murphy TF. Inflammatory profile of new bacterial strain exacerbations of chronic obstructive pulmonary disease. Am J Respir Crit Care Med 2008 Mar 1;177(5):491-7.

(8) Seifart C, Dempfle A, Plagens A, Seifart U, Clostermann U, Muller B, et al. TNFalpha-, TNF-beta-, IL-6-, and IL-10-promoter polymorphisms in patients with chronic obstructive pulmonary disease. Tissue Antigens 2005 Jan;65(1):93100.

(9) Monso E, Garcia-Aymerich J, Soler N, Farrero E, Felez MA, Anto JM, et al. Bacterial infection in exacerbated COPD with changes in sputum characteristics. Epidemiol Infect 2003 Aug;131(1):799-804.

(10) Drost EM, Skwarski KM, Sauleda J, Soler N, Roca J, Agusti A, et al. Oxidative stress and airway inflammation in severe exacerbations of COPD. Thorax 2005 Apr;60(4):293-300.

(11) Murray PR, Washington JA. Microscopic and baceriologic analysis of expectorated sputum. Mayo Clin Proc 1975 Jun;50(6):339-44.

(12) Isenberg HD. Clinical microbiology procedures handbook. 2004. 
(13) American Thoracic Society. Standards for the diagnosis and care of patients with chronic obstructive pulmonary disease. Am J Respir Crit Care Med 1995;152:s77-s120.

(14) Brand PL, Quanjer PH, Postma DS, Kerstjens HA, Koeter GH, Dekhuijzen PN, et al. Interpretation of bronchodilator response in patients with obstructive airways disease. The Dutch Chronic Non-Specific Lung Disease (CNSLD) Study Group. Thorax 1992 Jun;47(6):429-36.

(15) Monninkhof E, Van der Valk P, Van der Palen J, van Herwaarden C, Zielhuis G. Effects of a comprehensive self-management programme in patients with chronic obstructive pulmonary disease. Eur Respir J 2003 Nov;22(5):815-20.

(16) Van der Valk PDLPM, Monninkhof E, van der Palen J., Zielhuis G, van Herwaarden C. Effect of discontinuation of inhaled corticosteroids in patients with chronic obstructive pulmonary disease: the COPE study. Am J Respir Crit Care Med 2002 Nov 15;166(10):1358-63.

(17) Van der Valk PDLPM, Monninkhof E, van der Palen J., Zielhuis G, van Herwaarden C. Effect of discontinuation of inhaled corticosteroids in patients with chronic obstructive pulmonary disease: the COPE study. Am J Respir Crit Care Med 2002 Nov 15;166(10):1358-63.

(18) Van der Valk P, Monninkhof E, van der Palen J., Zielhuis G, van Herwaarden C., Hendrix R. Clinical predictors of bacterial involvement in exacerbations of chronic obstructive pulmonary disease. Clin Infect Dis 2004 Oct 1;39(7):980-6.

(19) Van der Valk P, Monninkhof E, van der Palen J., Zielhuis G, van Herwaarden C., Hendrix R. Clinical predictors of bacterial involvement in exacerbations of chronic obstructive pulmonary disease. Clin Infect Dis 2004 Oct 1;39(7):980-6.

(20) Quanjer PH, Tammeling GJ, Cotes JE, Pedersen OF, Peslin R, Yernault JC. Lung volumes and forced ventilatory flows. Report Working Party Standardization of Lung Function Tests, European Community for Steel and Coal. Official Statement of the European Respiratory Society. Eur Respir J Suppl 1993 Mar;16:5-40.

(21) Roche N, Kouassi B, Rabbat A, Mounedji A, Lorut C, Huchon G. Yield of sputum microbiological examination in patients hospitalized for exacerbations of chronic obstructive pulmonary disease with purulent sputum. Respiration 2007;74(1):19-25.

(22) Murray PR, Washington JA. Microscopic and baceriologic analysis of expectorated sputum. Mayo Clin Proc 1975 Jun;50(6):339-44. 
(23) Soler N, Agusti C, Angrill J, Puig De la BJ, Torres A. Bronchoscopic validation of the significance of sputum purulence in severe exacerbations of chronic obstructive pulmonary disease. Thorax 2007 Jan;62(1):29-35.

(24) Bhowmik A, Seemungal TA, Sapsford RJ, Devalia JL, Wedzicha JA. Comparison of spontaneous and induced sputum for investigation of airway inflammation in chronic obstructive pulmonary disease. Thorax 1998 Nov;53(11):953-6.

(25) Bathoorn E, Liesker J, Postma D, Koeter G, van Oosterhout AJ, Kerstjens HA. Safety of sputum induction during exacerbations of COPD. Chest 2007 Feb;131(2):432-8.

(26) Bhowmik A, Seemungal TA, Sapsford RJ, Wedzicha JA. Relation of sputum inflammatory markers to symptoms and lung function changes in COPD exacerbations. Thorax 2000 Feb;55(2):114-20.

(27) Fujimoto K, Yasuo M, Urushibata K, Hanaoka M, Koizumi T, Kubo K. Airway inflammation during stable and acutely exacerbated chronic obstructive pulmonary disease. Eur Respir J 2005 Apr;25(4):640-6.

(28) Roland M, Bhowmik A, Sapsford RJ, Seemungal TA, Jeffries DJ, Warner TD, et al. Sputum and plasma endothelin-1 levels in exacerbations of chronic obstructive pulmonary disease. Thorax 2001 Jan;56(1):30-5.

(29) Aaron SD, Angel JB, Lunau M, Wright K, Fex C, Le Saux N, et al. Granulocyte inflammatory markers and airway infection during acute exacerbation of chronic obstructive pulmonary disease. Am J Respir Crit Care Med 2001 Mar;163(2):349-55.

(30) Drost EM, Skwarski KM, Sauleda J, Soler N, Roca J, Agusti A, et al. Oxidative stress and airway inflammation in severe exacerbations of COPD. Thorax 2005 Apr;60(4):293-300.

(31) Hattotuwa KL, Gizycki MJ, Ansari TW, Jeffery PK, Barnes NC. The effects of inhaled fluticasone on airway inflammation in chronic obstructive pulmonary disease: a double-blind, placebo-controlled biopsy study. Am J Respir Crit Care Med 2002 Jun 15;165(12):1592-6.

(32) Gizycki MJ, Hattotuwa KL, Barnes N, Jeffery PK. Effects of fluticasone propionate on inflammatory cells in COPD: an ultrastructural examination of endobronchial biopsy tissue. Thorax 2002 Sep;57(9):799-803.

(33) Tumkaya M, Atis S, Ozge C, Delialioglu N, Polat G, Kanik A. Relationship between airway colonization, inflammation and exacerbation frequency in COPD. Respir Med 2007 Apr;101(4):729-37. 
(34) Sethi S, Sethi R, Eschberger K, Lobbins P, Cai X, Grant BJ, et al. Airway bacterial concentrations and exacerbations of chronic obstructive pulmonary disease. Am J Respir Crit Care Med 2007 Aug 15;176(4):356-61. 


\section{CHAPTER 7}

\section{GENERAL DISCUSSION}

Marjolein Brusse-Keizer 
In this thesis the results are described of several studies on exacerbations in Chronic Obstructive Pulmonary Disease (COPD). In this general discussion the specific hypotheses of this thesis will be reflected in the light of the observed results, and the findings will be reviewed in the context of existing literature. Also the strengths and weaknesses of the various studies will be discussed, and practical implications and avenues for further research will be addressed.

\section{Exacerbations in COPD}

Exacerbations in COPD are important features in COPD among others because of a close relation to morbidity and mortality. Repeated exacerbations have been associated with deterioration of health-related quality of life and a considerable economic burden(1). Before strategies to reduce exacerbation can be introduced successfully, patients at risk for frequent exacerbations need to be identified. The study on independent predictors for frequent exacerbations in moderate to severe COPD patients (Chapter 2) showed that HRQoL and a course of oral corticosteroids in the past 3 months together predicted best whether stable COPD patients would exacerbate frequently over the course of the next year. Both parameters can be measured easily, which is necessary for the use of these parameters in practice. The predictive value of the model found in this study however, was not deemed sufficient to aid in the identification of individual patients at risk.

Additionally, we were not able to replicate earlier observed associations between frequency of exacerbations and baseline cytokine levels in sputum. This contrasts with a study by Bhowmik et al who did find higher baseline sputum cytokine levels in frequent exacerbators(2). Although the COPD severity was comparable in both studies, the difference is that in the patient population of Bhowmik exacerbation frequency is indicated to have been a constant feature(3), which was certainly not the case in our study. We observed that from one year to the next, a sizable number of patients switched from being frequent exacerbators to being infrequent exacerbators and vice versa. This observed change in exacerbation frequency that was observed in our study warrants further exploration over longer time periods, since if it were confirmed, it would have implications for the prescription of ICS to patients with GOLD stage III and IV who suffer from repeated exacerbations(4).

\section{Treatment of exacerbations with antibiotics}

The management of exacerbations is still empirical and includes oral corticosteroids, often combined with broad spectrum antibiotics such as amoxicillin 
clavulanic acid or tetracyclines to treat a presumed bacterial infection(5). The necessity to prescribe these antibiotics, especially in mild to moderate exacerbations, is still not convincingly demonstrated(6). In clinical practice sputum colour and purulence are often used for decisions on antibiotic prescription in COPD exacerbations(7). Purulent sputum during an exacerbation has been shown to be correlated with the presence of bacteria in the lower respiratory tract(8). Furthermore it is an easily obtainable marker compared to the time consuming laboratory analyses that are necessary to verify a bacterial cause of an exacerbation at presentation. The study described in Chapter 3, however, shows that there is only a very weak association between bacterial load and sputum colour. Furthermore when sputum colour was dichotomised into purulent and mucoid sputum at exacerbation, the relationship with bacterial load vanished completely. This is inconsistent with results of earlier published studies by Stockley, Allegra, and Soler(9-12). There are some methodological differences that could possibly explain part of the contradictory results. One explanation might be that contrary to the abovementioned studies, in Chapter 3 we looked at total bacterial load on a continuous scale and not classified into bacterial growth or not, or infection or not. Another difference is that in the studies by Stockley, Allegra, and Soler, patients had not received antibiotic treatment 4 weeks prior to admission. In our study $68 \%$ of the patients received antibiotics 4 weeks prior to the study and $23 \%$ received antibiotics at admission. The decision not to exclude these patients was based on the fact that if sputum colour is to be used as an indication for antibiotic treatment, it should be usable in clinical practice. And in clinical practice, as in our study, many patients already receive antibiotics from their GP or chest physician before admission.

Next to the very weak association between bacterial load and sputum colour or purulence, we observed no consistent relationship between the individual changes in sputum colour and the accompanying change in bacterial load. Together, these observations make us reluctant about the usefulness of sputum colour as indicator for increase in bacterial load. So, if one believes that an increase in bacterial load is indicative of infections during exacerbations(13), sputum colour is an unreliable indicator for treatment with antibiotics.

Combined, our findings dispute the guidelines on antibiotic prescription(7;8), which are based on the Anthonisen criteria(14) in as far that they contain the parameter sputum purulence. 
But when sputum colour is not a valid parameter that can be used as an indicator for use of antibiotics, what other factor(s) can? In the COPE study by van der Valk et al., the combination of a positive Gram's stain of sputum, a clinically relevant decrease in lung function, and two or more exacerbations in the previous year was $67 \%$ predictive for a bacterial origin of an exacerbation, which was postulated to warrant antibiotic treatment(15). The absence of all three characteristics gave a negative predictive value of $100 \%$ for a non-bacterial origin of an exacerbation, suggesting to abstain from administering antibiotics(15). This left however the patients with only one or two of the abovementioned characteristics to guide treatment choices in.

This group was studied in the ABC-Trial, a randomised placebo controlled trial assessing the effectiveness of antibiotics in COPD exacerbations, which is described in Chapter 4. This study was remarkable because it is one of the very few studies in COPD exacerbations that compares the effect of antibiotic treatment with placebo in a randomised controlled trial (RCT). Most studies that are published on antibiotics in COPD are equivalence trials comparing two antibiotics, although antibiotics have still not shown to be beneficial in outpatients with mild to moderate exacerbations(6). Unfortunately, these studies are difficult to perform since most pharmaceutical companies do not support these studies financially nor are they willing to supply the necessary placebo medication.

Reviews that have been published on the effectiveness of antibiotics, conclude that antibiotics are useful in COPD exacerbations, but this has been studied mostly in patients with severe exacerbations needing hospitalisation(6;7). Next to this, the included studies in the reviews are old and were done without concomitant treatment with prednisolone which now has been demonstrated to be beneficial(16-18).

Due to the uncertainty about whether and when to prescribe antibiotics in COPD exacerbation, there are large differences in prescription between and within countries. Many physicians tend to be on the "safe" side and therefore give antibiotics. Also in the $A B C$ Trial we found that $66 \%$ of the patients would have been treated with antibiotics by their physician. This routine may have implications for costs, adverse effects and especially for the surge in antibiotic resistance $(8 ; 19 ; 20)$. Therefore, evidence underpinning antibiotic prescription needs to be established also in patients with less severe exacerbations. In our study in outpatients with moderately severe exacerbations, treatment with antibiotics showed no added value. What should be kept in mind is that the patients in the 
$A B C$-Trial did not have a high a priori probability of bacterial infection because they presented with only one or two of the following characteristics: a positive Gram's stain of sputum, a clinically relevant decrease in lung function, or two or more exacerbations in the previous year. Although antibiotics showed no added value in the studied patients, a remarkable number of exacerbations (27 of 35) were type I exacerbations and according to Anthonisen thus "likely" to be bacterial in the scoring system: exacerbations with increased dyspnoea, increased sputum volume, and increased purulence of sputum. In our study, upon checking this assumption, a bacterial infection was present in only 15 of 27 type I exacerbations (56\%). Our results question the usefulness of antibiotics in this type of exacerbation. This is supported by the results of Chapter 3 , in which the predictive value of sputum purulence, one of the necessary symptoms of a type I exacerbation, was insufficient for distinguishing patients that were likely to benefit from antibiotic therapy from those that were not. It is of course good practice to repeat our study to confirm the results. But we would also like to extend our findings and test the effects of antibiotics in the group with a high probability of an exacerbation of bacterial origin. This should be done in a placebo controlled trial in moderate severe COPD patients, who are planned to be treated for their exacerbation at home.

\section{Effectiveness of antibiotics in COPD exacerbations}

Another important factor that can influence the effectiveness of antibiotics is its concentration in target tissues. To be effective, the antibiotic concentration in target tissues should theoretically reach the Minimal Inhibiting Concentration of 90\% (MIC90) for pathogenic micro-organism. In Chapter 5 we studied the relation between the concentration of amoxicillin in sputum and length of hospitalisation, as a marker for the effectiveness of antibiotic use in patients with a COPD exacerbation. We observed that of the 33 included patients hospitalised for a COPD exacerbation, only 11 had a concentration in sputum $\geq$ MIC90 of $2 \mathrm{mg} / \mathrm{l}$. This is only one third of the included patients. Importantly, patients with a sputum concentration of amoxicillin $\geq 2 \mathrm{mg} / \mathrm{l}$ had a markedly reduced length of hospitalisation compared to patients with a concentration $<2 \mathrm{mg} / \mathrm{l}$, respectively 7.0 en 11.0 days ( $p=0.005)$. This lesser of effect of low dosed amoxicillin clavulanic acid is compatible with the results in Chapter 4, where we studied the same antibiotic in a different setting and observed a lack of effect in COPD exacerbations with a bacterial infection. Although the patients included in the ABC-Trial in 
Chapter 4 had less severe COPD exacerbations not needing hospitalisation, as compared to the hospitalised patients described in Chapter 5, the lack of effect observed in Chapter 4 could also at least be partly due to a large proportion of patients not reaching sufficient concentrations of antibiotic in their target tissues.

Since many patients do not reach the MIC90, we should advocate individual tailoring of the dose of antibiotics based on concentrations of antibiotics in sputum. Since the penetration of antimicrobial drugs across the blood-bronchus and alveolar-capillary barriers is influenced by host-related and drug-related factors(21), it is however theoretically also possible that increasing the dose will not lead to higher sputum concentrations. In these patients, other antibiotics or alternative routes of administration such as inhalation of antibiotics could be considered like in cystic fibrosis, bronchiectasis and other chronic airway infections. Aerosolised antibiotics have been proven to elicit high concentrations in the airways with low systemic bioavailability, thus reducing toxicity and potentially resistance(22).

The results of Chapter 5 need to be confirmed. We suggest doing this by testing the usefulness of a prospective algorithm of antibiotic dosing based on sputum amoxicillin concentrations with the aim to reduce hospitalisation length for acute exacerbations of COPD. Furthermore, the concentrations of other antibiotics in target tissues should be measured to see whether the insufficient penetration of antimicrobial drugs across the blood-bronchus and alveolar-capillary barriers, in COPD patients hospitalised for an exacerbation, is drug-related, host-related or both.

\section{Sputum quality}

Sputum analysis is an important clinical tool in the management of COPD exacerbations, where the choice of antibiotic is mainly guided by the presence and abundance of potentially pathogenic micro-organism in Gram's stain and/or culture. There is however a high variability in the quality of sputum samples obtained and although quality statements exist for many years(23;24), published studies involving sputum analysis often do not report on the quality control standards they used for sputum samples and whether samples of inadequate quality were removed from further analyses. In Chapter 6 we performed a study on sputa of COPD patients in stable state and during acute exacerbations to study the differences between sputum outcomes in adequate and inadequate sputum samples. Adequacy was based on the American Society of Microbiologists (ASM) 
criteria. We observed that in sputum samples obtained during acute exacerbations, considered appropriate according to the ASM quality standards, the criteria for a bacterial infection were met much more often (40\%) compared to inappropriate sputum samples (13\%). Moreover, by applying the same rules to sputum samples obtained during stable disease exactly the same pattern was observed (50\% infections vs $18 \%$ ). Applying stringent quality control criteria to sputum samples can therefore have a profound effect on clinical decision making. This is probably also true for the application and analysis of other biomarkers in sputum samples. It is therefore necessary that quality criteria are used and published in literature on sputum outcomes in COPD, as well as in clinical practice.

Next to this, we can conclude that a large number of sputum samples collected are inappropriate. This questions the usefulness of spontaneous collected sputum samples, especially during stable state since samples obtained during stable state were more often inappropriate than samples collected at exacerbation. A solution would be the use of sputum induction. Sputum induction has been proven to be safe in stable state, even in patients with moderate to severe $\operatorname{COPD}(25)$ and recently it has also been shown to be safe in COPD exacerbations in patients with mild to moderate $\operatorname{COPD}(26)$.

A remarkable finding of our study was that not only, as expected, a high number of samples collected at exacerbation met criteria for bacterial infection, but an almost equal number of samples collected during stable state met the same criteria for bacterial infection. Similarly, the concentrations of the inflammation markers TNF$\alpha, I L-6, I L-8$, and MPO did not differ between adequate samples obtained in stable state and at exacerbation. But one can wonder whether it is really inflammation due to bacterial infection that we measured during stable state, or from bacterial colonisation (and from the disease per se). It has been shown by many authors that a large number of stable COPD patients is colonised, varying from 25 to $50 \%$, and that this rate increases with progression of airflow obstruction(8). This airway bacterial colonisation in stable state is often associated with the same organisms as those at exacerbations, including Haemophilus influenzae, Streptococcus pneumoniae, Moraxella catarrhalis, Staphylococcus aureus, and Pseudomonas aeruginosa(27), which makes it more difficult to distinguish bacterial infection from bacterial colonisation in COPD exacerbations. Isolation of pathogens in stable state has been regarded as colonisation, primarily because of the absence of acute symptoms of infection. The we think more appropriate definition of colonisation however is the presence of a pathogen that does not cause damage to the host or 
elicit a host response(8). Several studies in stable COPD show that also in stable COPD bacterial pathogens are associated with host inflammatory and immune responses(8). For example bacterial colonisation has been associated with increased levels of airway inflammation measured in sputum(28), which suggests that bacterial colonisation of the lower airways in stable COPD is not innocuous. Also the development of specific adaptive immune responses to colonising bacteria supports the paradigm that in COPD colonisation is actually a smouldering infection(8). It can therefore be discussed whether it is possible to use a certain cut-off point to distinguish bacterial infection from bacterial colonisation either at stable state or during exacerbation. The host-pathogen interaction that underlies exacerbations of COPD seems to be more complicated than simple changes in concentrations of bacteria. For instance, Sethi et al have suggested that acquisitions of new bacterial strains play a central role in the pathogenesis of exacerbations(8), since acquisition of a new strain of Haemophilus influenzae, Streptococcus pneumoniae, Moraxella catarrhalis, or Pseudomonas aeruginosa has been strongly associated with occurrence of an exacerbation(29-33).

The situation with airway infections is further complicated by the fact that in many COPD exacerbations both respiratory viruses and bacteria are isolated(34). Since exacerbations caused by both viruses and bacteria are more severe and associated with higher levels of inflammatory markers $(8 ; 35)$, infection with the combination of bacteria and viruses might be of greater importance than bacterial or viral infection alone. Consensus within the field has however not yet emerged(35). It has been suggested that viruses alter the expression of receptors on respiratory epithelial cells, allowing increased adherence and invasion by bacteria(8). Similarly, bacterial infections may increase the susceptibility to viral infections by increasing expression of host-cell molecules that bind viruses(8). These scenarios represent potential mechanisms whereby a preceding infection potentiates secondary infection(8). This interaction needs further investigation, which will provide a better understanding of the importance of colonisation and infection in COPD and its exacerbations. 


\section{Conclusions}

In summary our main conclusions are:

- Health related quality of life and a course of oral corticosteroids in the past 3 months are predictors of future frequent exacerbations. Although both parameters are easily measurable, the predictive value of the model is still not very high. Furthermore, in contrast to previous observations, our data suggest that exacerbation frequency is not a constant feature.

- When patients present themselves with an exacerbation, the distinction between purulent and mucoid sputum is insufficient for distinction between patients that are likely to benefit form antibiotic therapy and those who are not.

- Treatment with antibiotics has no added value in outpatients with moderate to severe COPD exacerbations who do not have a high a priori probability of a bacterial infection.

- COPD patients admitted to the hospital with an acute exacerbation of COPD and who have a sputum concentration of amoxicillin $\geq 2 \mathrm{mg} / \mathrm{l}$ on the third day of dosing have a markedly reduced length of hospitalisation compared to those with a concentration $<2 \mathrm{mg} / \mathrm{l}$.

- Applying stringent quality control criteria to sputum samples can have a profound effect on the labelling of sputum samples as infectious, and therefore on clinical decision making.

Needs for future research:

- The observed change in frequency of exacerbations from one year to the next warrants exploration of this phenomenon over longer time periods. If confirmed, it would have implications for guidelines for prescription of ICS to patients with GOLD stage III and IV that suffer from repeated exacerbations.

- More studies are needed to determine which easily measurable factors can be used as an indicator for usefulness of antibiotics prescription; sputum colour is not the one. 
- Instead of more equivalence trials comparing two antibiotics, we need more placebo controlled studies to determine whether we can properly define subgroups of COPD outpatients in which antibiotics are truly of additional value.

- The relationship between amoxicillin concentration in sputum and the length of hospitalisation needs to be confirmed. We suggest doing this by investigating the usefulness of a prospective algorithm of antibiotic dosing based on sputum amoxicillin concentrations above versus below $2 \mathrm{mg} / \mathrm{ml}$.

- More longitudinal research is needed on the change in bacterial load from stable state to exacerbations. 


\section{References}

(1) Celli BR, Barnes PJ. Exacerbations of chronic obstructive pulmonary disease. Eur Respir J 2007 Jun;29(6):1224-38.

(2) Bhowmik A, Seemungal TA, Sapsford RJ, Wedzicha JA. Relation of sputum inflammatory markers to symptoms and lung function changes in COPD exacerbations. Thorax 2000 Feb;55(2):114-20.

(3) Burge PS, Calverley PM, Jones PW, Spencer S, Anderson JA, Maslen TK. Randomised, double blind, placebo controlled study of fluticasone propionate in patients with moderate to severe chronic obstructive pulmonary disease: the ISOLDE trial. BMJ 2000 May 13;320(7245):1297-303.

(4) Rabe KF, Hurd S, Anzueto A, Barnes PJ, Buist SA, Calverley P, et al. Global Strategy for the Diagnosis, Management, and Prevention of COPD - GOLD Executive Summary. Am J Respir Crit Care Med 2007 Sep;176:532-55.

(5) Wilson R. Bacterial infection and chronic obstructive pulmonary disease. Eur Respir J 1999 Feb;13(2):233-5.

(6) Puhan MA, Vollenweider D, Latshang T, Steurer J, Steurer-Stey C. Exacerbations of chronic obstructive pulmonary disease: when are antibiotics indicated? A systematic review. Respir Res 2007;8:30.

(7) Ram FS, Rodriguez-Roisin R, Granados-Navarrete A, Garcia-Aymerich J, Barnes NC. Antibiotics for exacerbations of chronic obstructive pulmonary disease. Cochrane Database Syst Rev 2006;(2):CD004403.

(8) Sethi S, Murphy TF. Infection in the Pathogenesis and Course of Chronic Obstructive Pulmonary Disease. N Engl J Med 2008 Nov 27;359(22):2355-65.

(9) Soler N, Agusti C, Angrill J, Puig De la BJ, Torres A. Bronchoscopic validation of the significance of sputum purulence in severe exacerbations of chronic obstructive pulmonary disease. Thorax 2007 Jan;62(1):29-35.

(10) Stockley RA, O'Brien C, Pye A, Hill SL. Relationship of sputum color to nature and outpatient management of acute exacerbations of COPD. Chest 2000 Jun;117(6):1638-45.

(11) Stockley RA, Bayley D, Hill SL, Hill AT, Crooks S, Campbell EJ. Assessment of airway neutrophils by sputum colour: correlation with airways inflammation. Thorax 2001 May;56(5):366-72.

(12) Allegra L, Blasi F, Diano P, Cosentini R, Tarsia P, Confalonieri M, et al. Sputum color as a marker of acute bacterial exacerbations of chronic obstructive pulmonary disease. Respir Med 2005 Jun;99(6):742-7. 
(13) Monso E, Ruiz J, Rosell A, Manterola J, Fiz J, Morera J, et al. Bacterial infection in chronic obstructive pulmonary disease. A study of stable and exacerbated outpatients using the protected specimen brush. Am J Respir Crit Care Med 1995 Oct;152(4 Pt 1):1316-20.

(14) Anthonisen NR, Manfreda J, Warren CPW, Hershfield ES, Harding GKM, Nelson NA. Antibiotic therapy in exacerbations of chronic obstructive pulmonary disease. Ann Intern Med 1987;106:196-204.

(15) Van der Valk P, Monninkhof E, van der Palen J., Zielhuis G, van Herwaarden C., Hendrix R. Clinical predictors of bacterial involvement in exacerbations of chronic obstructive pulmonary disease. Clin Infect Dis 2004 Oct 1;39(7):980-6.

(16) Aaron SD, Vandemheen KL, Hebert P, Dales R, Stiell IG, Ahuja J, et al. Outpatient oral prednisone after emergency treatment of chronic obstructive pulmonary disease. N Engl J Med 2003 Jun 26;348(26):2618-25.

(17) Davies L, Angus RM, Calverley PM. Oral corticosteroids in patients admitted to hospital with exacerbations of chronic obstructive pulmonary disease: a prospective randomised controlled trial. Lancet 1999 Aug 7;354(9177):456-60.

(18) Niewoehner DE, Erbland ML, Deupree RH, Collins D, Gross NJ, Light RW, et al. Effect of systemic glucocorticoids on exacerbations of chronic obstructive pulmonary disease. Department of Veterans Affairs Cooperative Study Group. N Engl J Med 1999 Jun 24;340(25):1941-7.

(19) Wilson R. Bacteria, antibiotics and COPD. Eur Respir J 2001 May;17(5):9951007.

(20) Goossens H, Ferech M, Vander SR, Elseviers M. Outpatient antibiotic use in Europe and association with resistance: a cross-national database study. Lancet 2005 Feb 12;365(9459):579-87.

(21) Baldwin DR, Honeybourne D, Wise R. Pulmonary disposition of antimicrobial agents: in vivo observations and clinical relevance. Antimicrob Agents Chemother 1992 Jun;36(6):1176-80.

(22) Rubin BK. Other medications for aerosol delivery. Paediatr Respir Rev 2006;7 Suppl 1:S76-S79.

(23) Murray PR, Washington JA. Microscopic and baceriologic analysis of expectorated sputum. Mayo Clin Proc 1975 Jun;50(6):339-44.

(24) Isenberg HD. Clinical microbiology procedures handbook. 2004. 
(25) Bhowmik A, Seemungal TA, Sapsford RJ, Devalia JL, Wedzicha JA. Comparison of spontaneous and induced sputum for investigation of airway inflammation in chronic obstructive pulmonary disease. Thorax 1998 Nov;53(11):953-6.

(26) Bathoorn E, Liesker J, Postma D, Koeter G, van Oosterhout AJ, Kerstjens HA. Safety of sputum induction during exacerbations of COPD. Chest 2007 Feb;131(2):432-8.

(27) Sapey E, Stockley RA. COPD exacerbations . 2: aetiology. Thorax 2006 Mar;61(3):250-8.

(28) Sethi S, Maloney J, Grove L, Wrona C, Berenson CS. Airway inflammation and bronchial bacterial colonization in chronic obstructive pulmonary disease. Am J Respir Crit Care Med 2006 May 1;173(9):991-8.

(29) Sethi S, Sethi R, Eschberger K, Lobbins P, Cai X, Grant BJ, et al. Airway bacterial concentrations and exacerbations of chronic obstructive pulmonary disease. Am J Respir Crit Care Med 2007 Aug 15;176(4):356-61.

(30) Sethi S, Evans N, Grant BJ, Murphy TF. New strains of bacteria and exacerbations of chronic obstructive pulmonary disease. N Engl J Med 2002 Aug 15;347(7):465-71.

(31) Murphy TF, Brauer AL, Sethi S, Kilian M, Cai X, Lesse AJ. Haemophilus haemolyticus: a human respiratory tract commensal to be distinguished from Haemophilus influenzae. J Infect Dis 2007 Jan 1;195(1):81-9.

(32) Murphy TF, Brauer AL, Eschberger K, Lobbins P, Grove L, Cai X, et al. Pseudomonas aeruginosa in chronic obstructive pulmonary disease. Am J Respir Crit Care Med 2008 Apr 15;177(8):853-60.

(33) Murphy TF, Brauer AL, Grant BJ, Sethi S. Moraxella catarrhalis in chronic obstructive pulmonary disease: burden of disease and immune response. Am J Respir Crit Care Med 2005 Jul 15;172(2):195-9.

(34) Wilkinson TM, Hurst JR, Perera WR, Wilks M, Donaldson GC, Wedzicha JA. Effect of interactions between lower airway bacterial and rhinoviral infection in exacerbations of COPD. Chest 2006 Feb;129(2):317-24.

(35) Wedzicha JA, Seemungal TA. COPD exacerbations: defining their cause and prevention. Lancet 2007 Sep 1;370(9589):786-96. 


\section{CHAPTER 8}

\section{SUMMARY}

Marjolein Brusse-Keizer 


\section{COPD}

Chronic Obstructive Pulmonary Disease (COPD) is defined as a preventable and treatable disease with some significant extrapulmonary effects that may contribute to the disease severity in individual patients. COPD is a major cause of chronic morbidity and mortality throughout the world. According to the Global Burden of Disease Study, COPD ranked sixth as the cause of death in 1990, and will become the third leading cause of death worldwide by 2020 .

\section{Exacerbations}

Morbidity and mortality among patients with COPD are for a large part related to acute exacerbations, which occur one to three times a year. To reduce the associated morbidity and mortality of the exacerbations, and to improve the quality of life of patients, strategies to reduce exacerbation frequency are urgently needed. However, before these strategies can be introduced, patients at risk for frequent exacerbations need to be identified. In Chapter 2 we tried to identify independent predictors for frequent exacerbations from multiple domains of COPD, including demographic data, clinical signs, sputum cultures, and quality of life during a stable phase of the disease in patients with moderate to severe COPD. This study showed that HRQoL and a course of oral corticosteroids in the past 3 months together predicted best whether stable COPD patients would exacerbate frequently over the course of the next year. The predictive value of the model found in this study was not deemed sufficient enough to aid in the identification of patients at risk.

In contrast to previous studies, our data suggest that exacerbation frequency is not a constant feature. This warrants further exploration with longer follow-up, if confirmed, it would have implications for GOLD guidelines for prescription of ICS to patients with GOLD stage III and IV with repeated exacerbations.

\section{Treatment of exacerbations with antibiotics}

The management of exacerbations is empirical and includes oral corticosteroids, often combined with broad spectrum antibiotics such as amoxicillin clavulanic acid or tetracyclines to treat a presumed bacterial infection. The need to prescribe these antibiotics, especially in mild to moderate exacerbations, is still not convincingly demonstrated. The controversy around antibiotic prescription is mainly based on the unclear role of bacteria as cause of the exacerbation. Furthermore, even when there indeed is a bacterial infection, treatment is 
empirical since results of cultures and tests for sensitivity to antibiotics usually take days to up to one week to become available. In clinical practice sputum colour and purulence are often used for decisions to prescribe antibiotics in COPD exacerbations. In the literature there are conflicting data and opinions about the association between sputum purulence and bacterial involvement in exacerbations. In Chapter 3 we describe a study to determine whether sputum colour and purulence, as assessed by the nine-point Stockley colour chart, correlate with bacterial load in patients admitted for an exacerbation of COPD. This study showed only a very weak association between bacterial load and sputum colour, which confirms our concerns over the usefulness of the colour chart. The distinction between purulent and mucoid sputum at exacerbation was insufficient for distinction between patients that are likely to benefit from antibiotic therapy and those who are not. Complementary studies are therefore needed to determine which other, easily measurable factors can be used as predictors for an indication for use of antibiotics. Other factors that have been studied are the combination of a positive Gram's stain of sputum, a clinically relevant decrease in lung function, and two or more exacerbations in the previous year. This combination showed to be $67 \%$ predictive for a bacterial origin of an exacerbation, which was postulated to warrant antibiotic treatment. Absence of all three characteristics showed a negative predictive value of $100 \%$ for a non-bacterial origin of an exacerbation, suggesting abstaining from administering antibiotics. The remaining patients with only one or two of the above mentioned characteristics were therefore studied in the ABC-Trial (Chapter 4). The ABC-Trial is a randomised placebo controlled study in which the effectiveness of antibiotics in COPD exacerbations with one or two of the above mentioned characteristics was assessed. It is a remarkable study, because it is one of the very few studies in COPD exacerbations that compares the effect of antibiotic treatment with placebo in a randomised controlled trial (RCT). The study showed no evidence for effectiveness of additional treatment with antibiotics, on top of prednisolone, in COPD outpatients with moderate to severe exacerbations. The lack of effectiveness was based on the absence of differences in time to resolution, severity, number of relapses, number of exacerbations 4 months after the study, and quality of life. Instead of more equivalence trials comparing two antibiotics, this study shows that there is a need for more placebo controlled studies to identify subgroups of COPD outpatients in which antibiotics indeed are of additional value. 


\section{Effectiveness of antibiotics in COPD exacerbations}

An important factor that can influence the effectiveness of antibiotics is its concentration in target tissues. To be effective, the antibiotic concentration in target tissues should theoretically reach the Minimal Inhibiting Concentration of 90\% (MIC90) for pathogenic micro-organism. In Chapter 5 we studied the relation of the concentration of amoxicillin in sputum on length of hospitalisation, as a marker for the effectiveness of antibiotic use in patients with a COPD exacerbation. We observed that of the 33 included patients hospitalised for a COPD exacerbation, only 11 had a concentration in sputum $\geq$ MIC 90 of $2 \mathrm{mg} /$ l. Importantly, patients with a sputum concentration of amoxicillin $\geq 2 \mathrm{mg} / \mathrm{l}$ had a markedly reduced length of hospitalisation compared to patients with a concentration $<2 \mathrm{mg} / \mathrm{l}$, respectively 7.0 en 11.0 days $(p=0.005)$.

Since many patients do not reach the MIC90, it seems worthwhile to test whether individualised treatment based on sputum amoxicillin concentrations of patients during hospitalisation for acute exacerbations can effectively reduce hospital stay. It is also possible that increasing the dose will not lead to higher sputum concentrations. In these patients other antibiotics or alternative routes of administration such as inhalation of antibiotics could be considered like in cystic fibrosis.

\section{Sputum quality}

Sputum analysis is an important clinical tool in the management of COPD exacerbations, where the choice of antibiotic is mainly guided by the presence and abundance of potentially pathogenic micro-organism in Gram's stain and/or culture. However, there is a high variability in the quality of sputum samples obtained and although quality statements exist for many years, published studies involving sputum analysis often do not report on the quality control standards they used for sputum samples and whether sputum samples of inadequate quality were removed from further analyses. In Chapter 6 we performed a study on sputa of COPD patients in stable state and during acute exacerbations to study the differences between sputum outcomes in adequate and inadequate sputum samples. Adequacy of sputa was based on the American Society of Microbiologists (ASM) criteria. We observed that in sputum samples obtained during acute exacerbations, considered appropriate according to the ASM quality standards, the criteria for a bacterial infection were met more often (40\%) compared to inappropriate sputum samples (13\%). Moreover, by applying the same rules to 
sputum samples obtained during stable disease exactly the same pattern was observed (50\% infections vs $18 \%$ ). Applying stringent quality control criteria to sputum samples can therefore have a profound effect on clinical decision making. This is probably also true for the application and analysis of other biomarkers in sputum samples. It is therefore necessary that quality criteria are used and published in literature on sputum outcomes in COPD.

In Chapter 7 the hypotheses of this thesis are reflected upon in light of the observed results, and the findings are reviewed in the context of existing literature. Also the strengths and weaknesses of the various studies are discussed, and practical implications and avenues for further research are addressed.

In summary our main conclusions are:

- Health related quality of life and a course of oral corticosteroids in the past 3 months are predictors of future frequent exacerbations. Although both parameters are easily measurable, the predictive value of the parameters model is still not very high.

- Exacerbation frequency is not a constant feature, if confirmed, it would have implications for guidelines for prescription of ICS to patients with GOLD stage III and IV that suffer from repeated exacerbations.

- The distinction between purulent and mucoid sputum is insufficient for distinction between patients that are likely to benefit form antibiotic therapy and those who are not. More studies are needed to determine which easily measurable factors could be used as an indicator for usefulness of antibiotics prescription; sputum colour is not the one.

- Treatment with antibiotics has no added value in outpatients with moderate to severe COPD exacerbations who do not have a high a priori probability of a bacterial infection. Instead of more equivalence trials comparing two antibiotics, we need more placebo controlled studies.

- A sputum concentration of amoxicillin $\geq 2 \mathrm{mg} / \mathrm{l}$ during hospitalisations for a COPD exacerbation is associated with a shorter hospital stay compared to lower concentrations. The next step is to investigate the usefulness of a 
prospective algorithm of antibiotic dosing based on sputum amoxicillin concentrations.

- Applying stringent quality control criteria to sputum samples can have a profound effect on the labelling of sputum samples as infectious, and therefore on clinical decision making. 
SAMENVATTING 


\section{COPD}

Chronic Obstructive Pulmonary Disease (COPD) is een verzamelnaam voor chronische bronchitis en longemfyseem. De voornaamste klachten van de COPD patiënt zijn kortademigheid bij inspanning, hoesten en een overmatige slijmproductie. COPD is wereldwijd een belangrijke oorzaak van chronische ziekte en sterfte. Volgens de "Global Burden of Disease Study", was COPD de zesde doodsoorzaak in 1990 en zal het de derde doodsoorzaak wereldwijd zijn in 2020. De belangrijkste oorzaak van COPD is roken.

\section{Exacerbaties}

De ziektelast en sterfte onder patiënten met COPD zijn voor een groot deel gerelateerd aan exacerbaties, die gemiddeld één tot drie keer per jaar voorkomen. Exacerbaties zijn min of meer acuut optredende verslechteringen van de ziekte, waarvan patiënten vaak niet $100 \%$ herstellen. Om de ziektelast en de sterfte die gerelateerd zijn aan deze exacerbaties te verminderen, en de kwaliteit van leven van patiënten te verbeteren, zijn strategieën om de frequentie van deze exacerbaties te verminderen dringend nodig. Hiertoe moet eerst worden vastgesteld welke patiënten een verhoogd risico op frequente exacerbaties hebben. In Hoofdstuk 2 probeerden we onafhankelijke voorspellers voor frequente exacerbaties te identificeren. Deze voorspellers werden gezocht in persoonsgegevens, klinische gegevens, sputumkweken, en kwaliteit van leven tijdens een stabiele fase van de ziekte bij patiënten met matig tot ernstig COPD. Deze studie toonde aan dat gezondheidsgerelateerde kwaliteit van leven en een kuur van orale corticosteroïden (prednisolon) in de afgelopen 3 maanden samen het beste voorspelden of stabiele COPD patiënten in de loop van het jaar er na frequent zouden exacerberen. De voorspellende waarde van het model dat in deze studie werd gevonden, wordt echter niet voldoende geacht om patiënten met een verhoogd risico te identificeren. In tegenstelling tot eerdere studies lieten onze gegevens tevens zien dat exacerbatiefrequentie niet een constant fenomeen is, maar van jaar tot jaar kan variëren. Dit vraagt om verder onderzoek met een langere follow-up. Indien namelijk bevestigd zou worden dat bij patiënten de frequentie van exacerbaties van jaar tot jaar wezenlijk kan verschillen, zou dit implicaties hebben voor het voorschrijven van inhalatiecorticosteroïden (ICS) bij COPD. Binnen de GOLD richtlijnen wordt geadviseerd aan patiënten met GOLD stadium III en IV met herhaalde exacerbaties ICS voor te schrijven. Indien de 
exacerbatiefrequentie echter blijkt te wisselen over de jaren, zou het voorschrijven van ICS wellicht regelmatig herzien moeten worden.

\section{Behandeling van exacerbaties met antibiotica}

De behandeling van exacerbaties bestaat uit een behandeling met een kuur van orale corticosteroïden (prednisolon), die vaak met een breedspectrumantibioticum wordt gecombineerd zoals amoxicilline clavulaanzuur of tetracycline om een veronderstelde bacteriële infectie te behandelen. De noodzaak om deze antibiotica voor te schrijven is met name bij milde tot matig ernstige exacerbaties nog niet overtuigend aangetoond. De controverse rond antibiotica is voornamelijk gebaseerd op de onduidelijke rol van bacteriën als oorzaak van de exacerbatie. Zelfs wanneer er inderdaad sprake is van een bacteriële infectie is de behandeling empirisch, aangezien de resultaten van kweken en testen voor gevoeligheid voor antibiotica gewoonlijk pas na dagen tot een week beschikbaar zijn. In de praktijk worden sputumkleur en sputumpurulentie daarom vaak gebruikt om te beslissen of antibiotica moeten worden voorgeschreven. Purulent sputum wordt vaak beschouwd als sputum met een wat dikkere consistentie en verkleuring die aan bijmenging met pus doet denken. In de literatuur zijn er tegenstrijdige gegevens over de associatie tussen sputumpurulentie en bacteriële betrokkenheid bij exacerbaties. In Hoofdstuk 3 beschrijven we een studie waarin we onderzochten of sputumkleur en -purulentie, zoals beschreven met de negen-punts kleurenkaart van Stockley, correleert met het aantal bacteriën in sputum van patiënten met een COPD exacerbatie. Deze studie toonde slechts een zeer zwakke associatie tussen het aantal bacteriën en sputumkleur aan, wat onze bezorgdheid over het nut van sputumkleur bevestigde. Het onderscheid tussen purulent en mucoïd (taai slijmig) sputum bij exacerbaties bleek ook ontoereikend om onderscheid te kunnen maken tussen patiënten die waarschijnlijk van antibiotische therapie zouden profiteren en patiënten waarbij dit niet het geval zou zijn. Studies naar andere factoren die kunnen worden gebruikt als voorspellers voor adequaat gebruik van antibiotica zijn daarom dringend nodig. Eén combinatie van voorspellende factoren is al onderzocht: een positief Gram preparaat van het sputum, een klinisch relevante daling in longfunctie, en twee of meer exacerbaties in het voorafgaande jaar. Deze combinatie toonde een kans van $67 \%$ op een bacteriële oorzaak van een exacerbatie, wat een antibiotische behandeling rechtvaardigt. Het ontbreken van alle drie kenmerken gaf een kans van $100 \%$ op een niet-bacteriële oorzaak van een exacerbatie, wat betekent dat geen antibioticum voorgeschreven dient te worden. 
Patiënten met slechts één of twee van de hiervoor vermelde kenmerken werden onderzocht in de ABC-Trial (Hoofdstuk 4). De ABC-Trial is een gerandomiseerde dubbelblinde placebo gecontroleerde studie waarin de effectiviteit van antibiotica, bovenop prednisolon, werd beoordeeld bij exacerbaties in poliklinische COPD patiënten met één of twee van de hiervoor vermelde kenmerken. De studie vond geen bewijs voor de effectiviteit van aanvullende behandeling met antibiotica. Er was ook geen verschil in tijd tot einde van de exacerbatie, ernst van de exacerbatie, aantal terugvallen, aantal exacerbaties binnen vier maanden na de studie, en kwaliteit van leven. Deze studie toont aan dat in plaats van meer equivalentiestudies, die twee antibiotica vergelijken, er behoefte is aan meer placebo gecontroleerde studies, om subgroepen van poliklinische COPD patiënten te identificeren waarin het voorschrijven van een kuur antibioticum bovenop prednisolon wel van aanvullende waarde kan zijn.

\section{Effectiviteit van antibiotica in exacerbaties van COPD}

Een belangrijke factor die de effectiviteit van antibiotica kan beïnvloeden is de concentratie van antibiotica in de weefsels, daar waar het daadwerkelijk werkzaam moet zijn. Om effectief te zijn, zou de antibiotische concentratie in deze weefsels theoretisch in ieder geval de "Minimal Inhibiting Concentration" van 90\% (MIC90) voor mogelijk ziekteverwekkende bacteriën moeten bereiken. Dit is de minimale concentratie waarbij de groei van mogelijk ziekteverwekkende bacteriën geremd wordt. In Hoofdstuk 5 bestudeerden wij de relatie tussen de concentratie van amoxicilline in sputum op dag 3 van de opname en de duur van de ziekenhuisopname, als maat voor de effectiviteit van antibiotica in patiënten met een ernstige COPD exacerbatie. Wij zagen dat van de 33 geïncludeerde patiënten die voor een exacerbatie waren opgenomen slechts 11 patiënten een concentratie in het sputum hadden $\geq$ MIC 90 van $2 \mathrm{mg} / \mathrm{I}$. Patiënten met een sputumconcentratie van amoxicilline $\geq 2 \mathrm{mg} / \mathrm{l}$ hadden een duidelijk verminderde duur van ziekenhuisopname in vergelijking met patiënten met een concentratie $<2 \mathrm{mg} / \mathrm{l}$, respectievelijk 7.0 en 11.0 dagen ( $p=0.005)$.

Aangezien een groot deel van de patiënten niet de MIC90 bereikt, lijkt het in de klinische praktijk lonend om te onderzoeken of een geïndividualiseerde behandeling op basis van amoxicilline concentraties in sputum de duur van deze opname kan reduceren. Als verhoging van de dosis niet leidt tot hogere sputumconcentraties, zouden bij deze patiënten andere soorten antibiotica of 
alternatieve toedieningsvormen zoals inhalatie van antibiotica kunnen worden overwogen.

\section{Sputumkwaliteit}

De analyse van het sputum is een belangrijk klinisch hulpmiddel in de behandeling van COPD exacerbaties. Het bepaalt namelijk de aanwezigheid en de overvloed van mogelijk ziekteverwekkende bacteriën in het Gram preparaat en/of de kweek en daarmee de keus voor antibioticum. Er is echter een grote mate van variabiliteit in de kwaliteit van de verkregen sputummonsters en hoewel kwaliteitscriteria al vele jaren bestaan, rapporteren studies vaak niet over de kwaliteitscriteria die ze hanteerden bij de sputumanalyses. Tevens geven ze vaak niet aan of monsters van inadequate kwaliteit werden verwijderd uit de analyses. In Hoofdstuk 6 voerden wij een studie uit waarbij we keken naar de verschillen tussen resultaten in adequate sputummonsters en inadequate monsters, verzameld bij COPD patiënten in zowel stabiele staat als tijdens een exacerbatie. Adequaatheid van de monsters werd gebaseerd op de criteria van de "American Society of Microbiologists" (ASM). Wij merkten op dat in sputummonsters die tijdens exacerbaties waren afgenomen en die volgens de ASM kwaliteitsnormen als adequaat werden beoordeeld, in vergelijking met inadequate sputum monsters, vaker een bacteriële infectie werd gevonden (40\% versus 13\%). Wanneer deze ASM regels werden toegepast op sputummonsters die tijdens een stabiele fase van het COPD werden verkregen, werd precies hetzelfde patroon waargenomen ( $50 \%$ infectie versus $18 \%$ ). Het toepassen van strikte kwaliteitscriteria op sputummonsters kan daarom een sterk effect hebben op de klinische besluitvorming. Dit geldt waarschijnlijk tevens voor de analyse van andere biomarkers in sputummonsters. Het is daarom noodzakelijk dat kwaliteitscriteria worden gebruikt en in literatuur over sputumresultaten bij COPD ook expliciet worden vermeld.

In Hoofdstuk 7 worden de hypothesen van dit proefschrift bediscussieerd op basis van de gevonden resultaten en worden de bevindingen bezien in de context van bestaande literatuur. Daarnaast worden de sterke en zwakke punten van de diverse studies bediscussieerd, en de praktische implicaties en ideeën voor toekomstig onderzoek besproken. 
Samengevat zijn onze belangrijkste conclusies en aanbevelingen:

- Gezondheidsgerelateerde kwaliteit van leven en een kuur orale corticosteroïden in de afgelopen 3 maanden zijn voorspellers voor frequente exacerbaties in de toekomst. Hoewel beide parameters gemakkelijk meetbaar zijn, is de voorspellende waarde van het model niet erg hoog.

- Exacerbatiefrequentie lijkt geen constant fenomeen. Wanneer dit in toekomstig onderzoek bevestigd wordt heeft dit implicaties voor de richtlijnen over voorschrijven van ICS aan patiënten met GOLD stadium III en IV die frequente exacerbaties hebben.

- Het onderscheid tussen purulent en mucoïd sputum is ontoereikend om onderscheid te maken tussen patiënten die baat zullen hebben bij antibiotische therapie en patiënten waarbij dit niet het geval zal zijn. Meer studies zijn nodig om te bepalen welke eenvoudig te meten factoren als indicator zouden kunnen dienen voor het voorschrijven van antibiotica; sputumkleur is niet zo'n factor.

- Behandeling met antibiotica heeft geen toegevoegde waarde in die poliklinische patiënten met matige tot ernstige COPD exacerbaties die niet al een hoge vooraf kans hebben op de aanwezigheid van een bacteriële infectie. In plaats van meer equivalentiestudies die twee antibiotica vergelijken, zijn meer placebo gecontroleerde studies nodig bij exacerbaties van COPD.

- Een sputumconcentratie van amoxicilline $\geq 2 \mathrm{mg} / \mathrm{l}$ tijdens de derde dag van opname wegens een COPD exacerbatie, is geassocieerd met een duidelijk verminderde duur van ziekenhuisopname in vergelijking met een concentratie $<2 \mathrm{mg} / \mathrm{l}$.

- Het toepassen van strikte kwaliteitscriteria bij de analyse van sputummonsters verhoogt sterk het percentage sputummonsters dat wordt gelabeld als infectieus. Dat heeft consequenties voor de klinische besluitvorming aangaande het wel of niet geven van antibiotica. 


\section{DANKWOORD}


Het proefschrift is af! Dit had ik echter niet kunnen doen zonder de hulp van velen om mij heen. Daarom wil ik iedereen die heeft bijgedragen aan de totstandkoming van het proefschrift heel hartelijk danken. Natuurlijk zijn er een aantal mensen die ik hierbij persoonlijk wil noemen en ik hoop daarbij niemand te vergeten.

Allereerst wil ik mijn beide promotoren bedanken, Job van der Palen en Huib Kerstjens. Beste Job, wat heb ik veel van je geleerd. Je was en bent een goede leermeester waar ik in de toekomst nog veel meer van hoop te mogen leren. Met name je enorme toegankelijkheid en de plezierige samenwerking heb ik zeer weten te waarderen. Ik hoop dan ook dat onze samenwerking nog lang stand zal houden. Ik wil je tevens laten weten dat ik het een eer vind om je eerste officiële promovendus te mogen zijn; mogen er nog velen volgen! Beste Huib, veel heb ik ook van jou mogen leren. Je heerlijk kritische blik zette me vaak aan het nadenken. Een grote blijk van waardering wil ik uitspreken voor je persoonlijke betrokkenheid tijdens mijn promotietraject, je wist precies welke woorden te gebruiken op de juiste momenten.

Tevens wil ik graag mijn assistent-promotor, Paul van der Valk bedanken. Beste Paul, door de zeer plezierige stage bij jou en Evelyn was ik overtuigd om in Enschede te blijven, dank daarvoor. Je hebt me tijdens mijn promotie op een aantal zeer belangrijke fronten geholpen en daar ben ik je enorm dankbaar voor. Nu we sinds juli 2008 het Onderzoeksbureau Longgeneeskunde samen runnen is onze samenwerking alleen nog maar toegenomen. Ik denk dat we een zeer goed team zijn en hoop dit nog lang met je samen te mogen doen.

Natuurlijk wil ik ook alle patiënten bedanken zonder wie het doen van de verschillende onderzoeken onmogelijk was geweest. Bedankt voor u inzet!

Ook zonder de datamanagers, Betty Rinsma, Manon Krabbenbos, Mandy de Jonge en Petra Meerlo had ik het onderzoek niet kunnen doen. Lieve Betty, veel heb ik van je mogen leren, van het maken van databases tot een workshop glas in lood. Ik heb je nuchtere kijk altijd zeer weten te waarderen en kijk uit naar onze verdere samenwerking. Lieve Manon, als stagiaire bij Tanja ontmoette ik je, maar als datamanager van de ABC-Trial en de COMIC studie leerde ik je pas echt kennen. We waren een zeer goed team en hadden aan een paar woorden genoeg om elkaar te begrijpen. Ik ben erg blij dat jij tijdens deze belangrijke dag mijn paranimf wil zijn. Lieve Mandy, je hebt in korte tijd veel geleerd en we hebben samen een 
plezierige tijd gehad. Ik wens je veel succes bij je volgende baan. Lieve Petra, je stond altijd voor me klaar om me werk uit handen te nemen. Je hebt een enorme bijdrage geleverd aan het onderzoek en onze literatuurverzameling. Ik hoop dat je nog lange tijd bij ons blijft. Zeer recent hebben we het Onderzoeksbureau met twee nieuwe datamanagers, Nicole Vos en Sylvia Punte, mogen uitbreiden. Ik wil jullie beiden heel veel succes wensen en hoop dat jullie een plezierige tijd bij ons mogen hebben.

De uitvoering van alle onderzoeken was niet mogelijk geweest zonder de inzet van de longafdeling van Medisch Spectrum Twente. Bij dezen wil ik dan ook alle longfunctieassistenten (Irma, Simone, Hans, Monique, Loes, Petra, Mirjam, Gerry, Willemien, Silvia, Marcel, Marquerite, Cor, Carmen, Renate, Moniek, Rolien, Karin en Martijn) bedanken voor hun bijdrage en de gezelligheid in de koffiekamer. Ook de longfysioloog (Frans) en de longartsen (Ilonka, Hugo, Albert, Michiel W, Michiel E, Nicolle, Wendy, Paul, Jaap en Louis) wil ik bedanken voor de medewerking. Ik waardeer het als jullie over het onderzoek meedenken. Daarnaast wil ik Clara, Maria, Marja Osinga, arts-assistenten en het secretariaat bedanken voor hun steun en bijdrage aan het onderzoek.

Het maandagavondteam, Ron Hendrix, Job van der Palen, Paul van der Valk, Maaike Telgen, Leonore ten Bokum, Kris Movig, Carlos Schwengle, Rogier van der Zanden. We hebben heel wat uurtjes samen doorgebracht om onderzoeksideëen en resultaten te bespreken. Ik denk dat onze multidisciplinairiteit onze grote kracht is. Ron, jij borrelt werkelijk waar van de ideëen en samen met de medewerkers van het laboratorium Microbiologie Twente Achterhoek hebben we veel onderzoeken uit kunnen voeren. Tessa, jij was hierbij een zeer belangrijke factor die altijd een stapje extra wilde doen. Leonore, samen hebben we de Aspect studie geklaard en tot een mooi artikel afgerond! Maaike, het eerste artikel hebben we geschreven, dat er nog velen mogen volgen!

De leden van de promotiecommissie, Prof. dr. T.S. van der Werf, Prof. dr. M.J. IJzerman, Prof. dr. M.A.F.J van de Laar en Dr. M.G.R. Hendrix wil ik bedanken voor hun bereidheid om zitting te nemen in de promotiecommissie.

Met onderzoekgegevens kun je niet werken zonder dat ze in de computer staan. Daarom wil ik Annika, Sjouke, Wiebe en Thijs bedanken voor al hun invoerwerk. 
De medewerkers van de apotheek van Medisch Spectrum Twente wil ik bedanken voor de "veelvuldige" bereiding van de placebomedicatie.

Alle apothekers en hun assistenten wil ik bedanken voor hun medewerking en voor het leveren van de opgevraagde medicatiegegevens.

De longafdelingen A4 en C4, de Spoedeisende Hulp en het laboratorium van Medisch Spectrum Twente wil ik bedanken voor hun bijdrages aan de ABC-Trial, COMIC, INSPECT en ASPECT studie.

De enthousiaste stagiaires die hebben meegewerkt aan de onderzoeken, Paul Brinkman en Anne Grotenhuis wil ik bedanken voor hun bijdrages. Paul, geen sputumonderzoek is je teveel, je bent zeer toegewijd. Anne, je bent erg gedreven en ons onderzoek heeft intussen zelfs al tot een publicatie geleid. Ik wil je veel succes wensen met je eigen promotieonderzoek waar je recent aan bent begonnen.

Lieve Marlies, sinds juli 2008 ben je mijn nieuwe kamergenoot en heb je de laatste loodjes van mijn promotie uitvoerig meegemaakt. Dank voor je hulp en je af en toe zeer bruikbaar luisterend oor.

Het 'promotieteam' Martine, Lieke, Yvette, Evelyn, Tanja en Astrid wil ik bedanken voor alle steun en vriendschap. Onze gezellige uitjes naar de sauna en de etentjes heb ik zeer weten te waarderen. Ik hoop nog vele ervaringen, zowel werk als prive, met jullie te mogen delen en te genieten van jullie gezelligheid!

Lieve Tanja, als kamergenoten begonnen, als vriendinnen geëindigd. We hebben heel wat gedeeld daar samen in ons hok, zowel werk als privé. Ik ben blij deze promotie samen met je te mogen afsluiten met ons feest.

Lieve vrienden en vriendinnen, door jullie interesse in het verloop van $m^{\prime} n$ promotie voel ik me erg gesteund. Bedankt voor jullie vriendschap!

Lieve (schoon)familie, bedankt voor jullie interesse en niet te vergeten de gezellige familiemomenten. Lieve Willemien, dank voor al je liefde en steun. 
Lieve zusjes, Dorian en Annika. Ik wil jullie bedanken voor jullie steun die zelfs bij het Onderzoeksbureau van waarde bleek te zijn, bij het benaderen van patiënten en het invoeren van gegevens. Ons intensieve contact betekent veel voor me.

Lieve pap en mam, ik wil jullie bedanken voor alle kansen die jullie me hebben geboden en jullie onvoorwaardelijke liefde en steun. Pap, het betekent erg veel voor me dat je me op deze bijzondere dag wilt bijstaan als paranimf.

Dan thuis. Lieve Peter, deze promotieperiode was een belangrijke tijd in ons leven, ons eerste huis gekocht, trouwen en papa en mama worden. Ondanks de soms drukke tijden hebben we van al deze gebeurtenissen optimaal genoten. Zonder woorden voelen wij elkaar haarfijn aan en dit is precies wat ik soms nodig had (en heb). Dank je wel!!

Lieve Lars, jouw geboorte is het beste wat me is overkomen. Je zorgt ervoor dat ik kan relativeren. Jouw ondeugende glimlach bezorgt me een intens gelukkig gevoel en maakt al het andere even onbelangrijk. Binnenkort mogen we ook een tweede kindje verwachten en samen met deze baby in m'n buik zal ik het proefschrift gaan verdedigen. Laat je een schopje voelen? 
CURRICULUM VITAE 
Marjolein Brusse-Keizer was born on February 5th 1981 in Stad Delden.

After graduating from secondary school (Twickel College in Hengelo) in 1999, she started the study Biomedical Health Sciences at the Radboud University Nijmegen. In 2003 she graduated with a major in pathobiology and a major in epidemiology and was registered as an epidemiologist $A$. Subsequently she started as a PhD student at the department of Pulmonology of Medisch Spectrum Twente in Enschede where she performed several studies that led to the articles in this thesis. Since September 2008 she is appointed as research coordinator of the department of Pulmonology of Medisch Spectrum Twente. 

